\title{
Global Governance and Food Security Discourses: The FAO and the Via Campesina
}

\author{
by
}

Erica Anne Drummond

A thesis submitted to the Faculty of Graduate and Postdoctoral Affairs in partial fulfillment of the requirements for the degree of

Master of Arts

in

Geography

Carleton University

Ottawa, Ontario

(C) 2012

Erica Anne Drummond 
Library and Archives

Canada

Published Heritage

Branch

395 Wellington Street

Ottawa ON K1A ON4

Canada
Bibliothèque et

Archives Canada

Direction du

Patrimoine de l'édition

395 , rue Wellington

Ottawa ON K1A ON4

Canada
Your file Votre référence

ISBN: 978-0-494-87792-0

Our file Notre référence

ISBN: $978-0-494-87792-0$

\section{NOTICE:}

The author has granted a nonexclusive license allowing Library and Archives Canada to reproduce, publish, archive, preserve, conserve, communicate to the public by telecommunication or on the Internet, loan, distrbute and sell theses worldwide, for commercial or noncommercial purposes, in microform, paper, electronic and/or any other formats.

The author retains copyright ownership and moral rights in this thesis. Neither the thesis nor substantial extracts from it may be printed or otherwise reproduced without the author's permission.
AVIS:

L'auteur a accordé une licence non exclusive permettant à la Bibliothèque et Archives Canada de reproduire, publier, archiver, sauvegarder, conserver, transmettre au public par télécommunication ou par l'Internet, prêter, distribuer et vendre des thèses partout dans le monde, à des fins commerciales ou autres, sur support microforme, papier, électronique et/ou autres formats.

L'auteur conserve la propriété du droit d'auteur et des droits moraux qui protege cette thèse. $\mathrm{Ni}$ la thèse ni des extraits substantiels de celle-ci ne doivent être imprimés ou autrement reproduits sans son autorisation.
In compliance with the Canadian Privacy Act some supporting forms may have been removed from this thesis.

While these forms may be included in the document page count, their removal does not represent any loss of content from the thesis.
Conformément à la loi canadienne sur la protection de la vie privée, quelques formulaires secondaires ont été enlevés de cette thèse.

Bien que ces formulaires aient inclus dans la pagination, il n'y aura aucun contenu manquant. 


\begin{abstract}
This research uses discourse analysis to critically examine the convergences and divergences in the post-2007-08 food crisis discourses on food security and sovereignty of two international organizations active in global food security governance, the FAO and Via Campesina. Rooted in the critical agri-food studies literature, which adopts a multidimensional approach to the challenges of the global food system, and drawing on critical political economy and global governance frameworks, this research is premised on the assumption that it is important that the global food security governance regime, as represented by the FAO, take into account many of the concerns of the Via Campesina with respect to a focus on rights, agency, participation, and transparency. It is shown that the two organizations have many commonalities relating to calls for improved governance of international agricultural trade, improved regional level governance, and in the role for states in encouraging global food security governance solutions. This research also reveals that shifts in the global discourses surrounding food security are taking place, there are now significant divergences between the two organizations in terms of approaches to agency and vulnerability, the role of current multilateral institutions, and the right to define the means through which ones food is produced, which in turn represent fundamental differences in norms and principles that frame each organization's participation in food security initiatives. These differences, along with powerful hegemonic structures, currently limit the possibility for change in line with food sovereignty objectives to occur. Furthermore, it is shown that intelligent agency will be an important component of any possibility for moving the food security regime forward towards the more progressive food security and sovereignty directions envisioned by the Via Campesina. In the long-term, it is this intelligent agency which may be able to bring about the participation, inclusivity, and the type of rational discourse seen as needed in order to bring about more coherent, comprehensive global food security governance, and a more food secure world.
\end{abstract}




\section{Acknowledgements}

First, I would like to acknowledge two quotes that I had jotted down and posted near my desk early on in the research process - I do not know where I found these quotes, nor have I been able to find their source, however they are words that I came back to time and time again for reassurance and reaffirmation, and these are:

Your work is to discover your world and then with all your heart give yourself to it.

The trick is to keep your idealism after you've lost your innocence.

I am incredibly grateful to have had the opportunity in life to undertake this type of work, and for all the wonderful people in my life who made bringing this research to completion possible. I especially need to thank my thesis supervisor, Michael Brklacich, for always being so patient, encouraging, and constructive, and for making sure that it was "Erica Drummond's thesis" all the way through. Deepest thank you also to Peter Andrée, for knowing what I was saying when I was not sure that I did, and special thank you to Natalie, for keeping me on-track. I feel so fortunate and grateful for my friends and family who provided so much love and support. Specifically though, I need to thank Sean, for always being there for discussions and inspiration. Trevor, for being my rock, Michelle, for being my light, and my Mom, Linda, and Dad, Paul, for being the most wonderful, loving and supportive parents that anyone could hope for. 


\section{Contents}

Chapter 1 -Introduction and Thesis Overview ....................

1.1 Introduction

1.2 Thesis overview

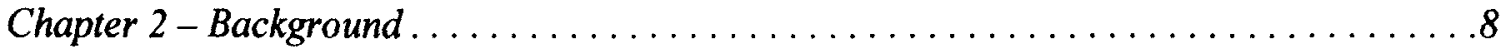

2.1 Establishing the Context for Food Security

2.1.1 Definitions and conceptual evolution

2.2 Insight into Current Food Security Institutions

2.2.1 The Food and Agriculture Organization of the United Nations

2.2.2 The Via Campesina

2.2.3 Moving Forward: IAASTD

2.3 Conclusion of food security background

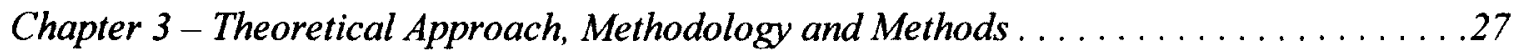

3.1 A Poststructuralist Approach

3.2 Positionality and Reflexivity

3.3 Policy and Purpose

3.4 Critical Political Economy

3.5 Global Governance

3.6 Critical Agri-food Studies

3.7 Global Food Security Governance

3.8 Governance by Discourse

3.9 Global governance and change within regimes and institutions

3.10Methodology and Methods

3.11 Concluding thoughts on theoretical approach, methodology and methods

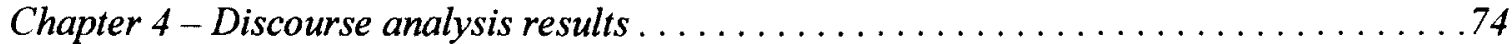

4.1 Situating the texts

4.2 Internal realities

4.3 Overview of discourse analysis results

4.4 Themed areas of analysis

4.4.1 Developed and developing, North and South

4.4.2 The role of international trade and domestic regulations

4.4.3 The role of rights

4.4.4 The role of global governance

4.5 Conclusion of discourse analysis results

Chapter 5-Discussion: Re-conceptualizing food security governance

5.1 The global food security governance regime: synergy and fragmentation

5.2 Food sovereignty, rights, and governance

5.3 Global food security governance and agency

5.4 Participation, democratic decision making, and transparency in global food security governance

5.5 Coherent policies, collective action

5.6 Concluding the discussion

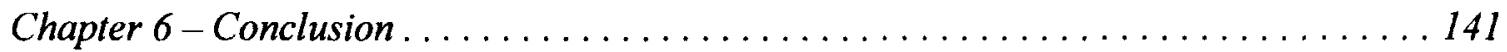

Appendix 1 - Summary of discourse analysis results $\ldots \ldots \ldots \ldots \ldots \ldots \ldots \ldots \ldots$ 


\section{Chapter 1 - Introduction and Thesis Overview}

\subsection{Introduction}

We live in a time where the term G-zero has been used to describe the decreasing cohesion of the international system (Bremmer, 2011; Bremmer and Gordon, 2011). From the increase in Free Trade Agreements (FTAs) to the revolutions in the Middle East, the multilateral system and the power and forces that have traditionally enabled for a certain degree of cooperation at the international level are losing relevance (Roubini, 2011). The recent global financial crisis brought many of the tensions of the international system into focus, so too did the 2008 global food crisis. Many authors have argued that these crises - food and finance - are not isolated instances, but rather they are symptomatic of deeper global governance problems (Conceição and Mendoza, 2009; Dupont and Thirlwell, 2009; Lang, 2010; Timmer, 2010). In the realm of global food and agricultural governance the term 'food security' has been applied to a range of global food related issues - from short term responses to crisis, to the long term deeper goal of realizing the right to food (Conceição and Mendoza, 2009; Lang, 2010). It is within this environment of complex and changing global systems that the debate over food security has taken shape (Salih, 2009).

It is important to recognize the role that food plays at many levels in society, from its ongoing role in our day-to-day lives, to the impact of food and agriculture on international co-operation and conflict. The production, consumption, and cultural representation of food: sustain us; are our biggest impact on the planet's ecosystems; and constitutes the materiality of our beings. Yet, despite this important and multidimensional role (Feindt and Flynn, 2009), many in the world are still subject to 
varying forms of food insecurity. The complexity of the global food system has increased significantly in the last half century, the integration of the global economy has increased, and the number of actors, both state and non-state, with a voice in the global governance of food has also increased (Salih, 2009). The complexity that characterizes the global food system exists in a world where, despite the importance of food in terms of both sustenance and cultural representation, an appalling number of people still go hungry, do not regularly consume enough nutrients, or spend a disproportionate amount of their time and resources on meeting their nutritional needs.

In 2009 estimates of the number of people suffering from hunger and malnutrition globally ranged from 833 million (USAID, 2009) to 1.02 billion (FAO, 2009). Children under five are particularly vulnerable with one child dying every five seconds from hunger and related causes, and almost 200 million children under five being underweight due to lack of food. Hunger and malnutrition kill more people each year than AIDS, malaria and tuberculosis combined (Shaw, 2007). Still yet, aggregate data may hide drastic differences between regions, as well as sub-regional inequities, complicating the ability to make accurate estimates.

Food security is crucial to these concerns, yet this term is contested by many actors, in its various invocations (Mooney, 2009; Barrett, 2010). Since it was first introduced into the international policy sphere at the 1974 World Food Conference, the concept of 'food security' has "evolved, developed, multiplied and diversified" (Maxwell, 1996, p. 385). Approaches to this topic range from economic, to rights and justice based, to approaches concerned with human well-being, with some estimates putting the number of definitions 
of the term at over two hundred (Shaw, 2007). The contested nature of this term speaks to its usefulness in describing a complex problem. Defining food security might be compared to creating a vision statement, that is, the definition encompasses what the one defining the term believes a food secure world should resemble. Subsequently, plans, programs, and priorities are developed with the aim of achieving this given vision of food security. Yet the definitions are so numerous and the differences between them so fundamental to how food security is understood in real and material ways, that the term no longer has a single, clear, meaning. As Mooney recognizes in his piece on the contested nature of food security "All vogue words tend to share a similar fate: the more experiences they pretend to make transparent, the more they themselves become opaque" (Mooney, 2009, quoting the work of Zygmunt Bauman, 2008)

That this term is contentious should come as no surprise given the important role of food and agriculture. Some groups have moved beyond trying to define or redefine food security given the baggage it caries, resulting in the introduction of new terms, such as 'food sovereignty' that aim to reframe the food security debate. These debates, or the on-going challenges currently taking place within the realm of food security governance, include the need to regulate or further deregulate agricultural markets, the role of human rights instruments in food security solutions, and the issue of representation in the

\footnotetext{
${ }^{1}$ The Via Campesina definition of food sovereignty is "the right of people to healthy and culturally appropriate food produced through ecologically sound and sustainable methods, and their right to define their own food and agricultural systems" (Via Campesina, 2009, p.74). An earlier definition from La Via Campesina as quoted in Patel's 2009, What does food sovereignty look like?: "Food sovereignty is the right of each nation to maintain and develop its own capacity to produce its basic foods respecting cultural and productive diversity. [...] Food sovereignty is a pre-condition to genuine food security" (Via Campesina, 1996, as quoted by Patel, 2009). Food sovereignty has challenged the traditional discussion over food security. It is recognized within the literature that the introduction of this term may be seen as an act of resistance to the productivist, market-driven responses that have characterized the food security regime (Desmarais, 2009).
} 
mechanisms and structures of global food security governance. The evolution of the definition of food security and food sovereignty, and the shifts and changes in the global discourses surrounding food security, are seen to be symbolic of the governance challenges facing the regime of global food security governance.

Still, despite this global focus on issues of food security, approximately $15 \%$ of the world's population is food insecure and this contributes toward many concerns, ranging from stunted growth of children to political instability. Clearly, there is an urgency to refine not only the definition of food security and its concepts, as this lack of precision and agreement can hinder responses to food insecurity, there is also the urgent need to address current challenges facing global food security governance. This research contributes to these discussions by evaluating the ways in which discourses construct how 'food security' is structured and practiced, and exploring the ways in which current discourses on 'food security' and 'food sovereignty' frame and shape global food security governance, and in turn food security outcomes and the potential to eradicate food insecurity.

To critically examine the use of food security and food sovereignty discourses within a contemporary global food governance context, this research uses discourse analysis to examine the convergences and divergences in the discourses of two international organizations active in global food security governance, the Via Campesina, an international farmers movement, and the Food and Agriculture Organization (FAO) of the United Nations (UN). Rooted in the critical agri-food studies literature, which adopts a multidimensional approach to the challenges of the global food system (Carr, 2006; 
Conceição, P. and Mendoza, 2009; Thompson and Scoones, 2009; Lang, 2010), this research is premised on the assumption that it is important that the global food security governance regime, as represented by the discourse of the FAO, take into account many of the concerns of the Via Campesina in terms of the organization's focus on rights, sovereignty, accountability, participation, and transparency. The aim is not only to identify convergences and divergences, but also to explore where these tensions and commonalities in discourse signal openings where this dialogue can be moved forward. The literature recognizes that the global food security governance regime needs to be progressively reformed to be more democratic and responsive to the needs of small farmers and others (Suppan, 2008; Patel, 2009; Thompson and Scoones, 2009), and this research explores whether the food crisis and responses to it by these two organizations represent a possibility for the regime to move forward in this progressive direction.

In order to accomplish this task, the food security discourses of these two international organizations were deconstructed and analyzed in order to gain a better understanding of the current state of global food security governance. To explore the often differing, yet at times convergent, discourses of these two organizations, official policy documents (texts) of the Via Campesina and the FAO, released in 2009, just after the 2008 global food crisis are analyzed using critical discourse analysis, which allows for the deconstruction of discursive events such as language and texts. Language and discourse are understood to be both social and political by being the primary means through which ideology and worldview are communicated, and as such differing discourses are seen to represent a site of contestation and struggle for power. 
Through multiple readings and re-readings of the texts various themes, inconsistencies, and 'regimes of truth" ${ }^{2}$ were identified and have come to form the basis of this in-depth analysis of change taking place within the global food security governance regime.

Rather than explore the texts of one organization over time, the texts of these two organizations were chosen. This was not meant to put them in opposition to each other or to dichotomize food security, but rather, it was thought that the discourses emerging from an assessment of two, in some ways very differing organizations, would shed light into some of the current challenges facing the eradication of hunger and malnutrition and the realization of food security globally. The global governance literature helps to explore the texts and discourses in terms of the challenges facing food security governance, and in order to come to some more normative conclusions about these challenges.

It is shown that, though there are commonalities which are identified in the discourses of these organizations, and that shifts in the global discourse surrounding food security may be seen to be taking place, there are significant areas of divergence between the two organizations, which represent fundamental differences in norms and principles. These differences, along with powerful hegemonic structures, currently limit the possibility for change in line with food sovereignty objectives to occur. It is also shown that intelligent agency has been important in the Via Campesina's ability to influence global food

\footnotetext{
${ }^{2}$ Elaborated further in chapter 3 , section 3.10 , on the critical discourse analysis methods and methodology employed in this research, as Berg highlights identifying 'regimes of truth' is useful in trying to understand "the mechanisms by which a particular discourse is seen to have both validity and worth" (Berg, 2009, p.220). First introduced by Michel Foucault in Truth and Power, an excerpted version of an interview with Alesandro Fontana and Pasquale Pasquino, initially published in 1972. Foucault described that '"Truth' is linked in a circular relation with systems of power which produce and sustain it, and to effects of power which it induces and which extend it. A 'regime' of truth" (Foucault, 1972).
} 
security discourses, and that, in the long-term, it is this intelligent agency which may be able to bring about the participation, inclusivity, and the type of rational discourse seen as needed in order to allow for movement forward in the more progressive direction envisioned by the Via Campesina.

\subsection{Thesis overview}

First, the context for food security is established by exploring the definitions and conceptual evolution of the term. Background on the two organizations being considered, as well as a discussion of shifts taking place within this regime of global governance, is then provided, using the evolution of the food security concept over time as a means of structuring this section. Next, the theoretical and methodological frameworks of poststructuralism, critical political economy, global governance and critical discourse analysis employed in this research are introduced and justified. The discourse analysis results are then provided, and are structured by examining the synergies and divergences in the food security discourses of these two organizations surrounding key themed areas (the distinction made between developed and developing countries, the role of international trade and domestic regulations, the role of human rights, the role of global governance). In order to examine the discourse analysis results, the global governance literature on synergies and divergences within regimes of global governance, governance and change within regimes and institutions, and governance by discourse is used to explore the areas of convergence and divergence between the two organizations with the aim of contributing a deeper understanding of the current state of global food security governance and in order to discuss the challenges going forward in terms of realizing food security or food sovereignty objectives. 


\section{Chapter 2-Background}

The complex nature of food security - the governance mechanisms, institutions, and multiple discourses which define it require an unpacking of sorts in order to contextualize the analysis and discussion which will follow. This section is not given with the assumption of completeness, or objectivity regarding events which have 'occurred', but rather, it is presented in order to provide a review and appraisal of food security concepts and evidence with the aim of positioning the research more broadly within the food security literature. It begins by establishing a context for food security by exploring the definition and conceptual evolution of this term and its related sphere of global governance. Insight into current food security institutions is then provided by exploring the inception of, and current literature on, FAO and Via Campesina, and also explores the changing relationship between these two organizations, structuring this discussion by examining the evolution of food security as a means to interpret recent discourses.

\subsection{Establishing the Context for Food Security}

\subsubsection{Definitions and conceptual evolution}

Global discourses surrounding food security emerged in the inter-war period of the 1930's amidst a range of changing global pressures (Shaw, 2007). The Great Depression played an important role in shaping how states perceived their roles', both domestically, as providers of more welfare-based economic policy, and as global actors, in their role in international institutions (Shaw, 2007). After World War II states began to work together for the first time on issues relating to international food and agricultural systems. The understanding at the time suggested a productivist model of food and agricultural systems as the best means to attain the desired ends of eradicating hunger and malnutrition. 
Some thirty years later the Green Revolution would further entrench this agricultural and development model. In the mid 1970s, during the global food and energy crises that occurred at this time, and at the height of the Green Revolution, the concept of food security, as it is more contemporarily discussed, began to take shape (Shaw, 2007). At the 1974 World Food Summit the international community invoked for the first time the term 'food security' to begin to describe a more integrated understanding of international food systems.

The first definition of food security was "the availability at all times of adequate world food supplies of basic foodstuffs to sustain a steady expansion of food consumption and to offset fluctuations in production and prices" (United Nations 1975, cited in FAO 2003, as cited in Patel, 2009, p.664), see table 4.1 (chapter 4) for overview of food security and food sovereignty definitions over time. The sole authors of this definition were states and it came about at a time when there was a "technocratic faith in the ability of states to redistribute resources if the resources could only be made available" (Patel, 2009, p.664). This first attempt to define food security as an international community recognized dimensions of food and agriculture that were global in scope. Food security was first and foremost about sufficient production to meet consumption demands. Overall, this was a significant initial step that moved agriculture, and especially food security, onto the global stage. However, the Report of the World Food Conference, published in 1975, by the FAO, begins with the following declaration: "Every man, woman and child has the inalienable right to be free from hunger and malnutrition in order to develop fully and maintain their physical and mental faculties" (FAO, 1975, emphasis added). This 
statement indicates quite early on in the food security discourse, the recognition of dimensions beyond production and consumption.

Issues of food availability, access, use, rights, health, supply, aid, food safety and nutrition are among the themes found within the many definitions of food security today (Borras et al., 2008; FAO, 2008; Patel, 2007; USDA, 2009). A more recent definition which can be contrasted against the earlier 1970's version defines food security as "a situation that exists when all people, at all times, have physical, social and economic access to sufficient, safe and nutritious food that meets their dietary needs and food preferences for an active and healthy life" (FAO 2001 cited in FAO 2003, as cited in Patel, 2009, p.664). Still, this new definition of food security "avoided discussing the social control of the food system" (Patel, 2009, p.665), something which critics of the global food and agricultural governance system were beginning to be more vocal about at that time (Desmarais, 2007; Patel, 2009). Via Campesina and other groups and organizations which critiqued the current global food system were of the position that in any discussion of food security that "the power politics of the food system needed very explicitly to feature in the discussion" (Patel, 2009, p.665). These differences in the way food security is understood by various actors within the food security regime point to fundamental differences in norms and values of these actors.

The many and varied definitions and interpretations of food security illustrate that it remains a contested and contingent concept (Barrett, 2010; Lang, 2010). It is often invoked, yet not concretely defined, its meaning encompassing a range of connotations, to a range of actors, in its frequent invocations. Much like the term 'security' studied by 
many critical scholars and demonstrated to be "not a thing or state of affairs that is universal or timeless in its meaning" (Williams, 2009, p.168). Rather, it is understood as "a fluid and socially constructed phenomenon, the meaning of which changes significantly across time and space" (Williams, 2009, p.168). Williams understands food security through this constructivist lens and argues that it is this changing and shifting meaning of food security that allows it to be constructed in such a way that it could be used by groups with differing or even conflicting understandings of the problem (Williams, 2009).

Similarly to William's analysis, Clapp and Fuchs show how the "contested nature of the concept of sustainability has enabled it to be used strategically by different actors" (Clapp and Fuchs, 2009, p.13). The same could be said of the concept of food security, where the term is invoked in such varying contexts and likely meaning different things to different actors each time it is employed. To some, food security means organic and local approaches which encompass the preservation of biodiversity, while to others it means technocratic and market driven approaches to agriculture and food which stress the potential of scientific fixes (Sell, 2009). Yet, while many try to redefine food security or even introduce new terms to describe this complex social, environmental, and economic phenomenon, little progress has been made in terms of meeting the objectives that have been set forth in these varying definitions, that is, at minimum, to eradicate hunger and malnutrition (Salih, 2009). 


\subsection{Insight into Current Food Security Institutions}

Both the Via Campesina and the FAO have a leadership role in international food security governance in terms of framing the debates and discourses which emerge surrounding food security. Between the state based membership of the FAO and the voices of farmers heard through the Via Campesina, these organizations may be seen to represent the food security objectives of a large portion of the world's population. Though the inception of these organizations occurred almost 50 years apart, it is important to note that the early roots of what would later become the transnational agrarian movement (TAM), of which the Via Campesina is a part, and the beginning of what would later become the FAO, both emerged in the ten year period between 1925 and 1935 (Shaw, 2007; Borras et al., 2008), at a time of great poverty and global financial turmoil. There was the increasing recognition at this time of the role of states in providing a certain level of social well-being for their peoples and there was also recognition in the international community that a global approach was necessary in order to address increasingly global problems.

\subsubsection{The Food and Agriculture Organization of the United Nations}

In the spring of 1943 during the Second World War, a United Nations Conference on Food and Agriculture was held in Virginia, USA, with one important outcome of this conference being the creation of the Food and Agriculture Organization (Shaw, 2007). An important declaration adopted at the conference stated that the Conference "has considered the world problems of food and agriculture and declares its belief that the goal of freedom from want of food [...] can be achieved" (FAO, 1943, as quoted by Shaw, 2007, p. 5). A little over two years later, the FAO was established at its first Conference 
in Quebec City, Canada on October $16^{\text {th }} 1945$. At this first Conference, the first Director General of the organization, Boyd Orr described the activities undertaken by the organization as those that are done "not because they will bring prosperity, but because they are right" (Boyd Orr, FAO Director, 1945, as quoted by Shaw, 2007, p. 5). This is a bold statement, and some wonder if the organization has lived up to its initial goals (Patel, 2007; Shaw, 2007; Fouilleux, 2009).

After WWII there was a feeling in the international community that nations had the chance to work together on issues of common concern. In 1942, the Declaration of the United Nations, and the adoption of the UN Charter in 1945, pointed toward the development of a more cooperative global framework. Nevertheless, the global food and agricultural situation continued to deteriorate, and in 1946, within a year of its first meeting, the FAO held a Special Meeting on Urgent Food Problems in an attempt to address immediate problems of world food supplies, as well as to develop more longterm proposals to address these problems at the international level. One outcome of this meeting was the proposal to establish a World Food Board (WFB), which would establish a world food reserve in order to stabilize prices and agricultural markets, and called for international action and cooperation.

However, the global climate of cooperation that was seen immediately following WWII declined quickly, and by 1946, when the WFB was proposed, the UK opposed it due to fears that it would lose the advantage it was experiencing importing food cheaply from certain markets. While the US opposed its creation due to the belief that, as a world power, US interests would be better served through bilateral aid to other countries, and 
also due to the increasing belief that food and agriculture, and the rules that govern it, belonged in the realm of trade arrangements. The US was invested in the development of an International Trade Organization which, due to similar crises of global cooperation, instead became the General Agreement on Tariffs and Trade (GATT), then in 1995 the World Trade Organization (WTO). This shift from the WFB proposal, where food is treated as a social good, to the increased inclusion of food in the discourse on international trade agreements, can be seen to have established the treatment of food as a commodity.

The FAO currently has 191 Member States, and claims that it "leads international efforts to defeat hunger" (FAO, 2011). In terms of organizational structure, the FAO Conference (of Member Nations) meets every two years to determine the policies of the organization, approve the organization's Budget and Programme of Work for the next two-year period, and is attended by all member states, as well as observers, NGO's, civil society and industry groups. FAO Council forms the executive organ of the organization and is made up of representatives from 49 Member States elected to the Council at Conference meetings. The Council meets four times between Conferences and is charged with assessing changes in food and agriculture which may occur in this two year interim period, looking at future activities for Programme and Budget, as well as attending to any constitutional issues of the organization. Regional Conferences are held every two years and contribute to Programme of Work and Budget activities of the organization. There are five Regional Conferences which take place in Africa, Latin America, Asia and the Pacific, the Near East, and Europe, which feed into this process. However, for the 2010 round of Regional Conferences, held between April and December, an informal North 
American Regional Conference was held for the first time, recognizing the increasing power of these Regional Conferences in contributing to the financial and programmatic policy of the organization.

Recent criticism surrounding the FAO has focused on its overly bureaucratic organizational structure and culture, and a lack of effective leadership (Fouilleux, 2009). Within the organization, Member States are prone to power struggles which have lead to the inability to move forward on key issues (Fouilleux, 2009). The organization has also had "major difficulties in forging outside alliances, whether with peasant organizations or in academia" (Fouilleux, 2009, p.757). All this, it is said, has lead to a failure on the part of the FAO to "make the most of its analytical and discursive resources" (Fouilleux, 2009, p.757). This "credibility and legitimacy deficit" (Fouilleux, 2009, p.757) has caused the FAO to look inwardly in recent years and undergo a process of reform, where its programme and financial structures are being rethought and reconfigured.

In 1995 , the FAO celebrated the $50^{\text {th }}$ anniversary of its first meeting, and it was also in this year that the Global Assembly on Food Security was symbolically held in Quebec City, the same city where the first FAO meeting had been held. The Global Assembly on Food Security was a meeting of over 200 representatives of NGOs and other civil society organizations who met in order to discuss issues of food security and decide on a set of principles and recommendations as a contribution to the discourse leading up to the World Food Summit to be held the next year, in 1996. 


\subsubsection{The Via Campesina}

It was at the Global Assembly on Food Security that "the Via Campesina made its first real appearance in the international arena" (Desmarais, 2007, p.98). The Via Campesina is the largest TAM of peasants, small- and medium-sized producers, landless, rural women, indigenous people, rural youth and agricultural workers (Borras, 2008;

Desmarais, 2008). It is an organization which claims to be "an autonomous, pluralist and multicultural movement, independent of any political, economic, or other type of affiliation" (viacampesina.org). The Via Campesina is made up of 149 organizations from 56 countries (Desmarais, 2007).

The first conference of the Via Campesina was held in Mons, Belgium, in May of 1993 (Desmarais, 2002). Originally meant to be a meeting that would establish a research project based on the needs and participation of farmers, those attending the meeting envisioned the creation of a new international farmer and peasant movement (Desmarais, 2007, p.76). At this conference, the Via Campesina constituted itself as a "world organization", and defined its structure and first strategic guidelines (Via Campesina, 2009). The formation of the Via Campesina symbolized an "internationalization" of the efforts of peasant and farm organization (Desmarais, 2007, p.32). What specifically set the policy statement emanating from this first meeting apart from definitions or policy statements regarding food security to come before it, is the recognition that every country should have the right to define its own agricultural policy (Desmarais, 2007, p.77). Since this first constitutive declaration, the definition of food sovereignty has evolved to include dimensions such as ecology, sustainability, and the cultural appropriateness of 
food (Via Campesina, 2009), see Table 4.1 for a comparison of food security and food sovereignty definitions that have evolved from 1974 to 2009.

The Via Campesina is Spanish for "Peasant Way" or "Peasant Road" (Desmarais, 2007, p.8). Although, it must be recognized that 'campesina' in Spanish means something slightly different than the word 'peasant' in English, and this is why the movement has decided not to translate 'Via Campesina' into English (Desmarais, 2007). Whereas in Spanish campesino means "Labrador, persona que vive y trabaja en el campo: los campesinos se levantaban al amanecer para labrar sus tierras (Diccionario de la lengua española, 2011), which can be translated as "Farmer, person who lives and works in the field: peasants rose at dawn to till their land, someone who lives and works in the field or on the land", in English peasant is defined as "A poor farmer of low social status who owns or rents a small piece of land for cultivation" (New Oxford English Dictionary, 2011). The difference here is that in English, peasant has a pejorative connotation, whereas in Spanish it means something closer to farmer. It is for this reason that Via Campesina is used as a proper noun, and has not been translated or italicized throughout this document.

In terms of organizational structure, the Via Campesina is divided into eight regions, two representatives (a man and a woman) from each region make up the International Coordinating Commission, "the ICC is the key decision-making and co-ordinating body of the Via Campesina. All major decisions are made in consultation with its sixteen members" (Desmarais, 2007, p.30). An International Conference of the Via Campesina is held once every three to four years, with Regional Conferences held leading up this, in 
order to ensure that the work of the organization links to "local realities" (Desmarais, 2007, p.30). The Via Campesina is "convinced that the current structures of economic, political, and social power are unjust and exclusionary", and as such are committed "to redefine rural development and to build an alternative model of agriculture" (Desmarais, 2002, p. 97). It is for this reason that the Via Campesina are generally recognized within the literature as offering a meaningful opposing vision to the dominant market-driven capitalist interpretation of agriculture and food (Desmarais, 2002, 2007, 2008; Patel, 2007, Borras, 2008; Suppan, 2008). This is important because as long as food is treated solely as a commodity, and so long as the governance of food and agriculture remains unjust and exclusionary, food sovereignty and food security can not be realized, from the point of view of Via Campesina and their supporters.

Critiques of corporate concentration in food and agriculture have "spawned movements such as those promoting "food sovereignty" $[\ldots]$ which seek to retreat from the global, corporate-led food and agricultural system, to a more local and ecologically sustainable food system" (Clapp and Fuchs, 2009, p.15). The Via Campesina is recognized as the "initial and most persistent proponent of food sovereignty" (Suppan, 2008, p.1). First appearing within the international discourse at the 1996 World Food Summit, the term 'food sovereignty' encompasses and is considered an agricultural and environmental policy framework, which seeks to advance food security aims through more local approaches "rather than reliance on international trade" (Suppan, 2008, p.2).

Many attempts have been made to define food sovereignty, and definitions of this term are numerous and evolving (Ishii-Eiteman, 2009). However, much like food security, the 
concept of food sovereignty remains at times muddled and contradictory. Patel argues that this "proliferation of overlapping definitions is, however, a symptom of food sovereignty itself, woven into the fabric of food sovereignty by necessity" (Patel, 2009, p.663), as there is not an uncontested, homogenized farmer or peasant identity (Desmarais, 2007). Patel argues that in defining food sovereignty, Via Campesina has often erred on the side of having a broad but shallow definition, or put in another way, have erred on the side of inclusivity at the expense of possibly diluting the impact of their message (Patel, 2009). The advantage of this approach involves the concept of "big tent" politics, the idea that "disparate groups can recognize themselves in the enunciation of a particular programme" (Patel, 2009, p.666). It is understood that these issues may be divisive, yet while there is conflict at times within the movement, there is enough common ground on core issues that these differences do not preclude the ability to work together (Desmarais, 2007).

\subsubsection{Moving Forward: IAASTD}

These organizations and their texts were selected for analysis as they offer two of the more influential discourses on food security. FAO benefits from the international recognition that comes from being a member of the UN system (ref.), while the Via Campesina is largely considered to be the most influential transnational agrarian movement (Desmarais, 2008; Patel, 2007). Both organizations recognize that important shifts have happened in the global discourse on food security since the fall of 2008 , despite this, there is little literature which explores this shifting discourse. In May of 2009, the UN Committee on World Food Security released a statement entitled 'Towards a renewed Committee on World Food Security', which expressed the following: 
The Committee on World Food Security (CFS) is undergoing a reform process, following the decisions of its Members States and of the extraordinary Conference of FAO during the Sessions of October and November 2008 respectively (FAO.org).

Around the same time, in reference to the same series of conferences being discussed above, a press release from the Via Campesina from October 2009 stated that:

Led with passion and sagacity by the Permanent Representative of Argentina to FAO acting as CFS Bureau Chair, the nine month negotiation process had taken the unusual step of opening up, beyond the Bureau, to all of FAO's member governments and to other concerned stakeholders, including civil society. Organizations of small-scale food producers of the south and NGOs made a fundamental contribution, facilitated by a global mechanism they have built up over the past decade under the banner of food sovereignty (viacampesina.org).

The changing positions of these two entities regarding global food security represent the constantly shifting nature of the concept itself. Nevertheless, there is a lack of literature on the changing relationship between food security and food sovereignty, in particular, on the changing discourses of the FAO on these concepts. The discourses employed throughout this shift were explored as a central theme of this research.

Many have recognized the Agriculture at a Crossroads Global Report (2009) from the International Assessment of Agricultural Knowledge, Science and Technology for Development (IAASTD) as representing a shift in the global discourse surrounding food security (Clapp and Fuchs, 2009; Ishii-Eiteman, 2009). The report is introduced here as a means to demonstrate shifts taking place within the global governance of food security. As was shown above, the Via Campesina's push toward the recognition of food 
sovereignty and the right to food is attempting to influence the global discourse on food security and food and agriculture more broadly, and this report may be seen as an example of this changing global discourse. Coming out of what has been recognized as a more inclusive approach (Ishii-Eiteman, 2009), the IAASTD aims to ensure that agricultural knowledge, science and technology fulfills its potential to meet the development and sustainability goals of the reduction of hunger and poverty, the improvement of rural livelihoods and human health, and facilitating equitable, socially, environmentally and economically sustainable development (IAASTD Global Report, 2009, p.8).

Initiated in 2002 by the FAO and the World Bank, the IAASTD can be seen as a multistakeholder initiative which included the input of multiple UN programmes and organizations, civil society, NGOs, as well as "the work of hundreds of experts from all regions of the world" (IAASTD Global Report, 2009, p.9), who contributed to the preparation of the report and the peer review process. The approach undertaken in the creation of this report has been compared to that used by the Intergovernmental Panel on Climate Change (IPCC), however it is recognized that "international scientific groups such as the IPCC are more embedded in the political process than suggested by conventional accounts of epistemic communities" (Levy and Newell, 2002, p.90).

Nonetheless, this process "injected into the debate a far wider array of voices, perspectives, and sources of empirical evidence than typically admitted in conventional policy making circles" (Ishii-Eiteman, 2009, p.690). In doing so, it also highlighted differing, and at times conflicting, understandings of the "multiple historical explanations and narratives" (Ishii-Eiteman, 2009, p.690) embedded within food and agricultural policy (Clapp and Fuchs, 2009; Ishii-Eiteman, 2009). Working through these narratives 
and understanding the tendency within food and agricultural policy to privilege certain narratives over others required that the IAASTD focus on "issues of equity, power, and influence" (Ishii-Eiteman, 2009, p.690). It is important to note the Syngenta, one of the world's largest agribusiness companies, dropped out of the IAASTD process before the final report was published, sighting differences in the perceived role of GM technologies as reason for their disengagement in the process, while the United States, Australia and Canada, did not fully endorse the final report, with an annex at the end of the document outlining the reservations of these countries (IAASTD Global Report, 2009).

The IAASTD recognises that technocratic and productivist approaches to food insecurity will not advance the goal of creating socially equitable and environmentally sustainable food and agricultural systems (Clapp and Fuchs, 2009; Ishii-Eiteman, 2009). The report recognizes the importance of the concept of food sovereignty, presenting the right-based approach that is embedded in food sovereignty as 'an explicitly moral enterprise that stands in contrast to the economic processes of marketdriven globalization' [...] 'this implies a radical shift from the existing hierarchical and increasingly corporate-controlled research system to an approach that devolves more responsibility and decision-making power to farmers, indigenous peoples, food workers, consumers and citizens for the production of social and ecological knowledge' (Ishii-Eiteman, 2009, p.691).

It has been argued that the "Via Campesina's call for food sovereignty is precisely about invoking a right to have rights over food" (Patel, 2009, p.663). Furthermore, it extends beyond food and nutritional concerns, to concerns about production processes, the long term ecological sustainability of production, and collective rights. The Via Campesina "insists that an alternative model [of food sovereignty] must be based on certain ethics 
and values where culture and justice count for something" (Desmarais, 2002, p. 101). Food sovereignty is seen, not as a technological issue concerned solely with access and availability, but rather, as a social and cultural issue with normative implications regarding the processes and practices which surround the production and consumption of food.

Despite the increasing recognition within the literature that the meaningful realization of food sovereignty may be required in order for food security to become a reality (Desmarais, 2007; Ishii-Eiteman, 2009; Patel, 2009), there is "the widely agreed notion that food sovereignty isn't what we have at the moment" (Patel, 2009, p.663). It is recognized that food sovereignty is a precondition for food security to be realized, as it is seen to extend beyond food security both in terms of its breadth of consideration in its concern for local, regional and global dimensions, and in its concern for issues of social justice and women's rights, as well as biodiversity and environmental sustainability. Proponents of food sovereignty have not failed to recognize the power that accompanies the term 'food security' with regard to the salience it has in describing a problem and invoking a certain set of policy responses. Yet what is invoked is found to be lacking, in that what is invoked fails to recognize the underlying causes of food insecurity. Therefore every effort has been made by the Via Campesina and proponents of food sovereignty to supplant the use of food security in the global discourse with the use of food sovereignty, as it is recognized that this term distinguishes an entirely different set of policy responses. 
The Via Campesina has tried to distance itself from food security because it sees the term as bogged down and wants to advance the discourse. It has set itself apart from food security by employing the concept of food sovereignty, and in maintaining that "food sovereignty is to be distinguished from food security" (Desmarais, 2007, p.34), and as such, it has been questioned whether it is worthwhile or appropriate to speak about these two terms in relation to each other (Patel, 2009). But as the international food policy regime increasingly appropriates and adopts this language of 'food sovereignty' (Jarosz, 2011), the implications of this shifting discourse can be seen both in terms of the global food and agriculture governance implications of this shift, and in terms of what this discursive shift means regarding issues of power and legitimacy for the actors involved. The texts of the FAO and the Via Campesina can be seen to offer insight into the ways in which food security and food sovereignty discourses are created, appropriated, and challenged at the international level, with very real implications for food security governance.

\subsection{Conclusion of food security background}

The magnitude of the issue of food insecurity, and the complexity of global food security governance, in terms of the multiple issue areas which interconnect, and the varied approaches to this issue, have shown the necessity for the food security concept to evolve over time. As responses continue to be ineffective in terms of addressing food insecurity around the world, there has been the need for food security concepts and food security institutions to evolve in an attempt to find ways to address these issues, and though the discourses have evolved from productivist to rights based, there is still seen to be a lack of food security globally. The goal of this background chapter was to provide an 
overview of the food security concept, and to illustrate the current state of global food security governance, in order to contextualize the analysis. The overview of food security definitions provided a means through which to examine the evolution of this concept overtime, while the background on food security institutions provided both a means through which to structure further elaboration of the evolution of the food security regime, as well as a starting point to begin discussing the convergences and divergences between these organizations in more depth. Finally, the IAASTD report provided a starting point to begin to discuss the changing relationship between these two organizations, as well as change within the food security regime.

The differing organizational structures and decision making processes of the organizations impact their ability to come to consensus and move forward on issues of concern. With the organization based membership and open and inclusive decision making processes of the Via Campesina greatly influencing its ability to come to consensus within the organization on potentially divisive issues. Whereas the state based membership of the FAO makes decision making and consensus building less nimble. Regional dimensions of governance were shown to be important for both organizations. It was also shown that the inclusion of food sovereignty in the IAASTD report represents an important shift in the food security regime, where this term is beginning to gain prominence and salience in the global food security governance discourse. How the Via Campesina has been able to influence the regime, and further obstacles to the meaningful implementation of food sovereignty approaches into the global governance of food security, are explored through critical discourse analysis and the global governance 
literature in order to come to more normative conclusions about the possibility for change within this regime of global governance.

The next chapter explores the theoretical approach, methods and methodology, which underpin this research. The postmodern and poststructural approach taken in this research in terms of the critical approaches of discourse analysis and political economy, and the more normative dimensions of this research, in terms of the need to move beyond critique and move toward reconceptualizing global food security discourses, are discussed. An overview of the critical agri-food studies literature is provided with the aim of further illustrating the positionality of this research. The global governance literature is explored, as it provides, along with the critical political economy framework, a basis for interrogating the food security discourses deconstructed in this analysis, and also provides a means to explore mechanisms for change within regimes, and the possibility of shifting the global food security discourse toward a more progressive direction. Finally, detail is provided regarding the methods and methodology which form the basis of the critical discourse analysis process employed to interrogate the texts and discourses of these two organizations. 


\section{Chapter 3 - Theoretical Approach, Methodology and Methods}

\subsection{A Poststructuralist Approach}

The Enlightenment Period represents a time in human thought which assumed the a priori existence of rationality as a basis for the production of 'knowledge' and 'truth' about the world. This modernist tendency, which presupposes objective reality, was critiqued for the creation of grand theories or metanarratives which assumed that 'true' knowledge of the world could be discovered. Poststructuralism emerged at a time that saw the questioning and rejection of these modernist interpretations to ontology and epistemology, and the recognition that metanarratives were an inappropriate means to describe and understand the world. In this sense postmodern, poststructuralist approaches recognize that all 'knowledge' is socially constructed and highly contextualized (Agger, 1994). What is known, and what is thought to be known, changes continuously over time and space and context. Therefore knowledge is not something that can simply be discovered and set in stone, it is something that is produced and cultivated over time.

There is recognition within the literature on poststructuralism that language and words and the discourses constructed by them, are powerful constructs (Dear, 1988; Creswell, 2009). Poststructuralist theories allow for text to be explored and understood as 'more than words'. These theories recognize the productive power of discourses and language how the way things are discussed and constructed is not only representational of the world that is being described, but also produces the world (Agger, 1994; Pryke et al., 2003; Berg, 2009). Poststructuralism comes from the understanding that "language lies at the heart of all knowledge [and] deconstruction exposes how language imposes limits 
on our thinking" (Dear, 1988, p. 266). As a theoretical framework, it allows for the deconstruction of text by "focusing on showing us how to read for absences in the text" (Dear, 1988, p. 266), thus allowing for a multifaceted interpretation of the text being considered.

Poststructuralism recognizes "how language is used to maintain the hegemony of the privileged discourse" (Dear, 1988, p. 265), and works under the theoretical assumption that:

Such texts at once are created by, impose, and maintain particular discursive formations that involve specific epistemological claims, circumscribe legitimacy, and provide the intellectual conditions of possibility of particular institutional and political arrangements (Creswell, 2009, p. 216).

Therefore, discourses may be seen to impose limits on the way the material world is understood, and also may be seen to produce a given reality. This is why it is so important to consider the discourses surrounding food security and food sovereignty, as these discourses may be understood as both produced by, and reproducing of, the dominant and competing discourses being employed. This understanding recognizes the power embedded within texts to shape the world in various ways, and it is this understanding which was used to approach the texts being explored.

\subsection{Positionality and Reflexivity}

Poststructuralism also recognizes the importance of the positionality of the reader. That is, that texts are not objective pieces of truth understood in a static state by all readers, rather, the meaning derived from text may be seen as changing and shifting depending on the temporal, spatial, and cultural experiences of the reader. This complicates the 
deconstruction of texts and the discourse analysis process in that it must be recognized that "knowledge is always a view from somewhere - partial, incomplete, embodied, situated" (Graham, 2005). It is understood that this analysis is based on my subjective readings of the texts being considered. Texts do not simply describe, nor are they based on any one 'true' experience of the world, and while this is seen to make discourse analysis empirically difficult, it is also seen to represent its usefulness in analyzing complex social phenomena. Although my reading of the text was inherently subjective, an attempt has been made to document the methods and approaches employed throughout this undertaking in order to provide for some degree of verifiability to the results of this research.

Throughout the research process the aim has been to remain reflexive of the lines of inquiry selected, the way questions were posed when interrogating the texts, and the language chosen in order to communicate the research process, analysis and results. In the deconstruction of text, it is recognized that, paradoxically, language is being used in order to represent and explain the language which has been deconstructed. The basis for this analysis, the texts, and the theories and methods employed to explore them "function as evidence only because they are bound this way into a narrative. It is a doubled narrative since it gives meaning to the things it claims are evidence of its truthfulness" (Crang, 2003, p.138). As a researcher, the selection of organizations and texts to be analyzed constitute a powerful act, placing one in the position to potentially legitimize in some way the very discourses being deconstructed. 
When analyzing complex social phenomena, it is important to see the "multiple interrelationships" between ideas, rather than some "straightforward sequence" (Crang, 2003, p.138). As has been shown food security and food sovereignty are contingent concepts which defy neat classification, their analysis requires an approach which is able to negotiate the complex dimensions of influence and power, and the multiple actors and framings which are involved in these discourses. This challenge surrounding the analysis of non-linear, subjective social constructs is perhaps best summarized in the following which provides an approach to overcoming these challenges. Writing of the work of theorist Walter Benjamin, Crang notes that:

His response was that instead of building a linear argument, he would work through images of juxtaposition and collage that would alter the meaning of each fragment and that this procedure would make new truths erupt, and, he hoped, disrupt the status quo, from the conjunctures and disjunctures between elements (Crang, 2003, p.136, writing of the work of theorist Walter Benjamin).

In order to work through the complex, dynamic, and shifting nature of the concepts being explored, the narrative employed attempts to deconstruct the creation, appropriation, and challenging of food security and food sovereignty discourses, and in so doing, it is hoped that a deeper understanding of global food security governance emerges.

In terms of the temporal scale being considered this research has focused on the period since the 2007-08 global food crisis. This temporal selection can be justified to some degree, as a time when issues of food security began to permeate global consciousness and hence as a time when those organizations addressing these issues began to receive a higher public profile, yet still, the impact is that only a partial account may be provided, as time does not stop when pen meets paper. As Crang notes "our interpretation is 
always shifting, contestable and more or less provisional, so that the decision when it stops is more one of pragmatics than completeness. [This] rejects 'totalization', where an interpretation purports fully to explain events" (Crang, 2003, pp.141-142). This understanding of the incomplete nature of any analysis is in line with poststructuralist epistemology, which as discussed in the previous section, finds the totalizing effect of the construction of metanarratives to be lacking.

Furthermore, it is recognized that any language, theory, or approach chosen is only one way of looking at or explaining the phenomenon being explored. An attempt has been made to contextualize, rationalize and justify these choices; nevertheless, it is recognized that they are embedded in my experiences, biases, and positionality as both a reader and writer of text. My interest in this line of research stems from a broad and varied interest in food and agricultural issues, and from the belief that food is more than nutrition; it is a political and cultural choice. Food security and food sovereignty, and the discourses surrounding these concepts, are understood to be at the nexus of a range of currently salient issues, from environmental sustainability and climate change, to issues of social justice and human health and wellbeing. As such, food is inherently political and it is believed that this important dimension as a driving force behind these discourses cannot be ignored.

\subsection{Policy and Purpose}

The texts of the organizations being considered presuppose knowledge of two kinds "of possibility and of purpose; of means and ends" (Daly, 2002, p.183). Possibility refers to things which could happen, states of the world which are likely to take shape, and purpose refers to the assumption that there are things which should happen, that there are 
goals or ends that are more desirable than others. Daly puts forth the notion that "[w]ithout both kinds of knowledge policy discussion is meaningless. [...] At a minimum the policy-maker must believe that there is more than one alternative future (nondeterminism), and that some possible futures are truly better than others (non-nihilism)" (Daly, 2002, p.183).

Postmodern approaches, such as poststructuralism, have often been critiqued for their nihilist tendencies. That is, for their tendency in some instances to lead to a level of abstraction which makes it difficult to make claims about better or worse states of the world. Policy making, to a certain degree, must be both modernist and post-modern. It is crucial that we accept, for policy to make sense, a certain degree of objective reality (Daly, 2002). This need to balance modernist and postmodernist approaches is also characteristic of academic research whereby in order to communicate a given line of inquiry one must assume a certain degree of objective reality while also recognizing the subjectivity of the researcher. Therefore, the approach applied here is both modernist, in its assumption that there are better or worse states of the world (a food secure world is better than a food insecure world), and also postmodern, in the recognition that local realities do matter (non-essentializing), and also in that the analysis of text and discourse is understood as both representing, and representational of, the material and textual worlds being explored (non-transcendentalizing).

\subsection{Critical Political Economy}

The economic dimensions of food insecurity and the focus within both texts on this aspect of global food security governance, necessitate a theoretical approach that allows for a critical analysis of these dimensions. In terms of theoretical positionality, this 
research is rooted in the critical theory of political economy, which allows for an interrogation and critique of the relationships between institutions, actors and the economy, with this framework being built around the notion that these relationships create the global political economy, while simultaneously being influenced by it. A critical political economy framework is recognized as a holistic approach which allows for the interrogation of global inequality (Shields, et al., 2011).

In the work of Erjavec and Erjavec, which employs discourse analysis to examine the Common Agricultural Policy in the European Union, a political economy framework is employed as it is recognized that "every discourse always functions within specific structural constraints and material interests" (Erjavec and Erjavec, 2009, p.218). In his work on the food regime McMichael argues that critically analyzing the food regime "is not about food per se, but about the relations within which food is produced, and through which capitalism is produced and reproduced" (McMichael, 2009), therefore a critical political economy approach engages with food, and food security, in relation to its geopolitical, economic and historical dimensions. In her work on food security definitions, Jarosz uses a critical political economy approach to examine food security policy discourse, and through this argues that changes to the definition of food security show that the definition increasingly represents neoliberal ideologies. Therefore critical political economy as a theoretical framework allows for the interrogation of the global food security governance solutions proposed by each organization, discussed further in chapters 4 and 5 , by allowing for the holistic and critical consideration of the implications of their positions and proposed solutions in terms of the broader global political economy. 
It is important to recognize also, that there is positionality to the discourses of the organizations being explored. That is, that the Via Campesina can be seen to be more in line with the assumptions of critical political economy in terms of their resistance of the current neoliberalism of the multilateral system of governance, whereas the FAO may be seen to tend more toward neoliberal tenets, largely due to the various states of which its membership is comprised.

Though there are many ways that global food security can be approached, in terms of the various theoretical perspectives which have been applied to this field of study, it was found that a critical approach, rooted in political economy, was the most in line with related literature on food sovereignty and food security governance. Authors such as Patel, Desmarais, Erjavec and Erjavec, Suppan, and Schiavoni, and others referenced throughout this research, may be seen to be rooted in this theoretical underpinning. This literature is often drawn on to interrogate this line of inquiry, as it is seen that:

[T]he notion of being critical is nothing if it does not have an emancipatory purpose at its heart. Merely destabilizing taken-for-granted ideas about the world is not enough; there must be a sense of how they could change, too, in favour of a more equitable world with human dignity and rights and possibilities at its core (Shields, et al., 2011, p.172).

Critical discourse analysis forms the basis of deconstruction, allowing for the unpacking of narratives being employed within the regime of global food security governance, while the theoretical frameworks of critical political economy and the literature on global governance are explored and employed in order to critically examine these narratives. Aligned with a critical political economy approach, there is a normative dimension to this 
research as well, where it is hoped that some conclusions reached might help to, in some small way, advance a more food secure world.

\subsection{Global Governance}

The application of a global governance framework in this analysis is employed for its critical and normative dimensions. Food security is examined through this lens because the need for improved governance emerged as a major theme through the discourse analysis process, and also because it provides a useful analytical framework to examine both governance through discourse as well as change within spheres of global policy and decision making. To build and justify this framework the term 'governance' is defined, followed by an historical account which links this framework to post World War II international relations theories of growing interdependence and the weakening of the state. Global governance and regime theory are used to explore the actors and institutions that make up this sphere of global thought and action. Global governance is seen as a useful framework for understanding food security as it allows for an analysis its complex and changing nature. Analytically, employing concepts of global governance is useful, but not without problematizing the hegemonic dimensions of power at play, and recognizing the potentially totalizing impact for which discussions of global governance have been critiqued.

More normatively perhaps, a global governance framework also allows for a discussion of the need for legitimacy, accountability, transparency, and discourse within regimes of global governance, and this is also discussed. The global food security governance literature is examined in more depth, and, theories of governance by discourse are also explored, explaining how global governance and discourse analysis are useful 
frameworks for exploring food security. Finally, the global governance literature is explored in order to help explain processes of change within regimes and institutions, with the aim of applying this to later analysis of the changing nature of food security governance.

\section{Governance}

Governance has been defined as "the exercise of power in an institutional context with the main aim of directing, controlling, and regulating activities concerned with the public interest" (Salih, 2009, p.501). Governance includes a range of international, domestic, and public and private actors, both formal and informal processes and institutions, and the decision-making procedures that may be seen to take shape, surrounding a given issue area (Hira and Cohn, 2003; Lio and Liu, 2008).

Dimensions of the concept of governance that make it useful in this analysis include the need to describe forms of governance that may be seen to transcend the traditional role of the state, and the concomitant need to create "more stable decision-making institutions amidst globalizing change" (Hira and Cohn, 2003, p.10). Also important to this analysis is the recognition that governance "includes but traverses government to denote how people govern themselves in terms of accountability, legitimacy, and transparency" (Salih, 2009, p.501). Use of the term 'governance' implies a broad range of considerations, including how actors and expectations converge, how authority is exercised through traditions and institutions, and how collective group activities are negotiated amidst common and differing issues and concerns. 
Growing interdependence and a weakening of the state

As previously noted, the end of the Second World War was characterized by changing relationships between states, where states began to work more collectively on issues of common concern (Young, 1982; Habermas, 2008). The level of commitment to this system of global governance has not been static over time, but rather can be seen to have strengthened and weakened depending on various geopolitical issues unfolding. The end of the Cold War is seen as a time when the current arrangement of interdependence began to take shape (Hira and Cohn, 2003).

This shift in the traditional role of the state has paved the way for non-state actors to have more influence in the institutions and regimes of global governance. It is analytically difficult to hold on to state-centered interpretations when they no longer allow for the consideration of all relevant actors. As Habermas has recognized:

For as international institutions form an increasingly dense network and nationstates lose competences, a gap is opening up between the new need for legitimation created by governance beyond the nation-state and the familiar institutions and procedures that have hitherto more or less succeeded in generating democratic legitimation only within the nation-state (Habermas, 2008, pp.444-445).

This move away from a state-centered understanding of global interaction allows for the role of non-state actors to be considered. In the realm of global food security governance the Via Campesina demonstrates these changing interactions between state and non-state actors well, with the increasing power in terms of influencing discourse. In his work on global ecological democracy, Dryzek (1999), has argued that civil society, as oppose to states, has an increasingly important role to play in the multilateral system in terms of its 
willingness and ability to tackle issues which are not politically salient for states, or in issues that cross state boundaries (Dryzek, 1999). Much important work has focused on how this shift in power and what is considered a legitimate voice has changed the role of business and corporate entities in the realm of global environmental governance (Rosendal, 2001; Levy and Newell, 2002; Clapp and Fuchs, 2009). Nevertheless, little work has focused on how this shift may be seen to influence and impact the realm of global food security governance (Salih, 2009).

Global governance as a framework - global governance as uneven and fragmented The global governance literature can be seen to have emerged at a time when traditional international relations theories were failing to explain the growing interdependence of states in the post-old war period. Useful to this analysis is the attention given within the literature on global governance to the impact that increasing globalization has had on the mechanisms and structures of global organization (Rosendal, 2001; Hira and Cohn, 2003). In the absence of a formal global government, global governance describes the actions and interactions of various actors in the global community and the power and imbalances that characterize these interactions (Hira and Cohn, 2003). Despite the role of the UN system, the lack of formal global government is apparent in the non-binding nature of the policy recommendations of the FAO, with very real implications for the possibility of achieving food security objectives.

The global governance literature has increasingly recognized that interactions between various regimes and international institutions may have a profound impact on the development and effectiveness of each institution over time (Gehring and Oberthür, 
2009). However, the interactions between institutions and actors do not occur in isolation, but rather often occur within a 'regime complex', where multiple institutions and actors may be seen to impact each other (Gehring and Oberthür, 2009). The interaction between the Via Campesina and the FAO demonstrate the complex and at times fragmented nature of global food security governance and the food security regime, with the discourses of these two organizations having impacted the evolution of the other over time.

\section{Regime theory and regimes as an analytical tool}

In International Relations literature regime theory, which was attempting to grapple with the increasing global complexity that characterized the period within which it emerged (Krasner, 1982), can be understood as a precursor to theories of global governance. The strength of regime theory lies in its ability to allow for the consideration of a full range of norms, laws, and institutions that can be seen to comprise a regime (Young, 1982; Krasner, 1982; Levy and Newell, 2002). Despite the shortcomings of regime theory, which are a product of its lack of attention to non-state actors (Hira and Cohn, 2003), and the inability of those employing the theory to consider the impact of the global political economy on a given regime (Levy and Newell, 2002, p.86), the concept of regimes as an analytical tool remains useful for interrogating dimensions of global governance (Levy and Newell, 2002).

Regimes are understood as social constructs, they are not seen to exist apart from the social world they are attempting to describe (Young, 1982; Krasner, 1982; Hira and Cohn, 2003). Hira and Cohn define regime as "principles, norms, rules and decisionmaking procedures that help to stabilize and guide international behaviour" (Hira and 
Cohn, 2003, p.8), in a given issue area. These principles, norms, rules, and decision making procedures are useful in that they allow for the interrogation of the various avenues of influence actors may have within a given regime. They also inherently allow for the consideration of discursive dimensions of regime formation and influence. Furthermore, regimes are analytically useful in that they allow for the exploration of governance which takes place outside of the state, by providing a framework for discussing how actors and ideas surrounding a given issue area may be seen to coalesce at the global level (Young, 1982).

Analytically, regimes may be understood as both a product of the increasingly complex global system, and may also be seen to be constitutive of the complexity and structures that are attempting to be described, therefore "regime structures and processes thus reflect the power, resources, preferences, and strategies of the various actors in these contests" (Levy and Newell, 2002, p.95). In the food security regime global food security governance may be seen as a product of the broader governance structures within which it is embedded, and may also be seen as constitutive of these broader structures. The Via Campesina and the FAO are part of the global food security governance regime, and while they are embedded within it and influenced by it, the regime is not static and they are also influencing its progression.

Yet, despite the analytical usefulness of regime theory, when employing this concept to an analysis of global governance, its shortcomings such as its lack of attention to nonstate actors, and its lack of ability to describe the broader structure within which a given regime may function, must be mitigated. Levy and Newell have found that applying a 
Gramscian understanding of hegemony to the regime concept allows for dimensions of power and legitimacy within a given realm of global governance to be explored.

Gramscian theories are also useful in their application to hegemonic forces behind ideas and discourses, in terms of understanding how certain discourses can gain power and influence over others.

\section{Gramsci and hegemony}

Gramsci introduced the concept of hegemony in order to describe social forces that privilege certain discourses and structures over others.

Hegemonic stability is rooted in the institutions of civil society, [...] which play a central role in ideological reproduction, providing legitimacy through the assertion of moral and intellectual leadership and the projection of a particular set of interests as the general interest (Levy and Newell, 2002, p.87).

Important to this analysis is the dual role of civil society in a Gramscian hegemonic framework which understands civil society as both reinforcing of hegemonic ideologies, and also as having the capacity to challenge them (Levy and Newell, 2002). This dual role of civil society points to its role as a sight of contestation, where there is perhaps the potential for previously non-hegemonic discourses to emerge (Germain and Kenny, 1998).

Related, and also important to this analysis, is the recognition that hegemony is contingent and unstable, with various regimes and realms of global governance interacting and evolving in "dialectical tensions, generating underlying fault-lines and contradictions" (Levy and Newell, 2002, p.87). Interrogating the discourses surrounding food security, and the discursive shifts occurring within this realm of global governance, 
requires the unpacking of dominant and competing discourses being employed. A hegemonic framework allows for civil society to be analyzed as a sight of contestation and allows for an analysis of the ways in which certain ideas and approaches are seen to gain legitimacy over others.

However, the application of a Gramscian hegemonic framework to interrogate dimensions that lie beyond the nation-state has been questioned (Germain and Kenny, 1998; Levy and Newell, 2002). These critiques surround how global consensus might be reached in absence of a supranational system of global governance. Therefore, the interrogation of a 'global civil-society' exclusively through a Gramscian lens is problematic, in that "the concept of a 'global' civil society cannot claim a Gramscian lineage except in relation to some kind of 'international' state" (Germain and Kenny, 1998, p.17), a level of cohesion which is currently not seen to exist in the global system.

Despite this absence of a formal global structure of government or political authority, the regimes of global governance that have formed demonstrate the need to coordinate the activities of an increasingly complex world society (Habermas, 2008). The "increasingly numerous and interconnected transnational networks and organizations" (Habermas, 2008 , p.446, author's emphasis), that have developed as a response to this complexity deserve attention regardless of the analytical difficulty that accompanies such an undertaking. This consideration of global governance is not meant to, as Hira and Cohn suggest, "obfuscate[] the injustice of the international system and the power of global hegemonic structures" (Hira and Cohn, 2003, p.9), but rather it is to question how "counterhegemonic" (Germain and Kenny, 1998, p.18) discourses might be seen to 
emerge despite this injustice and imbalance of power, and as Fuchs and Clapp recognize, "the issue of the democratic legitimacy of global food governance also requires further scholarly attention" (Fuchs and Clapp, 2009, p.294).

Legitimacy, accountability, transparency, and the inclusion of multiple actors There are many people around the world who are greatly impacted by decisions made, and the rules and principles which may be seen to develop, within regimes of global governance. Yet despite this impact, the people affected are largely excluded from global policy development and decision making processes (Hira and Cohn, 2003). Useful here are the concepts of the 'national' and 'cosmopolitan' citizen, where civil society may be seen to represent the voice of the cosmopolitan citizen. In many ways, cosmopolitan citizens see their roles and obligations to world society as taking precedence over their responsibilities to the nation (Habermas, 2008, p.447). This is not to say that the nation is no longer seen as important, but rather these actors recognize that the complex interconnectedness of global systems requires decision-making that extends beyond the considerations of the nation-state. This global civil society is demanding a higher degree of accountability, transparency, and meaningful participation and consultation in the processes of global governance (Hira and Cohn, 2003).

This call for greater transparency and the need for more meaningful participation reflect the desire of those impacted to be included in the decision making processes which may be seen to produce policy and governance at the international level. Discourse is the means through which norms, rules and principles are negotiated within regimes of global governance, with much attention being paid to the importance of discourse in democratic systems of global governance (Dryzek, 1999; Habermas, 2008). It has been argued that 
the discourses governing an institution are more amenable to change than the rules, and that it is important that actors "be astute enough to recognize the importance of the discursive realm" (Dryzek, 1999, p. 289). The introduction of the food sovereignty discourse into the regime of global food security governance represents and act of resistance against the more productivist based discourses dominating this regime.

\subsection{Critical Agrifood Studies}

There has been a rapid increase in the global movement of food and agricultural commodities (Cooke, et al, 2008b). Agricultural trade is expanding at a more rapid rate than agricultural output (Clapp and Fuchs, 2009), and changing trade arrangements have eroded national food security regimes (Cooke, et al, 2008b). All the while, there is an increasingly prevalent critique of the globalization of food and agricultural production and consumption and the impact that corporate concentration, are having on food security objectives (Clapp and Fuchs, 2009). This next section provides a rationale for approaching food security through a global scale of analysis, examines key challenges associated with food insecurity, such as the challenges inherent in measuring food insecurity, as well as the debate over extending the role of food beyond that of a commodity in terms of global policy are explored in order to illustrate the complexity of global food security governance, and the 'global food crisis' of 2007-08 is discussed in terms of its impact on the global governance of food security.

\subsubsection{Justification of the Global}

As part of this research is about deconstructing taken-for-granted categories, it is important to not take for granted discussions of the global or international. In order to 
justify the interrogation and analysis of food security at the global scale the global dimensions of food and agriculture, and postmodern understandings of food security will be discussed.

Many dimensions of the issue of food security demand global or international consideration (Cooke, et al, 2008a; Clapp and Fuchs, 2009; Conceição and Mendoza, 2009; Lang, 2010). Conceição and Mendoza identify three dimensions of food and agriculture that necessitate the analysis of food security at a 'global' scale, these are the international trade in food or inputs used in food production, the impacts of climate change on global agricultural productivity, and globalized financial and commodity markets (Conceição and Mendoza, 2009). The globalization of food and agricultural production, marketing, and trade, and the ability for practices in one part of the world to have multiple and wide ranging impacts, demand that the global dimensions of food security and food sovereignty be considered. Clapp and Fuchs note that:

We now have a globally integrated food system that affects all regions of the world. The recent volatility in food prices has illustrated the global nature of this food system, highlighting the ways developments in one part of the world can have multiple and wide-ranging impacts (Clapp and Fuchs, 2009, p.1).

It has been argued that food and agriculture are so globally integrated that "it no longer makes sense to speak of national food systems" (Clapp and Fuchs, 2009, p.4), but rather, terms such as "international agricultural economy" (Desmarais, 2007, p.20), the "global agricultural system" (Williams, 2009, p.161), "global food governance” (Clapp and Fuchs, 2009, p.), and "food globalization" (Clapp and Fuchs, 2009, p.) are used to 
describe the increasingly connected environment within which food and agriculture can be understood.

It is recognized that "agriculture is simultaneously place-bound and internationally integrated" (Cooke, et al, 2008a, p.101). Important to remember however, is that the production of food always happens in a particular place, and therefore, the local can not be forgotten (Desmarais, 2007). The aim here however, is not to discount the importance of the local in addressing issues of food insecurity, but rather it is to recognize that the commonalities between considerations of the local should not be ignored (Cooke, et al., 2008a). The global is taken in recognition that if there are problems in almost all the locals, the broader commonalities of the structure within which these varying food insecurities are taking place must be questioned.

Carr (2006) applies postmodernism to food security. He argues that doing so does not necessarily constitute a critique of current approaches to food security, but rather an attempt to better understand society's role in food security outcomes. Carr traces the development of the concept of food security, arguing that the literature has increasingly focused on more local scales of consideration, investigating the local contexts of food insecurities (Carr, 2006). Carr argues however, that although this turn to more local levels of consideration is often presented as postmodern, in that it becomes a rejection of the modernist attempt to construct a global metanarrative of food security. Carr calls for a different application of postmodern theory to food security, one which employs postmodern deconstructivist conceptualizations of power and knowledge in order to interrogate the social dimensions of food security at a more aggregate level (Carr, 2006). 


\subsubsection{Key Challenges associated with Food Insecurity}

Chronic and transitory food insecurity and long-term and emergency responses

Within the food security literature, and within programs designed to address varying forms of hunger and malnutrition, the distinction is often made regarding the longevity of the problem, termed as either chronic or transitory food insecurity, and the nature of response, with the distinction made between long-term and emergency responses (Maxwell, et al, 2010). Chronic food insecurity describes a prolonged and ongoing state of hunger and/or malnutrition, associated with longer-term issues of poverty. Whereas transitory food insecurity describes a more acute and temporary hunger, and is often associated with emergencies and crisis situations.

This attempt to classify hunger and malnutrition has traditionally determined the "architecture of response" (Maxwell, et, al, 2010, p.91), where a distinction is often made between development and humanitarian responses. However, many have argued that the current situation of food insecurity defies neat classification and that this attempt to classify food insecurities reflects a limited understanding or consideration of the underlying causes of poverty and vulnerability. Maxwell, et al. argue that "the somewhat artificial programmatic distinction made between transitory and chronic food insecurity leaves major gaps that will likely hinder a holistic and effective response" (Maxwell, et $a l, 2010$, p.91). It has been estimated that in 2004 only $8 \%$ of hunger related deaths worldwide can be attributed to humanitarian emergencies, with $92 \%$ being attributed to chronic and recurring hunger and malnutrition (Barrett, 2010). However, it must be noted that those suffering from what may be considered chronic food insecurity, are those 
likely to be more at risk when emergency situations arise, resulting in an exacerbation of existing problems and tensions, and skewing the ability to estimate causes and effects.

An example of an attempt to categorize the drivers of food insecurity can be seen in the work of Conceição and Mendoza (2009), who identify what they term short-term and long-term drivers of global food insecurity. Higher oil prices and financial speculation are identified as short-term drivers, while demographic shifts and the effects of climate change are seen as more long-term perturbations (Conceição and Mendoza, 2009). It is believed that categorization along these lines serves as a tool which helps to determine the nature of response. Still, the difficulty to classify these drivers is clear, with droughts caused by climate change contributing to financial speculation, and with high oil prices seen as cyclical in nature and symbolic of deeper structural and regulatory issues; the clear lines between the categories begin to break down.

Furthermore, the international food and agricultural governance system remains "a 'fragmented one' with weak coordination between humanitarian response undertaken to protect food security in the short term, $[\ldots]$ and longer-term efforts to address underlying causes of food insecurity" (Maxwell, et al, 2010, p.93). It becomes clear that the various states of food insecurity and its underlying causes defy easy classification, and that the false dichotomy created between short and long term and chronic and transitory food insecurity may lead to simplifications and become problematic when trying to understand complexities and eventually find solutions. What is more is that these attempts may serve to justify superficial responses which fail to address the root causes of the issue. 


\section{Measuring food insecurity}

Since the 2008 Global Food Crisis estimates of the number of those in the world considered to be suffering from hunger, malnutrition, or food insecurity have ranged from 833 million (USAID, 2009) to 1.02 billion people (FAO, 2009). There are two important points worth noting about these differing estimates. The first is that this difference represents estimates from varying national, regional, and international institutions. FAO figures are those most often quoted, yet estimates from USAID and other organizations are also found in the literature. Although there are differences between the estimates of USAID and FAO, the estimates of one organization are not necessarily higher or lower than the other over time. For their 2009 estimates, USAID estimated 833 million people were food insecure (USAID, 2009), and for the same year the FAO estimated that a considerably higher number of people, around 1.02 billion were food insecure (FAO 2009). However, in 2003, USAID estimated that in 2000-01, 896 million people were food insecure (USAID, 2003), while the FAO estimated the number to be, considerably lower, at around 798 million people for the same period (FAO, 2003).

The second point worth nothing is that this discrepancy also indicates differences in the ways in which food insecurity is defined and measured. It is recognized that food security is often conceptualized as encompassing three dimensions: availability, access, utilization. Barrett argues that when measuring food insecurity it is much more difficult to measure dimensions of utilization as these take place at the household level (Barrett, 2010). It is because of this that current attempts to measure food insecurity often focus on dimensions of availability as these can be assessed more easily and on a more macro scale. How one defines food insecurity, the dimensions considered in models and the 
ways in which the empirical data is gathered all contribute to the disparities seen in estimates.

For example, it is recognized that measures of food security "based on household and individual data routinely generate higher estimates of food insecurity than those derived from more aggregate data" (Barrett, 2010, p.826). Household data is usually higher than aggregate data because household data shows a more accurate picture of day-to-day reality, and peoples' access to, and consumption of food, whereas aggregate data shows what is supposed to happen given the availability of food in a given location. An influential quote from Amartya Sen is used to illustrate the flaw in this use of more aggregate, availability based models, "starvation is the characteristic of some people not having enough food to eat. It is not the characteristic of there being not enough food to eat" (Barrett, 2010, p.825). Essentially, it is an issue of access and distribution, where aggregate data has the tendency to hide local realities. Though estimates on the number of those that are suffering from other dimensions of food security, such as whether food is considered to be culturally appropriate are not available, these numbers might suggest a different estimate. Whether one considers the upper or lower end of the estimates, what is evident from the figures above is that the number of those who are food insecure is unacceptably high.

\section{Production versus distribution}

The amount of food produced and the apparent availability of food is often an inadequate predictor of how much food certain segments of the population can acquire (Conceição and Mendoza, 2009). Since 1990 per capita food production has increased by $12 \%$, at the same time however the undernourished population has increased by $9 \%$ (Barrett, 2010). 
Nevertheless, while production continues to outpace projected demand "much of the response is still constructed as though food insecurity - particularly in emergencies - is straightforwardly a short-term problem of inadequate consumption" (Maxwell, et al, 2010, p.93). Greatly influencing this shift in focus from issues of production to issues of distribution is the work of Sen. In 1981, Sen published Poverty and Famines: An Essay on Entitlement and Deprivation (1981). It was demonstrated in this book that famine occurs not only from a lack of food, but from inequalities built into mechanisms for distributing food. He used the Bengal famine to illustrate that, in this case, famine had not been a result of there not being enough food available, it resulted because people were not able to purchase the food that was available because of a multitude of other social, environmental, and economic factors which coalesced at this time.

Recognizing the work of Sen, Carr traces the important turn in the study of food security which saw a recognition that food insecurity was not necessarily associated with a lack of food in a given place, but rather, is often related to more social dimensions of access (Carr, 2006). We have enough food to feed the world; it is the system within which food is distributed that causes food insecurity (Salih, 2009). The paradoxical nature of this can not be ignored "when one in seven people today do not have access to sufficient food, and an equal number are over-fed" (Godfray, et al, 2010, p.2769), it becomes clear that lack of access to food and high food prices are only some of the "symptoms" of food insecurity - they fail to address the underlying causes, such as the lack of regulation of commodities markets, changing global weather patterns, and the need for improved governance at all levels, from the state to the multilateral system.(Conceição and Mendoza, 2009). 
Food as a commodity - Food as multidimensional

In order to address the issue of food security a critical examination of the underlying causes of world food insecurity need to be addressed (Conceição and Mendoza, 2009). The current system of trade rules and global financial markets approach food and agriculture as though they are not exceptional, with the same rules and mechanisms applied to food, as if it was just like any other commodity. Yet, many have argued that our treatment of food as any other commodity "is a philosophical error with profound consequences in reality" (Fullbrook, 2010, p.6). The tendency of governments to consider energy security and the interests of resource extraction sectors above those of food security, distort the fact that food is one of the most fundamental components of the human experience, that food is indeed remarkable (Fullbrook, 2010).

Both at the philosophical and material level, the current approach is not working. Many authors and groups have argued that our perception of food and the policies relating to it must change, both at the national and international level (Fullbrook, 2010), in order to recognize the multidimensional role of food. It has been recognized that food must be reconceptualized as not just another commodity, but as an ecological, social, and cultural good, as an integral part of human well-being and ecosystem health. This shift from the consideration of food as a commodity to the consideration of food as multidimensional, though necessary in terms of the realization of food security, would be paradigmatic in terms of the effects this would have on global food security governance, and though this shift is happening in some countries and circles, it is necessary that this shift happen at the global level. 
The agriculture, trade and growth paradigm

Current food and agricultural policy is often critiqued for functioning within the agricultural trade and economic growth paradigm. Within this understanding of the problem 'technology' and 'growth' are identified as key narratives used to justify an approach that relies heavily on science and technology, increased production for export markets, and realizing the benefits of comparative advantage and economies of scale (Friedmann, 2000). This narrative paints a picture of agriculture in the developing world as needing to move "from backward to modern, from subsistence to market-oriented, from 'old' to 'new"' (Thompson and Scoones, 2009, p.390). The agriculture, trade and growth paradigm commodifies food; quite poignantly Friedmann argues that within the current system "Post-animal humans appear to eat commodities rather than other living beings. Our need appears to be less food than money" (Friedmann, 2000, p. 481). Though this narrative of food as a commodity is ubiquitous, it has not gone unchallenged.

Thompson and Scoones question the narrative of agriculture as "an engine of economic growth" (Thompson and Scoones, 2009, p.390), arguing that the shortcomings of this narrative are both material and epistemological. Materially, this narrative, and the liberalization policies implemented in an attempt to bring it into being, have not lead to direct results in improving food security (Thompson and Scoones, 2009, p.390). This failure may be linked to the arguments mentioned above which advance the position that there is the need to see food as more than a commodity. The treatment of food as a commodity makes it subject to the same basic trade tenets that govern the trade of electronics and gold, limiting the policy options available to address food insecurity and undermining the ability of the global food security governance regime to make real and 
marked change toward achieving food security objectives. Epistemologically, the flaws of this narrative are two-fold, on the one hand are the limitations of the models used to empirically justify the benefits of the growth paradigm, that is, that the 'trickle down effect' has not been realized, and on the other hand, the core assumption of this narrative, that is that there are determined stages of growth has increasingly been brought into question (Thompson and Scoones, 2009, p.391). Despite this recognition in the literature that the underlying assumptions which justify this paradigm may be flawed, "prevailing narratives of technological change and economic growth have come to dominate key food and agricultural policy debates" (Thompson and Scoones, 2009, p.386).

The failure to reach a multilateral trade deal on food with the collapse of the Doha round of World Trade Organization (WTO) negotiations, which began in 2001 and collapsed in 2008 "shows that increasing trade liberalization is not a foregone conclusion" (Godfray, et al, 2010, p. 2774), with disagreements over issues of agricultural subsidies, intellectual property, and the very inclusion of food and agriculture within global trade regimes, factoring into the debate. Still, many recognize that the international discourse surrounding these issues "is too often narrow and technical" (Lang, 2010, p.87), with more multidimensional or holistic interpretations being precluded from the debate for not easily fitting within this dominant 'agricultural trade and economic growth' paradigm.

\subsubsection{The 'global food crisis' of 2007-08}

The 2007/2008 global food crisis changed the way various dimensions of food security are understood (Clapp, 2009) and highlighted to the world the severity of the issue (Dupont and Thirlwell, 2009). This latest global food crisis is recognized as a period where issues of food security came to the forefront of public thought (Conceição and 
Mendoza, 2009). This crisis and the resultant impacts on food insecurity were widely recognized as the point where, for the first time in decades, the number of those considered to be food insecure in the world actually began to increase (USAID, 2003, 2009; FAO, 2003, 2009). This increased attention to food security in the public makes this an important time in the history of global food security governance. The seeming suddenness of its onset, and the lack of ability to identify an obvious cause to the crisis, has lead to much debate as to how the various causes of the crisis should be addressed by public policy makers (Conceição and Mendoza, 2009). This crisis was global in scope yet there were multiple crises happening in countries and regions around the world. Though countries and regions were impacted differently, with varying responses seen in different countries in an attempt to deal with the crisis, these local policies were often seen to have global impacts. For example, policies to amass large reserves due to fear of shortage were seen to impact the global price of certain commodities, with this localglobal connection serving to highlight the integration of the global food system (Timmer, 2010).

Crop failures due to draught attributed to climate change (Lang, 2010), rising oil prices which drove up the costs of inputs and transportation (McMichael, 2009; Lang, 2010), changing consumption patterns (Conceição and Mendoza, 2009), futures trading on global agricultural markets and the increased production of biofuels which lead to the distortion of world agricultural markets (Dupont and Thirlwell, 2009; McMichael. 2009), have all been acknowledged within the literature as contributing to the sharp increases in global food prices seen at this time. It has been suggested that the 2007-08 food crisis "reinforced how the dominant twentieth century productionist policy paradigm is running 
out of steam" (Lang, 2010, p.87). Although high food prices seen at the height if the 2007-08 global food crisis had fallen, largely due to the depressing effects of the global recession of 2009 , "the challenge of addressing the root causes of the global food crisis remains" (Conceição and Mendoza, 2009, p.1159). Still, it was recognized that this lowering of prices was only temporary, and that within the foreseeable future prices would once again rise, responding to the same pressures in the global economy, and another 'crisis' would result. And it would not take long for these predictions to become reality, with world food prices again reaching a new record high in January 2011.

It is argued that there are both positive and negative effects of higher and lower global food prices. It is argued that lower food prices can be both positive (ie more accessible) and negative (ie. less money for farmers). While this is true for farmers in the developed world with access to capital and the ability and subsidies to respond quickly to changes in the global market, farmers in the developed world lack these resources and therefore are not as easily able to respond to the need to increase production, and are therefore less likely to benefit from higher global prices. These crises however, are not just about food prices; they are about the whole economy and the impacts on the most vulnerable.

Yet, we normalize these crises and fail to take steps that would reduce volatility in agricultural markets and prevent future perturbations (Maxwell, et al, 2009). Lang argues that the latest food crisis should not be considered an anomaly, but a "creeping normality" (Lang, 2010, p.95). Looking at the 1972-73 and the 2007-08 food crises Timmer shows that food crises tend to occur on a cyclical basis, responding to a number of market and government interventions and that better food policy management and 
governance at the national and international levels would help to mitigate these crises (Timmer, 2010), with all this pointing to the increasing importance of food policy and governance in the years and decades to come (Godfray, et al, 2009).

\subsection{Global Food Security Governance}

Within the global governance literature most attention has focused on the growing regime and institutional complexity of both trade and environmental governance and the influence of business actors within these regimes of global governance (Levy and Newell, 2002; Clapp and Fuchs, 2009), yet there has been very little focus on applying this framework to the global governance of food and agriculture and even less attention focused on its applicability to understanding the global governance of food security (Salih, 2009).

This omission cannot be explained because of irrelevance or lack of genuine interest in the significance of governance to food security. It certainly cannot be explained on the grounds that a 'good governance' regime in food security already exists. It clearly does not (Salih, 2009, p.502).

The aim here is to apply this framework to an analysis of the global food security regime and international food security governance and the role of civil society in influencing governance approaches and outcomes.

Food and agricultural systems have often been analyzed through the application of a commodity chain approach (Whatmore and Thorne, 1997; Friedland, 2004; Desmarais, 2007). This approach or framework attempts to make sense of the complexity of the global food system by visualizing it as a long chain extending from producer to consumer, with various stages of processing and distribution considered along this 
continuum. However, this approach has been criticized for not fully illustrating the complexity of food and agricultural systems (Desmarais, 2007; Cooke et al, 2008a; Curran 2008). Further refinement of this approach has extended this concept from a singular chain to multiple chains intersecting in a 'net' or 'web', helping to begin to illustrate the complexity of the system (Desmarais, 2007; Cooke et al, 2008a). Yet these approaches have been critiqued for their failure to accurately consider and describe the role and influence of actors functioning outside these chains, nets, or webs such as civil society and other international regimes (Desmairais, 2007; Curran, 2008; Clapp and Fuchs, 2009).

Food is integrated within a multi-level governance system (Feindt and Flynn, 2009) where multiple regimes, actors, and institutions overlap and converge at national, regional and global levels. The global "governance architecture" (Feindt and Flynn, 2009, p.411), where the formation of agriculture policy may be seen to take place, is influenced by activities and policy making taking place within various global regimes, including the climate change and environment regime, the trade and finance regime, and the development regime, and encompasses the varying standards, codes, rules, norms, and decision making processes which serve as tools of governance within these regimes. This regime and institutional overlap has very real implications for food security governance and the legitimacy and power of the actors involved.

The complexity of global food security governance invokes more than traditional definitions of food security, relating to the availability of, and access to food, imply (Salih, 2009). The globally integrated and highly commercialized food production, 
standard setting, grading, testing, inspection, storage, marketing, labeling, trade, and transportation and distribution systems, do not occur in a uniform way with the equal influence of all actors, and necessitate the consideration of food security which extends deep within the global governance of food. Salih defines food security governance as

"the exercise of power within institutional contexts, particularly crafted to direct, control, and regulate activities concerned with food security" (Salih, 2009, p.501). However, "good governance" within the food security regime is not a reality and this relates to the need for citizens and actors to view the activities of a regime of global governance as accountable, inclusive, transparent, and legitimate (Hira and Cohn, 2003; Salih, 2009).

\subsection{Governance by Discourse}

Increasingly, governance is understood as a discursive contest over the framing of policies, ideas, principles, and norms in order to influence policy outcomes within a given issue area (Fuchs, 2005; Graham, 2005). Discourses are created, appropriated, adopted, and challenged by actors and institutions at a global level. Actors engage in this discursive contest, as governance by discourse is seen as a powerful tool, where discursive power is seen when certain actors and discourses gain influence over others. Discourses frame the way issues are approached and influence the norms, principles, and decision-making procedures that shape the governance process, and it can therefore be argued that "governance can be brought to bear through discourse" (Fuchs, 2005, p.2).

The role of agency in discourse is contentious in theoretical literature. Foucauldian approaches place less importance on agency "arguing that actors are objects rather than subjects in discourse" (Fuchs, 2005, p.15), whereas Habermasian approaches "perceive actors to be able to choose and promote their respective arguments" (Fuchs, 2005, p.15). 
Habermas sees the process of discourse as key to arriving at a set of common moral principals upon which a more just global society could be based. Gramscian perspectives also view actors as both subjects and objects of discourse but in contrast to Habermasian approaches, Gramscian scholars take a more critical approach and see discursive power being employed by powerful actors to further specific interests (Fuchs, 2005).

Hegemony and power conflate the production and interpretation of texts, such that certain texts can no longer be understood as representations of society as a whole, or conversely, created by society as a whole.

Texts are part of the way principles, norms, rules, and policies are communicated within realms of global governance. The language used and discourses employed in these texts do not simply reflect an objective view of the world however, but rather, they are based on subjective interpretations which both construct, and are constructed by, the actors engaged in a discursive governance process. The constructed and contingent nature of governance points to the analytical utility of engaging with text and discourse in order to examine the shifting and changing nature of global governance within a given regime. Actors who engage in this process understand that "a discursive polity" can allow for norms and principles to be redefined (Fuchs, 2005, p.7).

\subsection{Global governance and change within regimes and institutions}

Approaches to describing change within regimes and institutions of global governance, range from the identification of internal contradictions within regimes as drivers of change, those which see shifts in underlying power structures as being responsible, and those which see regime change as being attributable to forces and changes taking place outside the regime (Young, 1982; Rosendal, 2001). However, these approaches to 
understanding regime change should not be seen as mutually exclusive, rather, when taken together, they offer insight into the processes which bring about changes within regimes of global governance. Central to the inquiry of regime change are questions which surface regarding the role of structure and agency in these process, and whether one is seen to take precedence over the other in terms of the potential for change (Levy and Newell, 2002; Cooke et al, 2008b). The approach taken here is that the structures within which regime change takes place, as well as the actors functioning to bring about or oppose change; both play an important role in influencing the direction of regime change over time.

In order to analyze the process and outcomes of regime change the following points will be used to interrogate the global food security governance regime and the shifts and changes in discourse which currently characterize this realm of global governance. Regimes and institutions which are seen to be unstable, or in a state of flux, have greater propensity for change, based on their own internal contradictions, or due to exogenous forces, than do those which are seen to function cohesively (Young, 1982; Feindt and Flynn, 2009). This instability may allow for the introduction of new ideas and new actors, who traditionally may not have been admitted into the governance process (Young, 1982; Hira and Cohn, 2003; Feindt and Flynn, 2009). However, it must be recognized that most often, change is not abrupt, but rather may be seen as a process of stretching and layering of different policies and approaches over others taking place within existing structures (Feindt and Flynn, 2009). 
Changes to rules and procedures, which constitute the day-to-day governance mechanisms of a regime, are seen as easier to effect than changes to the underlying principles and norms upon which a given regime or institution is based (Krasner, 1982; Curran, 2008). Furthermore, certain issue areas are more likely to experience change at the global level than others. Technical issues, which do not require political consensus, are seen as more amenable to the development of a common position (Habermas, 2008). Finally, the approach taken by actors in order to affect change, which range from passive to more active approaches, may be seen to greatly impact the likelihood that a certain idea or approach will take hold (Levy and Newell, 2002).

\section{Structure and agency}

The regimes and institutions of global governance can be seen as sights where the relationship between structure and agency is negotiated. It has been argued that the complex structure of international institutions and regimes functions as a barrier to change (Young, 1982; Levy and Newell, 2002; Cooke et al, 2008b). That actors working and participating in regimes have limited power to control, or even influence, policy outcomes due to historical dimensions of power embedded in the processes and structures of global governance.

However powerful, it is important to recognize that these structures do not exist apart from actors who build and reinforce them, and this complexity may be exploited by actors working strategically within a regime. With knowledge of the structure and processes of global governance actors are able to manipulate discourse and policy outcomes in a given issue area through "intelligent agency" (Levy and Newell, 2002, p.85). Agency implies that actors are not passive spectators in the regime, but rather, 
engage in intelligent, calculated, and strategic actions in order to shape policy directions and bring about change.

\section{A state of flux}

There is the recognition that crises, or significant shifts in the political, social, or economic environments within which a given regime may function, are events which highlight contradictions and tensions already existent within the system and serve to make these more visible (Feindt and Flynn, 2009). Where more tensions and frictions exist between actors and approaches in regimes of global governance, the likelihood of significant change in policy may be seen to increase (Feindt and Flynn, 2009).

Therefore, "[w]hen policy is in a state of flux, knowledge and expertise are much more likely to be contested" (Feindt and Flynn, 2009, p.392), leaving room for new actors to insert themselves in regimes of global governance, and for new ideas to emerge.

\section{New ideas, new actors}

The appearance of new actors and new ideas in a regime of global governance can be seen as a precursor to the possibility of substantial changes within the regime (Young, 1982). These new ideas and new actors disrupt the status quo, and essentially function to reshape deeply engrained discourses (Feindt and Flynn, 2009). The new discourses which emerge highlight new or underlying problems not recognized by actors traditionally involved in a regime of global governance. However, to gain prominence, actors must attempt to introduce ideas and discourses which fit within certain norms and principles that govern the regime (Feindt and Flynn, 2009). 


\section{Stretching and layering}

Taking a multi-level governance perspective, Feindt and Flynn examine policy stretching and institutional layering in British food policy. They argue that rather than abrupt paradigm shifts that would replace one set of policies and institutions with new ones, changes in British food policy can be better understood as having evolved through "processes of ideational and institutional stretching and layering" (Feindt and Flynn, 2009, p.387) which simply added new layers of policy and institutions to those already existing. This leads to confusion about mandates, resources and priorities within food policy and governance, and results in the creation of "multiple orders", with these multiple orders constituting sources of tension within the food policy regime (Feindt and Flynn, 2009). The global food security regime and the policies and institutions by which it is governed may also be seen to fit with this analysis and characterization of policy stretching and institutional layering, where changes within the regime are seen to occur incrementally and iteratively over time.

\section{Rules and procedures versus principles and norms}

It is argued that a distinction should be made between rules and procedures, and principles and norms within regimes of global governance (Krasner, 1982; Rosendal, 2001). This distinction posits that rules and procedures can change within a regime without altering the norms and principles upon which the regime is based, yet when principles and norms change the core direction of the regime itself can be seen to change (Krasner, 1982). Therefore changes to norms and principles, the underlying bases upon which a regime is built, can be seen to precede changes to rules and procedures, the governance mechanisms which arise based on previously established norms and 
principles. In the food security regime current changes and shifts in discourse represent changes in norms and principles that guide global food security governance.

\section{Technical versus political issues}

The type of issue being approached by a given regime may impact the possibility for change within that regime. Habermas distinguishes between 'technical' issues and 'political' issues facing world society. It is argued that the current system of global governance is sufficiently equipped to address issues of a technical nature, for example "the standardization of measures, the regulation of telecommunications, disaster prevention, containing epidemics, or combating organized crime" (Habermas, 2008, p.446), are seen to fit within this category. Whereas political issues which are seen to "impinge on entrenched interests which are deeply rooted in the structures of national societies, such as, for example, questions of global energy, environment, financial, and economic policy" (Habermas, 2008, p.446), may not be as amenable to change, and that the current system of global governance is not well equipped to address those issues which are political in nature. Food security is seen to fit within the category of contentious political issue areas where consensus on change is not easily attained.

\section{Passive revolutions versus wars of position}

The approaches taken by actors to bring about change in a regime or institution of global governance may be seen to impact the likelihood of success vis-à-vis the possibility for change within a regime. Approaches range from those which are seen to be more passive in nature described as "passive revolutions", and those which are seen to be more active in nature, described as a "war of position" (Levy and Newell, 2002, p.88). The concept of "passive revolutions" is understood as change which comes from within the traditional 
relations of power which govern a regime, whereas the concept of a "war of position" is often the approach taken by actors not traditionally seen to exert great influence within a given regime, who believe that significant and measured change is necessary. A "war of position" is used to describe a situation where actors are actively engaged in an attempt to bring about change, and strategically employ discourse in order to frame or reframe a given issue and advance a given position. Actors in the food security regime engage strategically in both these approaches to attempt to bring about change within the regime.

\subsection{Methodology and Methods}

\section{Critical Discourse Analysis}

The use of critical discourse analysis is largely guided by the objectives and theoretical framework of this research. In that, in order to gain an understanding of the ways in which discourses construct how food security is structured and practiced, and to explore the ways in which current discourses frame the way 'food security' is approached, there was a need to employ a method that would allow for a thorough deconstruction of the discourses and narratives being used within this regime of global governance. Critical discourse analysis allows for this; as Erjvec and Erjvec highlight "textually oriented critical discourse analysis is particularly helpful in uncovering different discourses integrated into a text and in identifying language elements of social change" (Fairclough, 1995, p.134, as quoted in Erjavec and Erjavec, 2009, p.218). The texts of the FAO and the Via Campesina can be seen to offer insight into the ways in which food security and food sovereignty discourses are created, appropriated, and challenged. Yet, rather than trying to produce a linear account of food security as an essentialized and static 
phenomenon, an attempt is made to construct a narrative which recognizes the contested, contingent, and changing nature of this term.

However, Berg highlights "the lack of methodological detail in many accounts of discourse analysis" (Berg, 2009, p.119) making it difficult to pin down specific methods for this undertaking (Agger, 1994; Berg, 2009). Alice Kaplan (1990) writing about work done using archives "notes that the tendency is to write down what you found, what you concluded, and not the processes in between - of finding and thinking" (Crang, 2003, p.134). Recognizing the work of Rose and Waitt in attempting to provide "a written canon of methods" (Berg, 2009, p.119) for this approach, Berg summarizes their work, and provides seven points to consider when undertaking discourse analysis. These seven points have been adapted in order to perform the discourse analysis portion of this research, with one added to reflect that this critical discourse analysis is being undertaken as comparison and contrasting of two texts.

First is the need to suspend "preexisting categories" (Berg, 2009, p.219). Being cognizant of hegemonic discourses that are embedded within texts, and remaining reflexive of ones positionality during the analysis process are seen as integral to undertaking discourse analysis (Berg, 2009). Throughout the research process, an attempt was made at all times to question the taken for granted categories found within the documents, and to explore the elements of these discourses that reinforce a given, perhaps hegemonic worldview. It is recognized however that the researcher does not lie outside these discourses and this has required a degree of reflexivity about how my position as a researcher has influenced both the construction of the research and the 
analysis undertaken. The need to suspend "preexisting categories" occurred early on in the readings of the texts - letting the texts speak for themselves, during the initial readings especially, made the process of looking for and identifying themes within the texts seem more objective.

The next method employed is that of "reading and re-reading", and immersing oneself in the texts being considered (Berg, 2009, p.219). Discourse analysis is understood as "a social practice primarily (but not exclusively) realized through language" (Erjavec and Erjavec, 2009, p.219). Therefore, careful reading of the documents formed an important part of the discourse analysis process, as it is only through the process of fully familiarizing oneself with the texts being studied that analysis can be made based on the themes, narratives and sub-texts found within them (Berg, 2009). When reading, I went back and forth between texts with each reading, and each time used a different pen or notation system. This allowed for the texts to be contrasted and compared, and allowed for an understanding of the nuances of the text to build over time. Things were noticed in the fifth and sixth reading that were not noticed in the second and third.

The need to identify the social contexts within which the texts are situated became an important part of the discourse analysis process. This step involved thinking about "how power operates $[\ldots]$ to (re)produce social relations" (Berg, 2009, p. 220). It must be recognized that as I have not personally experienced the social context within which the documents were created, and therefore there is a limit as to what can be said about the 'behind the scenes' discussions which took place while these documents were being created, while positions were being formulated. For the purpose of analysis an important 
assumption made within this research was that the official documents released by these entities represent their positions on the topics being discussed. A consideration of the social context within which these texts were created did help to minimize the potentially confounding effects of this assumption, in that it allowed for a deeper analysis of how dynamics of power serve to produce or reproduce a given discourse. The background given on food security and the overview of the organizations began to identify the social contexts within which the texts were created. The following section will also contribute to this end, by identifying the social context within which the texts themselves came to be.

Berg highlights the importance of looking for and identifying themes within the texts being analyzed (Berg, 2009). A series of question was employed while undergoing the reading and analysis portion of this research which helped to identify themes within the texts; these themes were used to highlight convergent and divergent norms within the texts of the organizations. Although it is recognized that the selection of themes or categories is powerful tool in its ability to frame a given discussion or analysis, and that any selection of categories is by no mean exhaustive, the paradoxical nature of this has not gone unrecognized, in that communicating the results of this analysis required that categories or themes be selected. An attempt has been made however, not to impose preconceived categories on the texts, but rather to let the texts speak for themselves. The categories of the artificial distinction made between developed and developing countries, the role of international trade and domestic regulations, the role of human rights, and the role of global governance represent themes or issue areas that are considered in both 
texts, and also link well to current debates within the literatures on food security and food sovereignty.

Another point employed when undertaking this discourse analysis involved exploring how knowledge claims were made in the texts by identifying 'regimes of truth' constructed within them (Berg, 2009). Berg highlights that "it is useful to try to understand the mechanisms by which a particular discourse is seen to have both validity and worth" (Berg, 2009, p.220), and offers two questions which one might ask while considering a text in order to interrogate this point. The first is "What patterns of 'truth' can be discerned?' and the second is "What experts are called upon to pronounce truth?" (Berg, 2009, p. 220). When identifying the 'regimes of truth' embedded within the discourses of the FAO and the Via Campesina, an attempt has been made to identify the ways in which these organizations use certain language to claim legitimacy and produce their own 'truths' surrounding food security.

A consideration of what the texts leave out, and questioning how these omissions lend power to the narrative being employed, is an important part of discourse analysis (Berg, 2009). What is not said may be seen to constitute an opposing opinion or worldview which the producer of the text does not want the reader to engage with or be reminded of, at the risk that it might weaken the given discourse being advanced. However, there is the risk in this approach of not being fair to the text, of making it into something the producer never intended it to be, and it was important to remain aware of this when employing this method. 
Central to the deconstruction of texts and the discourse analysis process is the need to identify "inconsistencies, contradictions, paradoxes" that are found within a text or document. The identification of inconsistencies and contradictions found within texts is important as these may be seen to represent sights of contestation within a given discourse (Berg, 2009). The contradictions identified through this discourse analysis process were seen to help illuminate contentious points within the food security discourses of these organizations, allowing for a deeper understanding of the ways in which differing discourses are constructed.

Finally, in order to reflect that this critical discourse analysis is being undertaken as comparison and contrasting of two texts, looking for differences and convergences between the texts formed an important part of the analysis. Being aware of overlap and synergy between the texts allowed for the identification of areas where the potential for agreement between the narratives and discourses of these organizations may lie. This level of analysis was only possible after becoming familiar with the texts, as it was only through knowing how one text treated a given issue area that it was possible to see how the other text might contradict or agree with that treatment.

\subsection{Concluding thoughts on theoretical approach, methodology and methods}

The global food security governance regime is multidimensional and complex with multiple actors, differing viewpoints, and various approaches as to how food insecurity ought to be addressed. With a range of challenges and debates, from the global food crisis, to the ability to accurately measure food insecurity, and the debate surrounding market driven versus multidimensional conceptualizations of food, characterizing this 
regime, and impacting the possibilities for food security. In order to unpack and explore the discourses which emerge from this complex regime of global governance, critical theories of poststructuralism, which allows discourses to be understood as both produced by, and reproducing of, dominant and competing discourses being employed, and as such provides the theoretical basis for critical discourse analysis, and political economy, which provides for the holistic consideration of the implications of global governance solutions proposed by the FAO and Via Campesina in terms of the broader global political economy, from the basis of the theoretical positionality of this research.

While these critical approaches allow for deconstruction and analysis of the embeddedness of this regime in broader global systems, the global governance literature provides a basis for exploring the dimensions of democracy, legitimacy, the role of the state, and themes of agency which emerge from the discourses being explored, and also allows for an exploration of the discursive dimensions of governance. The important link between these critical theories and a global governance framework is the literature on governance by discourse, which allows for governance to be understood as a discursive contest over the framing of policies, ideas, principles, and norms in order to influence policy outcomes within a regime of global governance. The global governance literature is also used to explore change within regimes of governance, where, within the food security regime, the introduction and evolution of discourses of food sovereignty is seen to represent a shift in the global food security discourse. Yet, though this research takes the position that change within the global food security governance regime is needed, and that this change ought to tend in the direction of the policies and approaches which emerge from a food sovereignty discourse, it is important to recognize that the need for 
change, and the recognition that change is necessary, do not always result in the change envisioned by the actors involved in these discursive contests. 


\section{Chapter 4-Discourse analysis results}

The critical discourse analysis undertaken allowed for the identification of common themed areas which occurred in both texts, and also allowed for the identification and assessment of contradictions and paradoxes within each text. In order to situate the texts and to identify the social contexts within which the texts have developed this results chapter begins with an overview of the creation of the texts; considering both the broader social, economic and political environment, as well as the internal realities of the organizations. The structure, scope, and content of the texts are discussed, followed with general results of the discourse analysis. The four themed areas identified in the texts help to structure the core findings of the analysis.

\subsection{Situating the texts}

As both organizations, and much literature has recognized, the 2008 global food crisis brought issues of global food security to the forefront of mainstream thought and debate, and also brought into focus some of the underlying challenges facing the governance of food security. It is within this environment of crisis and response that the two texts being considered were developed. The FAO text The State of Food Insecurity in the WorldEconomic crisis - impacts and lessons learned, and the Via Campesina text La Via Campesina - Policy Documents, were both planned publications prior to the global food crisis, with the FAO releasing a yearly State of Food Insecurity in the World report, and with the Via Campesina having planned for many years to create a comprehensive policy document for the organization. Yet, for both organizations, the crisis represented the opportunity, in an environment of increased public interest, to communicate that the root causes of food insecurity are underlying and structural, and deeply need to be addressed. 
The FAO is composed of and funded by member countries, with much if its funding, 12\%, coming from the United States (US Department of State, 2010; FAO, 2011). They work through consensus and this 'ties their hands', perhaps limiting normative claims and influencing their tendency to provide broader recommendations. The Via Campesina is made up of organizations and farmers' groups - not countries, these organizations join voluntarily, having to subscribe to certain core principles from the outset in order to gain membership, this changes the dynamics within the organization and allows them to be more normative and prescriptive.

It was observed that there are both advantages and disadvantages to these differing organizational structures. One result of this is that principles and norms of the FAO are muddled by various influences, perhaps diluting certain core messages. This is not so for The Via Campesina, who although also working through consensus, because there is a common set of the principles and norms underlying the decision-making processes of the organization, are able to stay more pointed and allow for the development of a more common position within the organization.

It is recognized that the Via Campesina and the FAO are only two players in the global food security governance regime - the agendas and goals of industry, governments (differences between regions), other multilateral organizations (WTO, IMF, etc.), NGOs, civil society, a well as climate change agendas and development agendas, all interact and sometimes collide here, and the ability of these other actors to influence the regime, while not in the scope of this present inquiry, is recognized. However, through the country membership of the FAO, and through the voluntary grassroots membership of the Via 
Campesina a broad, at times divergent, and perhaps surprisingly, often synergistic discourse between these two organizations emerges.

\subsection{Internal realities}

The FAO report The State of Food Insecurity in the World - Economic crisis - impacts and lessons learned represents a yearly publication by the FAO, each year focussing on a timely global issue surrounding food insecurity. In other words, each year food security is looked at through a different lens - the 2008 report looked at the impacts of biofuel production on food insecurity. However, the 2009 report was unique in that it involved collaboration between the FAO, the WFP, and the USDA, the FAO found that this collaboration was beneficial and allowed "new insights" to emerge.

The report is 58 pages, and was published and made available on the internet in 2009. It is divided into four parts: the first provides an overview of the state of food insecurity at the time the report was written, examining this through the lens of the global economic crisis; the second part provides a series of case studies looking at how five countries, considered to be at various levels of vulnerability had been affected by the economic crisis; the third part provides a more long-term, normative reflection, and contains a section on the right to food; and the fourth section presents a technical annex of the prevalence of undernourishment and progress towards the World Food Summit (WFS) and the Millennium Development Goals (MDG) targets in developing countries, as well as food and financial indicators in developing countries, classified by region. There are many summary tables, charts, and graphs throughout the report which allow for the communication of large amounts of statistical data. 
The report essentially switches between two temporal scales; on the one hand the report focusses on changes in food insecurity since the 2008 food crisis and then the 2009 global financial crisis, and on the other hand the report takes a more long term approach; looking at the state of food insecurity from 1970 into the future. Being an organization within the multilateral system of the UN, the scope of the FAO report examines global undernourishment statistics, and case studies of countries coping with simultaneous food insecurity and economic crisis. The report concludes that "structural problems of underinvestment" (FAO, 2009, p.58), and lack of coherent global food security governance have slowed progress in meeting various hunger reduction goals set by the multilateral system, these include the MDG and the WFS goals.

The Via Campesina report La Via Campesina - Policy Documents emerged through a collaborative and consultative process within the organization. As a result, it communicates a cohesive vision, and represents "an important basis to go further" (Via Campesina, 2009, p.4), in building the organization and in increasing the profile of their position.

The document is 203 pages and was made available in print and on the internet in 2009. Like the FAO text, the Via Campesina text is divided into four parts: the first provides an analysis of the current international context within which the text was written, background information is given, and a poem is included which, in contrast to the statistical figures in the FAO report, sets a tone of warmth to the document; the second part presents an overview of the work of the Via Campesina; the third part provides a series of position documents on a range of topics relating to food security and food 
sovereignty; and the fourth section provides the broader policy position of the organization. The position papers provided in the third section where not all original to this report, they had been previously published on the organization's website. The Via Campesina explains that they were included in the document in order to provide a comprehensive picture of their position. They have been excluded from this analysis as one criteria of the selection of texts for this analysis was that they be written after the 2008 global food crisis. These portions of text constitute 36 pages of the document.

The document provides an historical basis and rationale for the position of the organization - going back to the mid 1850's when slavery was being abolished. The text looks into the future implications of current food security approaches and provides a description of what a food sovereign world would look like.

Overall, the text offers an overview of the position and policy of the Via Campesina regarding their goal of helping to create a world where food sovereignty can be seen to exist. The organization has grown rapidly in recent years and in order to continue with the positive gains made in terms of having a voice in the multilateral institutions which attempt to govern responses to global food insecurity, they felt it necessary to record the reason that the goal of food sovereignty is a meaningful and attainable goal, and to explain the reasons why it is so necessary that a shift in the overall discourse surrounding food security needs to take place.

\subsection{Overview of discourse analysis results}

In order to discuss the deconstruction of texts more generally, it is useful to begin by contrasting the food security definition in the FAO text, and the food sovereignty 
definition found in the Via Campesina text. Areas of general agreement or synergy between the two texts are then discussed, looking at what seems to be a certain level of agreement on the root causes of food insecurity. Contradictions between texts are then highlighted, and a discussion of what the texts leave out follows. It is recognized that: "Texts of the concerned agents do not consist of only one homogeneous discourse" (Erjavec and Erjavec, 2009, p.220), and in each organization considered here, changes in membership, funding, and overall global and domestic political climates have shifted the focus, discourse, and policy of these organizations vis-à-vis food security over time.

\section{Food security and food sovereignty definitions}

For the FAO food security exists "when all people, at all times, have physical, social and economic access to sufficient, safe and nutritious food that meets their dietary needs and food preferences for an active healthy life" (FAO, 2009, p.8). This definition encompasses dimensions of access, food quality and appropriateness, and human wellbeing. The Via Campesina definition of food sovereignty is "the right of people to healthy and culturally appropriate food produced through ecologically sound and sustainable methods, and their right to define their own food and agricultural systems" (Via Campesina, 2009, p.74). This definition includes such concepts as the right to food, ecological sustainability, and a broad consideration of agricultural systems.

Whereas food security as defined by the FAO focusses on elements of "physical, social and economic access" (FAO, 2009, p.8), food sovereignty as defined by the Via Campesina focusses on dimensions of ecological sustainability and "agricultural systems" (Via Campesina, 2009, p.147). These differences illustrate the extension of the food sovereignty concept in terms of its inclusion of a broader range of considerations 
when compared to food security (see table 4.1 for evolution of food security and food sovereignty definitions), which is why it is said by the proponents of food sovereignty that food sovereignty is a pre-condition for food security to be realized (Patel, 2009). Another important difference between the two definitions, and therefore in the two terms, can be seen in the definition of food sovereignty which invokes the language of human rights, implying a sense of agency to those who are food insecure. Similarly however, both definitions address issues of human wellbeing, with the FAO definition focussing on "nutritious food" and "dietary needs", and the Via Campesina focussing on "healthy" food.

\begin{tabular}{|l|l|l|l|}
\hline $\begin{array}{c}\text { Term being } \\
\text { defined }\end{array}$ & Source/Date & \multicolumn{1}{|c|}{ Definition } & Key assumption or position \\
\hline Food security & $\begin{array}{l}\text { United Nations } \\
\text { 1975, cited in } \\
\text { FAO } 2003\end{array}$ & $\begin{array}{l}\text { "The availability at all times of } \\
\text { adequate world food supplies of } \\
\text { basic foodstuffs to sustain a } \\
\text { steady expansion of food } \\
\text { consumption and to offset } \\
\text { fluctuations in production and } \\
\text { prices." }\end{array}$ & $\begin{array}{l}\text { Recognized dimensions of food } \\
\text { and agriculture that were global } \\
\text { in scope. Food security was } \\
\text { first and foremost about } \\
\text { sufficient production to meet } \\
\text { consumption demands. }\end{array}$ \\
\hline Food security & FAO, 2009, p.8 & $\begin{array}{l}\text { "A situation that exists when all } \\
\text { people, at all times, have } \\
\text { physical, social and economic } \\
\text { access to sufficient, safe and } \\
\text { nutritious food that meets their } \\
\text { dietary needs and food } \\
\text { preferences for an active and } \\
\text { healthy life." }\end{array}$ & $\begin{array}{l}\text { Shows an attempt to distance } \\
\text { food security from productivist } \\
\text { approaches of the past. Brings } \\
\text { food security out of the } \\
\text { 'market'. Includes dimensions } \\
\text { of human health and wellbeing. }\end{array}$ \\
\hline $\begin{array}{l}\text { Food } \\
\text { sovereignty }\end{array}$ & $\begin{array}{l}\text { "the right of people to healthy } \\
\text { and culturally appropriate food } \\
\text { produced through ecologically } \\
\text { sound and sustainable methods, } \\
\text { and their right to define their } \\
\text { own food and agricultural } \\
\text { systems." }\end{array}$ & $\begin{array}{l}\text { Illustrates the extension of the } \\
\text { food sovereignty concept in } \\
\text { terms of its inclusion of a } \\
\text { broader range of considerations. } \\
\text { Invokes the language of human } \\
\text { rights, implying a sense of } \\
\text { agency to those who are food } \\
\text { insecure. }\end{array}$ \\
\hline
\end{tabular}

Table 4.1: Summary table of food security and food sovereignty definitions from 1975 to present day: The first definition of food security, the current definition of food security, and the current definition of food sovereignty are compared. 
Agreement on the enormity of the crisis

In terms of areas of convergence between the discourses of the organizations, there was a great degree of agreement between the two on the enormity of the crisis and the depth of response needed. Both organizations see the most recent food crisis as only one in a long string of crises that have impacted the global food system. For the FAO: "The present crisis is not a new crisis. It is the sudden worsening of a structural crisis" (FAO, 2009, p.39), and for the Via Campesina: "The current food crisis in the midst of a multiple crisis should provide a wake up call to all those who are trying to provide solutions by only focusing on food" (Via Campesina, 2009, p.17). Both organizations recognize that short term crises only bring into focus problems which have existed in the much longer term.

Furthermore, both texts address the most recent crisis as symptomatic of deeper structural problems underlying the global food system. For the Via Campesina "The food crisis is one of the multiple manifestations of humanity approaching a dead end" (Via Campesina, 2009, p.32), similarly, for the FAO, "The current situation points to the urgent need to tackle the structural, root causes of hunger" (FAO, 2009, p.39). Therefore it can be seen that there is some degree of consensus between the two organizations on the enormity of the crisis, in terms of deeper structural issues embedded within the global food system, and the depth of response needed to address the crisis in the long term. Though how both these organizations view these structural causes does differ.

For the FAO the structural causes at the root of food insecurity include the lack of macroeconomic stabilization, the need for governments to increase and encourage investment in agriculture and at the same time expand social safety nets, as well as the 
need for improved governance and the realization of the right to food (FAO, 2009). For the Via Campesina, structural causes include global inequality, the lack of realization of human rights objectives, the need for improved global governance, and the lack of inclusion of multiple voices (Via Campesina, 2009). The next section addresses these, and other, contradictions between the organizations in more depth, however, it is important to note here that there is agreement between the organizations on the need for improved global governance and the realization of human rights objectives in order to begin to resolve the structural causes at the root of the food crisis, and at the root of food insecurity.

\section{Contradictions between texts}

When considering contradictions between the texts, the messaging of both texts on the issue of migration, the root causes of food insecurity and the way each organization addressed issues of power, vulnerability, and agency where seen as particularly contradictory. Contradictions point to issue areas where the two organizations do not align and may be seen to represent divergent principles and norms of the organizations.

In terms of migration, the texts of both organizations offer opposing narratives on this issue area. Where the Via Campesina addresses migration by discussing the negative implications of this trend, portraying it as a form of "rural exodus" (Via Campesina, 2009, p.141), the FAO has a very different interpretation of its impacts, and draws attention to migration as leading to as a source of remittances. "For a significant share of the population living in developing countries, migration and subsequent remittances represent an important livelihood strategy and source of income for family members who 
stay behind" (FAO, 2009, p.15). Contradicting this discourse which champions the role of migration, the Via Campesina sees the issue of migration as a negative force present in society. "At present, societies are facing one of the more important social and human crises to [have] presented itself in the history of humanity. That crisis is forced migration, the movement of millions of human beings" (Via Campesina, 2009, p. 191). Whereas the FAO document considers the economic dimensions of the issue area, the Via Campesina's considerations extend to the broader social and more long-term implications of this trend, with implications for the policy responses seen as appropriate by both organizations.

As previously noted, there are both convergences and divergences between how both organizations view the structural causes at the root of food insecurity. Where there are contradictions between the organizations on this issue largely relates to the Via Campesina focus on global inequality versus the FAO focus on the need for increased investment in agriculture as root causes of food insecurity. Although there is convergence here in terms of what is being addressed, with both global inequality and investment in agriculture being statements related to the state of the global economy, the divergence in terms of how this issue should be addressed is notable.

More generally than the issue of migration or structural causes, the texts of both organizations also may be seen to offer differing discourses on power, vulnerability, and agency. The language in each text surrounding the 'power' of the actors involved is remarkably different. The Via Campesina discourse is empowered, while the FAO discourse is powerless, speaking mainly of vulnerability "each year such vulnerability is 
intensified either because of internal factors, including weather-related domestic production short-falls and inadequate domestic policy responses, or external factors such as global economic shocks currently being experienced" (FAO, 2009, p.25). In drastic contrast to this victimizing discourse, the Via Campesina highlights how, by working on the text, the members collectively felt as though they were "defending certain values and a way of life in society based on justice, simplicity and sustainability" (Via Campesina, $2009, \mathrm{p} .4)$. The divergence here is largely based on the differing approaches of both organizations toward agency.

\section{Gaps and silences: What the texts leave out}

Though both texts are quite comprehensive, and when considering the scope of each document, may be seen to offer messaging that is aligned with the mandates and position of each organization within the regime of global food security governance. A consideration of what the texts leave out, and questioning how these omissions impact the narrative being communicated, offered important insights into the texts during the discourse analysis process.

It was observed that the FAO report lacks concrete attention to how the governance changes outlined within the text as needed for food security to be realized should and could be implemented. For example, one governance solution outlined by the organization is to "provide science-based analysis and advocacy concerning the key determinants and possible evolution of food security" (FAO, 2009, p.46), yet there is no further elaboration as to how this should be carried out and who should be responsible. This omission may be seen to reduce the strength and power of the substantive policy statements made within the text, in that it has the effect of leading one to question the 
feasibility of implementation. For any project or plan to be successful, there is the need for implementation to be fully considered. Speaking about the need to accomplish certain tasks requires that one set out a feasible, well researched and well articulated implementation plan. Failure to be able to communicate how ideas and plans will be made into reality, in the case of food security governance, is particularly disastrous.

At certain points within the Via Campesina document there is a lack of statistical data and referencing to back up and substantiate policy positions. Though measuring food insecurity is contentious, specific statistics may not have been necessary in most cases, undertaking the task of quoting studies which substantiate the benefits of more local agricultural production would have helped to strengthen arguments made. Also, recognizing spaces throughout the text where further research is needed, or rather, where there are gaps in the ability to substantiate would have added further depth and utility to the text.

An area of focus in the Via Campesina text, which did not receive attention in the FAO document relates to the self-referential nature of the text. Throughout the Via Campesina document the organization refers to its place in the global system and the challenges it faces. Related to this, is the focus within the text on the need for education and the need to more actively participate in the systems of global food security governance, in order to strategically position itself and gain influence. Evidence of this is the recognition that "The Via Campesina must distribute analysis, strategy and proposal documents relevant both to the international context and to the central themes of the organization" (Via 
Campesina, 2009, p.180). The FAO text is largely silent on its position within the global system, with the report largely focusing outward.

In order to examine the impacts of the crisis, the FAO text includes case studies of five countries and their responses to the food crisis in terms of minimizing the impacts on food security. These are given in order to demonstrate that "a variety of coping mechanisms have been used by the poor to adapt to the crisis" (FAO, 2009, p.29). Given the state membership of the FAO it is perhaps not surprising that there is a focus on individual states within the text, as the internal governance of the organization in terms of coordinating responses, mirrors this membership profile. Whereas the Via Campesina falls silent on any discussion related to the local realities in the various regions that make up the organization, focusing instead on global dimensions.

\subsection{Themed areas of analysis}

Through the discourse analysis process, themes were identified in the texts being considered, and these four themed areas have been used to structure the core findings of the analysis. The themes of the distinction made between developed and developing countries, the role of international trade and domestic policies, the role of rights, and the role of global governance are introduced, followed by a discussion of how each organization/text addresses this themed area. Inconsistencies, contradictions, and paradoxes within the texts are identified, and the texts are also discussed in relation to each other by examining the contrasts, differences, and convergences between the texts. This allowed for the identification of areas of agreement and disagreement, as well as 
areas where it was seen that there was room for change (see Appendix 1 for summary of discourse analysis results).

Gillian Rose writing about archives (2000) describes the creation of categories as the "disciplining" of knowledge (as quoted by Crang, 2003, p.133). It is recognized that the selection of themes is inherently arbitrary to some degree, and the themes selected are by no means exhaustive of those present within the texts being considered. Themes which were thought to be significant upon reading the texts were largely influenced by what had emerged from the food security literature. Other themes discussed in both texts, yet perhaps less prominently, include the role of technology, the gender component, the issue of migration, food aid, and the role of international standards.

The themes identified represent issue areas that are considered by both organizations, and also link well to current debates within the literatures on food security and food sovereignty. The theme of the distinction between developed and developing countries was selected because it was very easily identified early on in the multiple reading of the texts - the tone and approach taken by each organizations vis-à-vis this theme was vastly different, and further study of this was seen to be of interest. This theme also linked well to many of the current debates within the food security literature including the debate surrounding chronic and transitory food insecurity and long-term and emergency responses, in that the types of responses and policies considered are often differentiated between those appropriate for developing countries and those fit for the developed world.

The theme of the role of international trade and domestic regulations is touched on at numerous points throughout both tests. They are discussed as one theme as they were 
often apparent when similar issue areas were being discussed, and it was also observed that they were quite regularly in close proximity within each text. The role of international trade and domestic regulations in global food security governance may also be seen to link well to the literature and contemporary debates on food security, linking to the food as a commodity, food as multidimensional, and the agriculture, trade and growth paradigm debates within contemporary food security outlined in chapter 3 . Though trade governance may be seen to be part of broader systems of global governance discussed below, the decision to separate this themed area from this broader governance discussion relates to its prominence in both texts, with both organizations specifically addressing economic dimensions apart from discussions of the structure, transparency, and inclusivity of global food security governance.

The role of human rights was a theme that came out quite unambiguously in both texts, but is invoked in substantially different ways. The FAO discusses the human right to food in relation to food insecurity, and the Via Campesina invokes the theme of human rights at various points as a proposed remedy to many of the ills facing the global food and agricultural system. This themed area links to the production versus distribution debate, in that arguments made for increasing production often fail to recognize the distributional issues that may inhibit access, and a right to food approach provides mechanisms for addressing these social dimensions of food insecurity. The theme of the role of human rights also links closely with the theme of the role of global governance, as it is recognized within the literature that human rights mechanisms in general, and specifically for food security, the human right to food, are important global food security 
governance mechanisms, that may be employed to realize certain governance goals (Salih, 2009).

Global governance as a theme was selected based upon the more normative or prescriptive portions of the texts; the identification of problems and possible solutions to those problems within both texts often touched on this theme as a means of explaining and offering insight into food security and insecurity, and this was thought to be significant in terms of areas where the texts may be seen to converge, or rather, where synergies can be seen. This themed area is becoming increasingly prevalent in global food security discourses, and as such, links to many of the contentious contemporary debates surrounding food security including the debates regarding chronic and transitory food insecurity and long-term and emergency responses, this debate brings to light governance challenges such as what is the appropriate response to food insecurity in the short and long-term and who should be responsible for creating, coordinating, and implementing solutions and programs.

\subsubsection{Developed and developing, North and South}

To ensure that hunger is conquered in the years to come, developing countries must be assisted with the development, economic and policy tools required to boost their agricultural sectors in terms of both productivity and resilience in the face of crises (FAO, 2009, p.4).

We have realized that however diverse our bases are - from landless farmers in Bolivia to organic farmers in Canada, from plantation workers in Indonesia to milk producers in Spain or vegetable growers in the Congo - we share a surprisingly common analysis of the causes of the long lasting crisis in agriculture (Via Campesina, 2009, p.4). 
The FAO report addresses developed and developing countries by differentiating between the two, and focusses policy responses to food insecurity toward developing countries. It is argued that the appropriate path for developing countries revolves around the need "to boost their agricultural sectors in terms of both productivity and resilience in the face of crises" (FAO, 2009, p.4). This productivist approach is in line with the dominant food security discourse seen since the early 1970's. The long-term role of developed countries in the process of overcoming food insecurity is not addressed in the FAO text, other than in the form of the need for further investment in agriculture.

Within the FAO report the integration of developing countries into the global economy is recognized and addressed at various points throughout the text. This is discussed in terms of the increased vulnerability of developing countries due to greater integration (FAO, 2009, p.4, 26), the number of international migrants from developing countries and the impact this has on the home country and the households and families left behind (FAO, 2009, p.16), and in terms of the potentially negative impacts of both import and export dependency for developing countries (FAO, 2009, p.13, 18). Yet, the FAO discusses the financial crisis as though there were some degree of surprise at how impacted developing countries had been, with the organization expressing that there had been "some optimism that the developing countries might be decoupled from the crisis and recession that had started in advanced economies" (FAO, 2009, p.9). Given the recognition throughout the report that developing countries are so intimately linked to the global economy, it seemed contradictory and inconsistent that the impact of the crisis was addressed in this way. 
The Via Campesina uses North and South, rather than developed and developing, to refer to the obvious disparity between countries in the global system. Consistent with this differing use of terms, the discourse surrounding the distinction made between North and South is also quite different in the Via Campesina text. Similarities between the countries of the North and countries of the South regarding the uncertain future of food and agricultural policy are discussed (Via Campesina, 2009, p.47), and the common struggles of farmers in the North and farmers in the South are highlighted. The Via Campesina claims that it has "formed in the North and the South around common objectives" (Via Campesina, 2009, p.41). Identifying the commonalities between the struggles and goals of many farmers around the world is a fundamental component of the approach of the organization.

However important these commonalities may be in terms of strengthening the organization, Via Campesina does not fail to recognize the differences between the North and South in terms of the significant impact economic policies in the North can be seen to have on the agriculture of the South (Via Campesina, 2009, p.101). This inconsistency appears quite obviously in the text, and though the organization attempts to build on the commonalities, the disparities are hard to ignore. Agricultural subsidies in the North are an example of a policy that is having an impact on countries and farmers in the South. These subsidies, which encourage farmers to produce for export, lead to the distortion of agricultural markets, negatively impacting farmers in the South who do not benefit from the same subsidies, and causes increased migration from the South, often to do seasonal work in the North. As the organization itself recognizes this is paradoxical, in that the 
migrants help to produce the exports that may be seen to cause further migration.

Therefore, in as much as the text attempts to build unity by highlighting the common bonds between the North and South, it does not fail to recognize that the North and South will require differing policy approaches in the short term in order to achieve the goal of a more food sovereign world.

Although there is significant difference between the texts of these organizations in their treatment of developed and developing countries, with this difference beginning with the contrasting use of terms of North/South, developed and developing used to describe the obvious inequality in the global system, and extending to the alternate ways the texts describe agricultural work. Yet, despite the attempt by the Via Campesina to focus on the commonalities between North and South, and despite the tendency of the FAO to treat developed and developing countries differently, there are points where the organizations may be seen to converge regarding this issue area. Both organizations portray the economic links between North and South as an important consideration in both long- and short-term responses to food insecurity. The types of responses needed in order to address this North/South disparity do differ however, yet there is agreement that a governance solution in this issue area is needed.

\section{Links to the literature}

When considering both texts, the vastly different treatment of this themed area was notable. The treatment of developed and developing countries is a contentious issue within food security discourses and this is apparent in the literature. Cooke, et al. foresee that "conflicts between producing and consuming nations threaten to undermine not only international organizations like the WTO but bilateral trade relations as well" (Cooke, et 
$a l, 2008 \mathrm{a}, \mathrm{p} .101$ ). Since the Doha round began in 2001, the differences between developed and developing countries, specifically the differences in relation to agricultural policy, has eroded the international multilateral system. As Suppan argues, the implications of this distinction have real policy implications. Suppan highlights that the United States and other developed countries frame the debate in terms of food security which brings about a more narrow range of responses, usually following a productivist, trade driven response of ensuring the ability of developing countries to import enough food to feed their people (Suppan, 2008).

However, is this bifurcation between North and South, and developed and developing countries creating an artificial distinction in food security discourses? Sell recognizes that "pro-GMO and anti-GMO discourses do not strictly fall along 'industrialized country-Global South' or 'industry-public sector' fault lines" (Sell, 2009, p.196, with quotes from Fukuda-Parr, 2007). The assumption that developed and developing countries have vastly different food security needs fails to question or address the underlying causes of poverty and hunger, and leads to responses that have, over time, proven to be ineffective (Salih, 2009).

\subsubsection{The role of international trade and domestic regulations}

The volatility in the food markets is mainly due to deregulation, the lack of control on the big players and the lack of necessary state intervention at the international and the national level to stabilize markets (Via Campesina, 2009, p.87). 
Food security is a function not only of production and market access, but also of the environment created by economic and political institutions at all levels (FAO, 2009, p.47).

As the FAO report centers on the impacts of the economic crisis on food insecurity, it focusses quite heavily on the role of international trade and domestic policies. Not surprisingly perhaps, the treatment of this themed area in the text was consistent with the narrative that increasing investment in agriculture in order to boost productivity, and increasing agricultural trade, are key components in eradicating food insecurity (FAO, 2009). The FAO also recognizes the role of individual countries to enact appropriate policies in order to keep markets open, and attract investment in agriculture, while simultaneously balancing the need to ensure that those vulnerable to food insecurity within the country are not adversely affected by these policies (FAO, 2009).

The consideration of this themed area brought into focus a telling contradiction within the FAO text. While the organization puts forward the position that trade and agricultural productivity are vital components of alleviating food insecurity (FAO, 2009, p.23), there is also the recognition that reliance on trade increases vulnerability (FAO, 2009, p.31) and that more open economies were less resilient to external shocks (FAO, 2009, p.24). This inconsistency leads one to question which position the organization is advancing, and is perhaps symbolic of contradictory approaches within the organization.

The discourse presented in the Via Campesina text regarding the theme of international trade and domestic policies centers around the need to drastically change the way that food and agriculture are treated in the global economy. The organization recognizes the negative impacts of import dependency in terms of dimensions of vulnerability to 
external factors, and in term of the increased political dependency that results. The ideal scenario presented, is one where there is the "implementation of agricultural and trade policies at local, national and international levels supporting sustainable agriculture and local food consumption" (Via Campesina, 2009, p.75). At a minimum however, they call for the reform of global agricultural trade, which includes the need to eliminate agricultural subsidies that distort world markets. The reasons for this are twofold, on the one hand market distortions make participation in trade unpredictable and volatile for many of the world's farmers, and on the other hand the elimination of subsidies would prevent the dumping of surpluses on the global South.

Within the Via Campesina text, an inconsistency emerges regarding the treatment of this themed area, which brings into focus the production versus distribution debate. The organization largely puts forth the position that there is no need to increase production, that issues of food insecurity are related to distributional dimensions of global food policy. It is claimed that: "There is enough food to feed the whole population of the world" (Via Campesina, 2009, p.153). However, in a few instances there is mention of the need to increase production, albeit with the caveat that this increase not be at the expense of certain principles: "It is necessary to adopt certain technological models which are apt for increasing production without being detrimental to the health of peasants or the population in general" (Via Campesina , 2009, p.132). Though it is interesting that Via Campesina recognizes the need to increase production, as this does seem to conflict with their position that there is enough food to feed the world, and many authors have recognized, as discussed in chapter 3 , that distributional issues, not availability largely underpin most instances of food insecurity. The inconsistency here is 
not necessarily related to the need to increase production, as this statement may have been intended to convey that the need there is the need to increase production in the long term, though it was not put in this context. The remarkable inconsistency here relates to the inclusion of technological models in its description of this need to increase production given the opposing stance of the organization toward technological and productivist approaches. It does perhaps however, indicate a space where room for compromise between the discourses of these organizations may be seen to exist.

Another area within the theme of international trade and domestic policy where some degree of convergence might be seen to exist between the two texts is in the need to consider dimensions other than trade when constructing food policies. The Via Campesina text puts forth a model where "agriculture plays an important social function while at the same time being economically viable and ecologically sustainable" (Via Campesina, 2009, p.43). Similarly, the FAO text recognizes that food security "is a function not only of production and market access" (FAO, 2009, p.47), but rather is a product of the environment created by institutions of governance. This convergence, however minor it may be, is significant as it signals areas where growth and change between the two organizations, and the global discourse on food security is occurring.

Although there is agreement regarding the multifunctional and multidimensional role of food, an important area of divergence in this themed area relates to the role of existing international institutions in global food security governance. The Via Campesina puts forth the position that the WTO has that agriculture should be taken out of the WTO (Via Campesina, 2009, p.62). The FAO text on the other hand does not specifically mention 
the WTO, it does however mention that global food security governance should draw on "existing structures" (FAO, 2009, p.46). Perhaps bound to some degree by the international governance system within which it is embedded, the FAO is cautious to remain uncontroversial, and to be as inclusive as possible. It may be that the membership of these organizations is the cause of this divergence. The FAO's country based membership, and the Via Campesina's organization based membership, make for very different environments within these organizations when positions are being discussed.

\section{Links to the literature}

Appearing numerous times throughout both texts, the theme of international trade and domestic regulations remains a key policy focus within each organization and within the food security regime more broadly. There is much debate within the contemporary food security literature regarding the role of world markets for sending appropriate signals relating to food supply, demand, and price (Timmer, 2010). Those who promote a productivist trade driven agenda for food "argue that farmers benefit from increasing production for export and increasing levels of agricultural trade. Yet, as the numbers indicate, this is clearly not the case" (Desmarais, 2007, p.65). It is argued that policies designed to address food insecurity focussing on food aid, export growth, and import dependency, have been unsuccessful in bringing about desired food security objectives, as Salih concludes: "Not only have these policies failed to solve food crises, they have miserably failed to ensure long-term food security" (Salih, 2009, p.504). The treatment of this themed area in both texts brings these debates into focus.

This themed area also brings into focus issues of sovereignty and the role of individual countries in ensuring food security. Suppan argues that in the current system, trade 
concerns too often take precedence over concerns for food security. Obligations under the WTO usurp other rights and obligations in the international system. And although the WTO recognizes the rights of all countries to control trade related to food in order to protect the health and wellbeing of its peoples and environment, the provision that these actions must be based on science functionally limits the ability of many countries to enact sovereign agricultural trade policies.

\subsubsection{The role of rights}

The Right to Food Guidelines also recommend that states promote good governance as an essential factor for sustained economic growth, sustainable hunger eradication, as well as the realization of all human rights including the progressive realization of the right to adequate food (FAO, 2009, p.46).

Human right instruments provide a means to facilitate the elimination of oppression. These instruments attempt to cover all sphere of human life. Indeed, human rights exist for the oppressed to defend or obtain their human standards in situations of oppression (Via Campesina, 2009, p.173).

In the FAO text, food as a human right is presented as an important component of food security governance. The organization recognizes that in order to address current food insecurity, which has been worsened by food and financial crises, the "business-as-usual" approach will not be effective (FAO, 2009, p.44). The FAO invokes the concept of food as a human right, and argues that precedence has been set for this approach, citing that in 2008 "the right to adequate food was recognized as a fundamental component of a sustainable solution to the world food-security crisis" (FAO, 2009, p.44). Current approaches to food insecurity are contrasted with a right to food approach and the 
position is put forth that "a right-to-food approach has an important role to play in eradicating food insecurity" (FAO, 2009, p.1, emphasis added).

Though the language of human rights is invoked at multiple points throughout the body of the document, as well as in the final section of the text where governance solutions are discussed, in the introductory section signed by the Director General, Jaques Diouf, the text shies away from fully embracing this approach. Stating that "food, the most basic of all human needs, is no more affordable, leaving more and more people without the means to consistently obtain nutritious food throughout the year" (FAO, 2009, p.5, emphasis added). The use of needs as oppose to rights was found to be a significant inconsistency in the FAO text. This inconsistency may be the result of a simple oversight, it may be because needs was used in the Forward of the report and the reference to rights appears in the later parts of the document, or again, it may be symbolic of greater tensions within the organization.

The Via Campesina presents a broad and inclusive approach to rights, invoking not only the right to food, but other human rights as well. It is argued that the right to water, education, health care, and culture, must be respected and protected (Via Campesina, 2009, p.61). Though this list of basic human rights is not exhaustive of those mentioned in the text, it begins to illustrate the more comprehensive consideration of human social interaction a food sovereignty approach necessitates. Via Campesina defines the use of rights and cites that "the organization works so that human, social, political, economic, cultural and individual and collective rights are respected in all communities, in all social groups, and by all political regimes and governments" (Via Campesina, 2009, p.61). The 
organization also provides recommendations as to how these rights might be enshrined in global governance mechanisms, arguing that what is needed are "international institutions that can control national governments if they are repressive, corrupt, if they do not respect the rights of their people" (Via Campesina, 2009, p.61). The position is put forth that the right to food sovereignty, which includes considerations of collective rights is more encompassing than the right to food, and that it is this right to food sovereignty that needs to be pursued.

While discussing human rights instruments, the Via Campesina report mentions the need for the recognition of peasant's rights. It is highlighted that the organization needs to "continue to work with the peasant's rights charter and we hope that eventually our rights as peasants, men and women, will be recognized" (Via Campesina, 2009, p.52). However, how peasant's rights differ from those rights described in a food sovereignty approach is not described; the right to food, land, water, genetic resources, etc., are common between the treatment of the rights of peasants and food sovereignty within the text. It is therefore unclear how the mention of a peasant's rights charter contributes to the organization's goal of a food sovereign world.

The FAO defines the right to food as "the right of every person to have continuous access to the resources necessary to produce, earn or purchase enough food not only to prevent hunger, but also to ensure health and well-being" (FAO, 2009, p.44). When comparing the FAO definition of food as a human right, with that of the Via Campesina definition of food sovereignty, it is interesting to note that missing from the FAO definition of the right to food, and where the definition of food sovereignty goes further, is the right to 
decide whether one produces, earns, or purchases their food, in other words, what is missing is the "right to define their own food and agricultural systems" (Via Campesina, 2009, p. 74 , from the definition of food sovereignty).

Yet, whether it is a right to food, or food sovereignty approach, both texts agree that these models provide frameworks for addressing the global problem of food insecurity. The FAO describes a right to food approach as providing "a framework for the diagnosis of the food security problem as well as guidance for the design, implementation and monitoring of initiatives taken in response to the food crisis" (FAO, 2009, p.45); while the Via Campesina describes food sovereignty as "the key to provide livelihoods to millions and protect life on earth" (Via Campesina, 2009, p.74). This convergence may be seen as agreement that the human right to food approach should factor into governance solutions.

\section{Links to the literature}

It is recognized that covenants and declarations at the international level have set precedence for the right to food (Desmarais, 2007, p.110). Both organizations discuss the importance of a right to food approach, while also invoking other human rights language. There is precedence set for this both in the literature, as well as in the texts of other international food policy structures. Ishii-Eiteman recognizes that one of the implications of the IAASTD report is that states and other actors must now "cooperate internationally to address structural impediments to fulfilling the right to food" (Ishii-Eiteman, 2009, p.697). Furthermore, highlighting the scope of a food sovereignty approach, Patel argues that food sovereignty is not just about the right to food, but is about the right to have rights over food (Patel, 2009, p.667). Both organizations recognize that human rights 
instruments may provide important governance mechanisms in eliminating food insecurity.

\subsubsection{The role of global governance}

Change is needed... "change that improves livelihoods, enhances local food production for local consumption, and opens up democratic spaces, change that empowers the people of the land with a great role, position, and stake in decision-making on issues that have an impact on their lives" (La Via Campesina, 2009, p.41).

The persistence of undernourishment and its aggravation during the recent food and economic crises underscore the need for improved global food-security governance to address fundamental weaknesses in the fight against hunger (FAO, 2009, p.46).

The governance of international agricultural trade may be seen as an area where there is some level of agreement between both organizations. For the Via Campesina "International trade in agriculture needs to be regulated" (Via Campesina, 2009, p.146), and for the FAO "Stable and effective policies, regulatory and institutional mechanisms, and functional market infrastructures that promote investment in the agricultural sector are paramount" (FAO, 2009, p.4). Though the organizations agree that some level of regulation is necessary, the extent to which this regulation would take place is seen as slightly more contentious. Though the FAO is looking to markets and investment for solutions, and the Via Campesina is focusing on the democratic deficit in decision making, the important convergence here is that they are both using the discourse of global governance, in terms of the need for strengthened institutions and effective regulation, in order to describe how the issues need to be addressed. 
Both organizations see the need for improved governance at all levels of the global system, with the Via Campesina calling for governance mechanisms "that create the space and set a framework that allows national and local governments to respond to the need of their people" (Via Campesina, 2009, p.62). The FAO too sees the governance process as taking place "not only at the national level but also at the regional, village and even family levels" (FAO, 2009, p.46). That both organizations see improved governance as occurring at multiple levels, and see the interactions between these levels of governance as important, shows that there is some degree of agreement as to how responses should be structured. And though the responses envisioned at these various levels do differ, the framework within which solutions are to take place is seen as similar. This convergence between the two organizations is significant as it points to an area where governance solutions might focus, and where there is perhaps room for constructive dialogue.

It is the last portion of the FAO report, which is more normative in nature, where there is the most reference to governance. There is recognition that the global food and economic crises dramatically highlighted the need for "stronger global food-security governance mechanisms" (FAO, 2009, p.5). The FAO addresses problems in the global food system, and argues that improving governance structures is a vital component in addressing these weaknesses. The position is put forward that resolving the underlying problems causing food insecurity "would require coherent and coordinated action over the long term" (FAO, 2009, p.46), and would require the recognition of "food security as a policy issue that cuts across several sectors and has multiple dimensions" (FAO, 2009, p.47). Given 
that the FAO is perhaps seen by many as the most obvious organization to be at the center of global food governance, which, it may be argued, results in the focus on governance within the text, the mention of global food security governance weaknesses points to the fact that the treatment of the importance of strengthened and improved governance is not altogether self-serving.

The FAO text puts forth a comprehensive plan that attempts to address both economic and social dimensions of food security governance. On the one hand the organization puts forward the position that as long as there is a lack of "global food-security governance mechanisms, many countries will continue to struggle to increase production in line with demand" (FAO, 2009, p.5). It is also argued that "governments should boost and encourage their investment in agriculture (including non-farm rural activities), expanding safety nets and social-assistance programmes" (FAO, 2009, p.39). Therefore, it becomes apparent that there is a distinction between governance mechanisms to address economic dimensions of food security, such as increasing production, and governance mechanisms to address social dimensions of food security, such as improving socialassistance. This distinction forms the basis of the FAO's approach to governance, where these two approaches are seen as complimentary.

In term of governance, the Via Campesina discusses food security governance problems quite globally, arguing that "the system is in crisis" (Via Campesina, 2009, p.45). The issue of representation in systems of global governance is addressed, and the position is put forth that more democratic global governance institutions are needed. It is argued that "Democracy means that everyone thinks, that everyone deserves respect and dignity" 
(Via Campesina, 2009, p.27), and it is with this principle that the Via Campesina believes global food governance should be approached. It is argued that the solution to current challenges facing the global food system relate to the need to realize the benefits of a food sovereignty approach, and the need for "sufficient political will" (Via Campesina, 2009, p.197), at all levels of governance.

The Via Campesina puts forth five governance solutions to problems of food insecurity, and they are as follows:

[1] Reinstate the rights of governments to intervene and regulate in the food and agriculture sector in order to achieve food sovereignty. [2] Reject Green Revolution models. Industrialized agriculture and fisheries are no solution. This view was clearly supported by the broad based international assessment [IAASTD]. [3] Prioritise the participation of small scale farmers, pastoralists and fisher-folk in the formulation of policies. [4] Make food sovereignty and the right to food prevail over trade agreements and other international policies. [5] Restructure United Nations (UN) agencies involved in food and agriculture to make them more effective (Via Campesina, 2009, p.198).

If considered individually, and compared to the FAO approach to governance solutions, it is interesting to note the areas of divergence and convergence between the two positions. In terms of the first Via Campesina proposal, which focusses on the role of states, there is some degree of convergence here, as will be discussed, with both organizations seeing that there is an important role for states in global food security governance solutions. The second solution put forward relates to the need to reject overly technocratic approaches to food security, with the FAO clearly arguing for a balanced approach which considers the social dimensions of food security governance, and endorsing the IAASTD report, this 
rejection of technocratic approaches is an obvious area of convergence between the two organizations.

The third governance solution calls for greater participation of small scale farmers in decision making in the processes of global food governance. The FAO is largely silent on the issue of participation, and as previously noted, focusses on a narrative of vulnerability, not agency, throughout the text. This area of divergence between the texts is important, as it speaks to fundamental differences in the approaches of the two organizations to food security governance, with the FAO approach tied to the state-based decision-making structure of the UN, and the Via Campesina proposing a different, perhaps more representative approach. The fourth solution puts forth the position that food sovereignty and the right to food must take precedence over other considerations, such as trade related concerns, in systems of global governance. This point signals both convergence and divergence between the texts, where both organizations see the right to food as an important governance solution, but where the FAO does not put forth the position that it should trump other concerns.

The fifth proposed solution relates to the need to restructure UN agencies to make them more effective. This is an important area of divergence between the two organizations, and centers on the role of current governance structures in solutions to achieving global food security. The FAO discusses the need to build on the current system, arguing that "the governance of the fight against food insecurity needs to be consolidated at the global level, drawing and building on existing structures" (FAO, 2009, p.46), whereas the Via Campesina calls for this change to be more drastic, calling for the need to "Restructure 
UN agencies" (Via Campesina, 2009, p.198). The FAO uses drawing and building, whereas the Via Campesina text uses restructuring, this disagreement between the two texts may be seen as significant in terms of how each organization views the changes that need to take place in the global system, where the Via Campesina envisions a deeper, more structural change as needing to occur.

It becomes apparent that the two organizations, though using the discourses of global governance, in some ways, envision differing governance solutions. This will be elaborated further in chapter 5 , however it is important to note here that both the convergences and divergences are important as the global governance literature on changes within regimes governance indicates that these both signal areas where there is room for change to occur.

In terms of the broader governance changes envisioned by the Via Campesina, much like the FAO (FAO, 2009, p.46), the organizations calls for the need for greater regional integration (Via Campesina p.146). Given that the internal governance of both organizations rely heavily on regional level work, with the FAO relying largely on the work done at regional conferences in its work planning, and with the Via Campesina, organizing itself first at the regional level, in order to ensure that the work of the organization is grounded in local realities, it is perhaps not surprising that both organizations recognize the importance of greater regional integration in global governance solutions to food insecurity.

The food security governance problems or challenges identified within both texts may be seen as an important area of convergence. The FAO argues that there is the need "to 
tackle the root causes of hunger" (FAO, 2009, p.46), while the Via Campesina puts forth the position that the global governance of food "has to be dramatically improved" (Via Campesina, 2009, p.201). This synergy in discourse speaks to the important role of governance in food security solutions. Quite poignantly, the FAO states that:

In spite of on-going global food-security analysis and timely warning of likely immediate and long-term problems, such knowledge has not translated effectively into appropriate and timely policies, programmes, institutions and response mechanisms (FAO, 2009, p.46).

The global governance of food and agriculture is lacking and this is seen by both organizations to have very real implication for food security.

Another area of convergence between the texts of the two organizations, as it relates to global governance, can be seen in the treatment of the role of states. There is agreement between the texts that states have an important role to play in eradicating food insecurity. The FAO recognizes that "The provision of national safety nets is a key component of the social contract and mutual accountability between states and citizens" (FAO, 2009, p.41). With the Via Campesina acknowledging that "It is the responsibility of states to make sure that this fundamental right [the right to food] takes precedence over, for example, commercial law" (Via Campesina, 2009, p.158). Given that the Via Campesina is a nonstate actor, with less power and influence in the multilateral system as a result, this agreement between the texts on the role of states may seem surprising; however, when one considers that the membership of the Via Campesina is often made of national farmers groups, this position is less unexpected. Perhaps another reason for this position is the rights and obligations of states in international law, as recognized by Via Campesina "International law allows nation states to govern sovereign unilateral acts in 
order to protect their agriculture and to guarantee the sovereign utilization of national resources" (Via Campesina, 2009, p.158). Given that the Via Campesina sees global governance solutions, and rights based approaches as important, it is not surprising that they would see the importance of the role of the state in the international system.

\section{Links to the literature}

In the food security literature current global governance mechanisms are seen as insufficient and lacking with regard to the goal of eradicating hunger and malnutrition. While identifying the current governance of food as a problem, it is important to note that the literature also addresses the importance of governance in solutions to food insecurity. Improved governance is seen as a means for addressing various challenges facing the global food system. The issue of representation in decision making is seen within the literature as a current problem within the governance of food, with Lang arguing that one of the greatest governance challenges of the global food system is the need to coherently bring together so many diverse perspectives (Lang, 2010). Also addressed, is the need for global food governance mechanisms to "pursue more far-sighted food policies" (Timmer, 2010, p.2). The Via Campesina and FAO text are in line with this treatment, both seeing global food governance as an important consideration in terms of identifying causes, and in terms of providing solutions, to the issue of food insecurity.

\subsection{Conclusion of discourse analysis results}

Through the discourse analysis process, the themes, narratives, paradoxes, synergies and divergences identified may be seen to offer insight into the ways in which food security, right to food, and food sovereignty discourses are appropriated and employed at the international level. The synergies and divergences identified in the four themed areas 
speak to the broader implications these discourses may be seen to have for global food security governance, in terms of their ability to construct certain understandings of the causes of, and solutions to, food insecurity. These areas of synergy and areas of divergence between the organizations, and the contradictions and paradoxes identified within the texts, are explored through a political economy and global governance framework in the following chapter. The literature on governance by discourse and regime change is used to interrogate the global governance implications of these discourses, in order to better understand the current state of global food security governance.

The themes of developed and developing and North and South, the role of international trade and domestic regulations, the role of rights, and the role of global governance, where used to structure the results of this analysis. With regard to the theme of developed and developing and North and South there are obvious convergences and divergences between the two texts, where the divergences relate to alternative approaches to agency and vulnerability, and where the convergences relate to the need to consider the economic dimensions of North/South relations in food security governance solutions. To be more in line with the Via Campesina approach, the FAO would need to shift from a narrative of vulnerability, to one which recognizes the agency of those who are seen as vulnerable and their role in food security solutions, whether this is possible however, will be discussed further in the following chapter in a section on global food security governance and agency. 
In terms of the role of international trade and domestic regulations, certain contradictions within the text of the FAO regarding this themed area were illustrated, these contradictions relate to the seemingly inconsistent position that promoting agricultural trade has an important role to play in food security solutions, while also maintaining the position that global agricultural trade contributed to the food crisis. There is significant divergence between the two organizations regarding the role of current multilateral institutions in the realm of global food security governance, with the FAO taking the position that minor changes are needed, and the Via Campesina taking the position that more dramatic change is needed. The divergence here signals a significant gap between the approaches of the two organizations toward economic dimensions of food security governance solutions, this and the role of the membership of these organizations in this divergence is discussed further in the following chapter, in a section which will examine in more depth the synergy and fragmentation identified throughout the discourse analysis process.

When considering the role of rights, a significant inconsistency was found in the FAO text, which presents the human right to food as an important component of food security governance. Yet though the language of human rights is invoked at multiple points throughout the body of the document, in the introductory section the text does not go so far as to fully embrace the language of rights, stating that food is a need. The use of needs as oppose to rights was found to be a significant inconsistency in the text, as it is seen to be symbolic of greater tensions within the organization. The Via Campesina text invokes not only the right to food, but other human rights as well, food sovereignty is positioned as more inclusive as the human right to food, as it includes considerations of 
collective rights, and that it is therefore this right to food sovereignty that needs to be pursued. A telling contradiction between the two organizations relating to this themed area can be seen in the comparison of the FAO definition of the right to food and the Via Campesina definition of food sovereignty, where the FAO definition does not include dimensions of the right to define the means through which ones food is produced. This contradiction will be explored further in the following chapter, in the section on food sovereignty, rights, and governance.

In terms of the role of global governance, the governance of international agricultural trade may be seen as an area where there is degree of convergence between both organization, not necessarily in terms of the specific policies which each organization envisions, but in terms of the use of global governance discourses relating to the need for strengthened institutions and effective regulation, when characterizing how this issue ought to be addressed. Another area of convergence relates to the recognition that improved regional level governance is an important competent of food security solutions. The governance solutions proposed by the FAO attempt to address both economic and social dimensions of food security governance, with the proposed solutions of the Via Campesina being perhaps more broad reaching in scope.

When considering the specific policy recommendations of the Via Campesina, against those of the FAO several areas of convergence and divergence were noted. Both organizations put forth the position that there is an important role for states in global food security governance solutions. The state-based organizational structure of the FAO makes this an obvious governance approach for this organization, and given that the Via 
Campesina sees global governance solutions, and rights based approaches as important, it is not surprising that they too see the importance of the role of the state in the international system. The divergence between the texts regarding the role of participation was seen as important, where the Via Campesina solutions propose that more meaningful participation is a vital component of food security governance, and the FAO is largely silent on the issue of participation, this will be discussed further in the following chapter, in a section on participation, democratic decision making, and transparency in global food security governance.

Further divergence and convergence was noted between the Via Campesina position that food sovereignty and the right to food must take precedence over other considerations in systems of global governance. Both organizations see the right to food as an important governance solution, yet the FAO does not put forth the position that this should necessarily take precedence over other concerns. This point signals both convergence and divergence between the texts, where both organizations see the right to food as an important governance solution, but where the FAO does not put forth the position that it should trump other concerns, discussed further in the section in the following chapter on food sovereignty, rights, and governance. The need for change in the structures of global food security governance is another important area of divergence between the texts, where this divergence speaks to the, in some ways, very different governance solutions envisioned by these organizations.

This research takes the position that change within the global food security governance regime is needed, and that this change should tend in the direction of the food sovereignty 
solutions proposed by the Via Campesina. However, it is important to recognize that though much literature recognizes the need for change, and though there is indeed the opportunity for change, obstacles which may be attributed to the current state of global governance and the global political economy, may preclude the possibility for change to occur, this will be further elaborates in the next chapter, where it will be argued that the growing influence of the right to food and food sovereignty discourse represents an important progressive step forward for the food security regime. 


\section{Chapter 5-Discussion: Re-conceptualizing food security governance}

The production and consumption of food is influenced and regulated by a myriad of institutions, agreements, standards, norms and customs which govern the food system (Cooke, et al, 2008a). This complex governance structure is a result of the multitude of often divergent or at times synergistic goals, approaches, and experiences of actors which have actively or passively created the system. What emerged from the texts of the FAO and the Via Campesina deconstructed in this analysis is a broad, at times divergent, and perhaps surprisingly, often synergistic discourse between these two organizations.

This chapter explores governance and fragmentation and what the synergies and divergences identified in the texts might mean more broadly, it examines how discourses impact governance and what this says about the shift to food sovereignty and right to food discourses. As this research is premised on the assumption that it is important that the global food security governance regime, as represented by the discourse of the FAO, take into account many of the concerns of the Via Campesina in terms of the organization's focus on rights, sovereignty, accountability, participation and transparency, the role of agency in this shift and how democratic decision making, coherent policies, and collective action must all play a role in governance solutions are discussed. Concepts from the global governance literature such as discursive governance, fragmentation, and regime change are used in order to more deeply interrogate and explore the areas of synergy and divergence in the texts.

There is divergence between the texts on issues such as the types of responses needed in order to address North/South disparity, yet convergence on issues such as the need to 
consider issues other than trade in agricultural policy. These areas of agreement and disagreement between the texts help to illuminate how the global food security regime is structured and how food security discourse are constructed, and in so doing provide a better understanding of the current state of global food security governance.

The fragmentation and synergy which may be seen to characterize global food security governance is examined, with concepts of policy stretching and layering and the importance of norms and principles used in order to explore areas of convergence and divergence in the texts. The various discourses and narratives identified in the texts are discussed in terms of their influence of on global food security governance. Broader geopolitical changes and changes within the global food security governance regime, and the influence of food sovereignty and right to food discourses on governance are explored. Structure and agency in global food security governance are discussed in terms of how both texts approach agency and what this means vis-à-vis the current state of global food security governance and the room for change. The importance of participation, democratic decision making, and transparency are discussed in terms of their influence in changing discourses and shifting the debate, and the convergence of the two texts on the need for more coherent policies and more collective action is also explored.

The literature presented in the third chapter on global governance and change within regimes and institutions is employed throughout this discussion in order to explore the convergences and divergences identified more deeply, where these tensions and commonalities in discourse are seen to signal openings where this dialogue can be moved 
forward. The role of structure and agency, the role of a changing geopolitical environment, the introduction of new ideas and new actors, the stretching and layering of policy, the influence of changing principles and norms, a consideration of the political nature of this governance issue, and the approaches of the actors involved, all help to inform an understanding of the current dynamics of global food security governance, and help to explore whether the food crisis and responses to it by these two organizations represent a possibility for the regime to move forward in a more progressive direction.

\subsection{The global food security governance regime: synergy and fragmentation}

Global food security governance may be seen to be characterized by various degrees of synergy and fragmentation. Differing principles and norms of the actors involved in this realm of global governance, as well as the stretching and layering of certain policies and approaches over time have lead to areas of convergence and divergence within the regime. This synergy and fragmentation occur to varying degrees within a regime and may be seen to change and shift over time. Within the food security regime actors and institutions may be seen to co-evolve so that neither institution would be seen to exist in its current state without the interaction with the other; these interactions between actors within a regime may have a profound impact on the development and effectiveness of each institution over time (Gehring and Oberthür, 2009). These synergistic or fragmented interactions may be seen to result from differing norms, principles, and approaches of the actors or institutions in question.

As was outlined in chapter 3, synergy is characteristic of a situation where the principles and norms of the actors involved in a realm of global governance largely align. This 
synergy results in convergent policies and approaches, which over time, reinforces the goals and objectives of the actors involved (Rosendal, 2001, Beirmann et al., 2009). Whereas conflictive or fragmented relationships within regimes of global governance, are characteristic of situations where the principles and norms of the actors do not align. Fragmentation in a realm of global governance results in actors, institutions and organizations approaching the issue area with largely differing approaches and policy responses (Rosendal, 2001, Beirmann et al., 2009).

The texts of the FAO and the Via Campesina exhibit synergy and fragmentation between the two organizations on a range of issue areas. For example, there is divergence between the organizations on the role of existing international institution, with the Via Campesina text putting forth the position that a complete reconfiguration of the institutions involved in global food security governance is necessary, and the FAO text claiming that what is needed is simply to build on and draw upon existing institutions. However, consensus between the two texts may be seen regarding the enormity of the present crisis and the challenge ahead. These synergies and divergences between the texts point to fundamental deviations in the norms and values of the two actors, as well as pointing to larger areas of agreement and disagreement within the global food security governance regime.

The synergy and convergence between the texts may largely be seen to result from the differing norms and principles of the organizations on a range of issue areas. Changes to rules and procedures, which constitute the day-to-day governance mechanisms of a regime, are seen as easier to effect than changes to the underlying principles and norms 
upon which a given regime or institution is based (Krasner, 1982; Curran, 2008). This is because norms and principles, as opposed to rule and procedures, may be seen to represent the overall core policy objectives of an organization. It is argued that the performance of a system or regime is reduced as a result of conflicting norms and principles, as this fragmentation leads to incoherent and contradictory approaches.

The norms and principles of an organization are influenced by a range of factors, from the membership of the organization, FAO being state based and Via Campesina being made-up of many smaller like-minded organizations in countries and regions around the world which influences the norms and principles of each organization. Where the FAO's norms and principles are shaped by a range of nations with differing approaches to economy, environment, politics, and differing social and cultural norms, and where the norms and principles of the Via Campesina are influenced by a common position of critique of the political and economic structures which are believed to be at the heart of food insecurity. How the organization came to be may also be seen to influence the norms and principles of each organization, where the Via Campesina arose as an act of resistance, making the norms and principles of the organization more progressive in approach, where the FAO was created by the multilateral system of UN nations, making the norms and principles of the organization more tempered and restrained. The representation of the organizations also influences norms and principles, in the case of the Via Campesina this means small scale farmers and peasants and for the FAO this is governments of member countries. Therefore the positions put forth by the FAO are only as democratic and inclusive as the processes which take place in the countries of its 
membership. Whereas in the case of the Via Campesina, representation and inclusivity in decision making are at the heart of the organizations principles.

Within the organizational structure of the Via Campesina the importance of common norms and principles is exemplified well. Membership to the organization is based upon the acceptance of basic principles and goals, whereas for the FAO, membership is country based, with these countries having divergent and contradictory norms and approaches regarding the mandate and programs of the organization. The lack of contradictory discourses within the text of the Via Campesina when compared to that of the FAO is symbolic of this difference, where the common norms and principles of the Via Campesina allow for the development of a more common position within the organization.

As outlined in chapter three, the shift in the traditional role of the state has paved the way for non-state actors and civil society to have more influence in the institutions and regimes of global governance (Habermas, 2008; Dryzek, 1999). Via Campesina demonstrates these changing interactions between state and non-state actors well, with their increasing power in terms of influencing the discourses which emerge from the regime of global food security governance. This is exemplified by the inclusion of right to food discourses in the FAO text, and the inclusion of food sovereignty discourses in the IAASTD report. Therefore, though the Via Campesina was created as an act of resistance, acting largely outside the regime it was attempting to influence, the increasing attention paid to the discourses which it has introduced make it an increasingly powerful player in this regime of global governance. 
At the same time as the Via Campesina may be seen to have benefited from this changing power of the state in systems of multilateral governance, they advance the position that states have an important role to play in solutions to food insecurity, putting forth the position that states have a role in both guaranteeing that the right to food is ensured within individual countries, and in terms of the need to reinstate the power of states to regulate and control agricultural trade within state borders. The FAO also envisions an important role for states in food security solutions, and as noted in chapter four, the statebased organizational structure of the FAO makes this an obvious governance approach for this organization. Though there is convergence here between the two organizations regarding the role of states to ensure the right to food, there is divergence regarding state sovereignty over agricultural trade envisioned by the Via Campesina, where the FAO does not put forth this position. When considering the embeddedness of the FAO in the multilateral system it is unlikely that a shift in position regarding the power of states to control agricultural trade would take place.

Still, when considering the mechanisms for change within regimes of global governance, where it is recognized that significant shifts in the political, social, or economic environments within which a given regime may function, may dramatically impact the ability for significant change to take place within the regime. Current global economic turmoil, as evidenced by the European debt crisis, and the impact this is having on economies around the world, as well as the wave of democracy which has spread to the Middle East, point to the fact that the world is currently experiencing significant political, social, and economic shifts, with this shift representing an environment where significant 
change may be possible. With discourses surrounding the hegemony of the US and the EU as global economic superpowers, and the need for increased trade liberalization, which have traditionally dominated this regime of global governance increasingly being brought into question, due to these larger geopolitical shifts taking place.

When considering both texts, many of the contradictions and convergences which emerge may be seen to be based on differing norms and principles between the two organizations. The contradiction between the two texts on the issue of migration, and the convergence on the need to consider dimensions other than trade in global food policy, are representative of issue areas where the principles and norms of the organizations do not align. Whereas the FAO text views migration largely in terms of remittance pay, the Via Campesina sees it as a larger structural and humanitarian problem. This contradiction points to fundamental divergences between the two organizations on how the issue of migration should be addressed by the global community. It also points to the very differing positions of the two organizations toward the global political economy, where the FAO considers changes to gross domestic product (GDP) and foreign direct investment (FDI), as important indicators of the ability of nations to cope with food insecurity, and where the Via Campesina sees the existence of democracy, community, and consultation, as important indicators.

Therefore, for the FAO issues such as migration are analyzed through a narrower neoliberal lens, whereas for the Via Campesina issues such as migration are considered more holistically, taking into account the impact on the individuals impacted by these policies. This difference in position and approach is largely due to the differing 
membership, representation, and organizational structure of these organizations, however, what this means for food security is that there is a significant gap between the realities of small scale farmers and the policies and approaches which currently emerge from this regime of global governance. How alignment on this issue area might be achieved is outside the scope of this research, as it would require an in depth analysis of other regimes of global governance, and the relationships and power dynamics between these, and the food security governance regime.

Yet, where there is fragmentation on the issue of migration, there is convergence on the need for considerations other than trade in global food policy. Both organizations agree that this is a food governance priority, and that the multidimensional role of food and agriculture need to be addressed. With the governance solutions put forward by the FAO proposing the need to consider both economic and social dimensions of food insecurity, and with the Via Campesina definition of food sovereignty recognizing both environmental and social dimensions of food, when considering that the since its 1975 definition of food security, the FAO's definition has evolved and expanded to now consider dimensions other than the mere availability of food, to dimensions such as human health and well-being, this convergence is significant as it signals an area where growth and change between the two organizations is occurring.

Though this synergy and fragmentation within the food security governance regime occurs largely as a result of the differing norms and principles of the actors involved, it also may be seen to result from the stretching and layering of various policies, positions and institutions over time. In the Via Campesina text, it is argued that the current 
stretching and layering of institutions responsible for various dimensions of global food security is leading to further conflictive fragmentation within this realm of governance. They argue that the creation of more structures further confuses roles, responsibilities, and mandates in this already complex regime. Rather than lead to synergistic situations, stretching and layering usually represents decisions being made, and policy being created in an ad hoc manner, which, in not considering the range of implications, usually results in fragmentation and conflict, as exemplified by the global food security governance regime.

This is not to say that conflict does not signal points of tension where there are obvious problems which need to be addressed, and that these tensions should be ignored or smoothed over, simply for the sake of being able to say that everyone agrees, but rather, the areas of divergence outlined throughout this research point to fundamental challenges at the heart of global food security governance that need to be explored further and addressed. If the performance of a given regime may be seen to be largely influenced by the degree of fragmentation which characterizes it, stronger cooperation to facilitate synergies and promote policy coherence is needed in the regime of global food security governance. Pointing to areas of convergence throughout this research is meant to signal areas where the FAO might be moving in the more progressive direction envisioned by the Via Campesina. These convergences and shifts are important as they represent models for how more synergistic positions between the multilateral system and small scale farmers might be achieved, which may have important implications for food security outcomes. 


\subsection{Food sovereignty, rights, and governance}

The various discourses and narratives on food sovereignty and rights identified in the texts, as well as broader geopolitical changes taking place which impact the food security regime, may be seen to greatly influence current outcomes of global food security governance. Sovereignty, rights, and governance are becoming increasingly salient topics in a changing global society, and this is apparent in the global food security governance regime, as well as in the texts of the two organizations. A consideration of the definitions in the texts on food security, food sovereignty, and the right to food, helps to illuminate how the discourses of these organizations are impacting food security governance. Yet, while there is convergence between the organizations that rights have a role, there is divergence on the need to ensure the right to define agricultural systems.

The strength of food sovereignty is that it appeals to a rights based approach to food, with human rights discourses largely being considered legitimate appeals in the current system of global governance. What is important though is not that these rights exist, but that these rights are implemented. This requires global governance mechanisms able to ensure that rights are guaranteed and protected (Patel, 2009). What is needed is a system of global governance where rights are protected at the local, national, regional, and global levels, and though open and transparent discourse is seen to be key to arriving at a set of common moral principals upon which a more just global society could be based, the lack of a supranational state, with the powers that such an entity would encompass in terms of ensuring the provision of human rights globally, or the lack of sufficient political will in the governments which make up the current multilateral system, negate the ability to effectively implement these rights globally. The effective implementation of such rights 
would dramatically impact global food security governance, in that it would provide governance solutions which would make a right to food approach possible.

In terms of the possibility for change, it is recognized that crises, or significant geopolitical shifts within which a given regime may function, increase the likelihood of significant change within a regime, as these events leave room for new ideas and new approaches to emerge. Increasing trade and the increasing complexity of international institutions and international engagement represent challenges at both the international and domestic level. It is recognized that globalization, and its resultant challenges, have changed the way actors pursue their interests in an increasingly integrated world.

Both the FAO and Via Campesina texts discuss the changing geopolitical environment within which they are functioning. The Via Campesina text recognizes the shifting global power dynamics which are impacting the influence of the FAO in the multilateral system, with the new regional conference in North America being indicative of this shift in power. The concurrent global food and financial crises are also referenced in both texts, with both texts recognizing the impact of these crises on food insecurity, and both also recognizing that the crises represented an opportunity, in an environment of increased public interest, to communicate that the root causes of food insecurity deeply need to be addressed. In terms of global food security, the recognition of the impact of exogenous forces on the regime and on food security outcomes is extremely important, with both organizations and the regime more broadly, being impacted by various external factors. The geopolitical and economic environment, within which food security governance is taking place, is complex. Yet all regimes operate within complex 
environments, the global governance challenge is to develop and implement policies and programs which are able to mitigate the risks caused by external forces. In the case of global food security governance this means developing food systems that are designed to withstand short term spikes and drops in food commodity prices, which have been shown to be quite cyclical in nature.

While both organizations recognize that human rights instruments may provide important governance mechanisms in eliminating food insecurity, there is divergence on the need to recognize the right to define agricultural systems. In the FAO text, food as a human right is presented as an important component of food security governance, and while the Via Campesina text agrees with this approach, food sovereignty goes further, in that it is also apparent that what is missing from a right to food approach is the right to define the agricultural systems where ones food is produced. Yet, while these organizations try to define and redefine food security, food sovereignty and the right to food, these definitions are meaningless if no steps are made for achieving the objectives that that are being presented in these varying definitions, and while there is divergence in this issue area, there is agreement that the human right to food approach should factor into governance solutions. However, if there is agreement on this issue area, why has agreement on certain issue areas not translated into action and reality? The answer lies in the lack of effective governance in this regime, where actors have been unable to turn a vision of a world without food insecurity into a food secure world. 


\subsection{Global food security governance and agency}

Regimes of global governance are sights where the relationship between structure and agency is negotiated, and this is true of the global food security governance regime. The texts of the FAO and Via Campesina may be seen to offer insight into how this negotiation takes place in this regime of global governance. What the texts say in terms of agency, how both texts approach agency, and what this means vis-à-vis the current state of global food security governance is seen to be important. Also important however, is what these differing approaches to agency communicate regarding how the organizations view their own agency in the global system and the possibility for change.

It is recognized that the intelligent, calculated, and strategic actions engaged in by actors within a regime implies that these actors are not passive spectators, but rather, that they have agency to shape policy directions and bring about change. Better governance within the global food security regime is necessary, and in order to bring about this goal there is a need for actors impacted by the activities of a regime to view these activities as inclusive, transparent, and legitimate. This requires not only a well functioning democratic system, but would also require that "the global political order be founded upon the will of its citizens" (Habermas, 2008, p.448). The need for greater coherence between national and international policy, as well as the need for important and concrete action from both the unilateral and multilateral sphere, requires the type of "cosmopolitan federalism and moral universalism" (Patel, 2009, p.668), that proponents of strengthened

global governance mechanisms are attempting to advance. This means that there needs to be a greater number of voices within the decision making mechanisms of global food security governance, as effective governance necessitates the inclusion of those seen to 
be impacted by the decisions made within the regime. This also means that the synergy between the texts on major issue areas, such as the role of human rights instruments, represents a convergence of sorts which, as was shown, increases the likelihood of progress and movement forward.

Though Fuchs is correct in saying that "the difficulty of attributing intent and agency to discursive governance provides serious obstacles to empirical assessments of any given actors' respective efforts" (Fuchs, 2005, p.4), policy documents may be seen to blur this assumption. The texts of the FAO and the Via Campesina are seen as policy statements, communicating the positions of the organizations vis-à-vis issues of global food security. Both texts may be seen to offer differing discourses on power, vulnerability, and agency and this was seen to be an important area of divergence between the texts. In contrasting the definition of food security provided in the FAO text, with that of food sovereignty provided in the Via Campesina text, it becomes apparent that this power and agency communicated in the Via Campesina text is accomplished through the invocation of the language of human rights. This dimension of agency is largely lacking from the FAO definition, which focuses on more technical dimensions of food insecurity.

The divergence here is largely based on the approach of both organizations toward agency - the FAO text originates from a large bureaucratic organization, where those impacted by the policies and approaches are relatively removed from the process. Whereas the Via Campesina text, having been created in an open and inclusive process, where those to be most impacted by the approach taken in the document have been fully involved in its creation, results in a tone which addresses the agency of the actors in a 
more powerful light. As was noted in chapter four, to be more in line with the Via Campesina approach, the FAO would need to shift from a narrative of vulnerability, to one which recognizes the agency of those impacted by food security policies.

As was noted in chapter three, in the background on change within regimes of global governance, the relationship between structure and agency can be seen to be negotiated within regimes of global governance, where the complexity of global governance structures is seen as a barrier to change. Actors are seen to have limited ability to negotiate and influence a regime due to historical dimensions of power embedded in the processes and structures of global governance, where hegemony describes social forces that privilege certain discourses and structures over others. In the global food security governance regime, the FAO, as a vehicle of states, may be seen as the hegemonic actor, where the Via Campesina may be seen as the "counterhegemonic" actor, impacting the ability of this organization to influence the regime.

Yet, how can "counterhegemonic" discourses emerge despite this injustice and imbalance of power? Within this hegemonic framework, it is important to recognize the dual role of civil society, as both reinforcing of hegemonic ideologies, and also as having the capacity to challenge them, where civil society, by providing a challenge function and acting as a sight of contestation, works strategically in order for previously non-hegemonic discourses to emerge. Though hegemonic structures are powerful, they do not exist apart from actors who build and reinforce them, where actors working strategically are able to manipulate discourse and policy outcomes in a given issue area. This agency, or "intelligent agency", as described by Levy and Newell (2002), means that complex 
regimes of global governance may be negotiated by actors in order to shape discourse and policy directions, and in so doing, bring about change (Levy and Newell, 2002, p.85).

In terms of change within regimes of global governance, a consideration of the concept of "passive revolutions" and "wars of position" illustrates important dynamics relating to how the organizations view their own agency in the global system and the possibility for change. "Wars of position" are undertaken by actors who are often seen to be less influential, who see that significant change in a regime is necessary. These actors actively engage with the system and employ discursive tactics in an attempt to frame or reframe a given issue and advance a given position. "Passive revolutions" in contrast are usually undertaken by those actors traditionally seen to exert influence within a regime. Levy and Newell (2002) have argued that through "intelligent agency" and knowledge of the structures and processes which characterize a regime, actors are able to influence discourses and policy outcomes.

The Via Campesina may be seen to approach their role in the global food security governance regime in this way, starting with its organization-based membership which allows for stronger positions to emerge from within the organization, to the approach of advancing the definition of food sovereignty, as oppose to food security, in an attempt to reframe the discourse; with this "war of position" undertaken by the Via Campesina, contrasting sharply with the more passive approach taken by the FAO. The Via Campesina, see the need for improved governance as linked to the need for the FAO to better and more actively use the mechanisms of global governance already in place such as the human right to food, to advance food security objectives. This lack of initiative for 
traction in this regard is viewed as a major shortcoming of the current approach, with very real implications for the governance of food security and the roles and responsibilities of states vis-à-vis food security outcomes.

\subsection{Participation, democratic decision making, and transparency in global food security governance}

Participation, democratic decision making, and transparency may be seen to constitute the issue of representation in global governance. Mechanisms that allow for these elements to exist allow for the influence of new ideas and new actors in a regime of global governance. These new ideas and new actors introduce new considerations into a regime which may result in changing discourses and a shifting of debates. When true participation, democratic decision making, and transparency are seen to exist, the functioning of a regime is thought to be completely synergistic; and though it is recognized that this ideal situation does not exist, it is thought to be an important global governance goal. How the texts of the FAO and the Via Campesina view representation compared to what the literature sees is needed, and what this means in terms of global food security governance are seen to be important areas of consideration.

In a global society where true representation is seen to exist, only those actions which have been agreed to by all possible participants are considered valid. Habermas calls this "rational discourse" and he argues that this approach to representation "is supposed to be public and inclusive, to grant equal communication rights for participants, to require sincerity and to diffuse any kind of force other than the forceless force of better argument" (Habermas, 1999, p.332). Fairness and equality through participation, democratic decision making, and transparency in systems of global governance are vitally 
important in terms of the overall effectiveness of a regime in the long term. In truly democratic global governance, every one has a voice, "participation demands more than consultation with a few" (Desmarais, 2007, p.102), it means approaching decision making with openness and flexibility that changes in position are possible.

In terms of global food security governance, the issue of representation is understood within the literature to be a key component to good governance within the regime. It is argued that those affected by food and agricultural policies should be closely involved in the decision making processes that affect them (Schiavoni, 2009). As improved global food security governance is seen to be necessary, an important component of this is the issue of representation. The global food security regime involves many actors, and may be seen to impact on the food security situation of much of the global population, it is therefore important to ensure that transparent, participatory, and accountable governance characterize this regime.

The food sovereignty movement demands inclusive representation. It is argued that a food sovereignty approach would facilitate the democratic decision making, participation, and transparency necessary for functioning global food security governance to be a reality (Patel, 2009). Issues of transparency, decision making, and participation are at the heart of many of the governance solutions proposed in the Via Campesina text. The Via Campesina puts forth the position that more democratic global governance institutions are needed in order to ensure progress is made toward achieving food sovereignty, and though the FAO also recognizes the importance of having relevant stakeholders as part of the decision making processes of global food security governance, the organization is 
silent on which stakeholders should be considered relevant, and what that participation should mean in terms of reflecting the ideas and contributions of stakeholders in subsequent policy outcomes. In order to engage in the sort of rational discourse envisioned by Habermas, the FAO would have to engage in more meaningful and inclusive consultation, and though, due to the hegemonic influence of states and certain ideologies within the global food security governance regime, this may not be achieved in the short-term, it is a goal that ought to be worked toward in the long-term.

\subsection{Coherent policies, collective action}

Both texts agree that what is needed most are coherent policies and collective action. Food security is a deeply political issue entrenched in the fabric of societies and cultures - it is not simply a technical issue that can be solved through science and technological approaches alone. The complexity of the system requires that all possible voices and solutions be heard and considered. Therefore, in order to come to coherent policy and governance solutions it is important to act collectively. That there is convergence between the two texts on the need for more coherent policies and more collective action is not surprising considering the goal of both organizations to address such a complex problem, with improved governance being at the heart of the solutions proposed by each organization.

Coherent policies are those which provide a framework for effective and collective action, they are policies and approaches that allow long running problems to be resolved in a manner which is acceptable to all involved actors. Godfray, et al, indicate that a "global strategy" is required in order to ensure food security (Godfray, et al, February 
2010, p.812). The current system is characterized by a vast disparity between policy and on the ground reality, where speaking about governance and rights does little in the short term to assist those who are food insecure. There is the need to holistically approach food security policy through improved governance. Much like the regionally based organizational structure of both the FAO and the Via Campesina, Habermas describes "regional or continental regimes equipped with a sufficiently representative mandate to negotiate for whole continents and to wield the necessary powers of implementation for large territories" (Habermas, 2008, p.447), and though neither organization might be considered to have the "necessary powers" to fully address global implementation, the convergence with the global governance literature on this issue indicates that these organizations are both well placed to addressed global food security governance challenges.

The consensus between the two documents on the enormity of the crisis, in terms of deeper structural issues embedded within the global food system, and the depth of response needed to address the crisis in the long term, indicates that there is the urgent need to address the lack of coherent food security policy. Whether a right to food, or food sovereignty approach, both texts agree that what is provided by these approaches are frameworks for action, and although to what extent this action should be collective is not stated as strongly in the FAO text, there is a certain degree of synergy between these two approaches. In terms of global food security and governance, and collective action, a broader range of voices complicates decision-making to some degree, yet also infuses into the process a broader range of opinions and concerns, which increases the legitimacy of the process and the likelihood of success. 
It has been shown that the two organizations, though using the discourses of global governance, in some ways, envision differing governance solutions. Meaningful participation and more democratic decision making, by allowing for the inclusion of multiple voices and allowing for rational discourse to take place, can, in the long-term be seen to be the means through which agreement on these solutions might be realized. Certain obstacles, such as the hegemony of global economic structures and certain ideologies might be seen to limit the possibilities for change, while other factors, such as the intelligent agency of the actors in this regime, and the current geopolitical shits and economic turmoil, might provide opportunities for change to occur.

\subsection{Concluding the discussion}

In order to reconceptualized food security governance in light of the discourses of these organizations, the synergies and divergences identified through the discourse analysis process, and the application of concepts from the global governance and critical political economy literature which allowed for the interrogation of these areas of synergy and divergence, were key to providing what is hoped is a more complete picture of the current state of global food security governance. There is a surprising degree of synergy between the two texts on a range of issues that implicate the fundamental norms and principles of these organizations. The areas of agreement and disagreement identified illustrate how the global food security regime is structured and how current discourses on food security have evolved over time. The role of human rights instruments and improved global governance are seen as integral to realizing food security and food sovereignty objectives, yet the issue of agency and the need for participation and democratic decision, 
and the current lack thereof, complicates the ability to formulate and implement coherent policies within this realm of global governance, with very real implication for food security objectives.

The synergies and divergences between the texts point to differences in the principles and norms of the organizations being considered, and these divergences are influenced by a range of factors. For example, the differing membership and organizations structure of the organizations, where the norms and principles of the FAO are shaped by the differing positions toward economic, social, and political dimensions of food security of the states which make up its membership, and where the Via Campesina by a common position of critique of political and economic structures. This divergence in norms and principles is further exemplified by the actors these organizations represent, where the FAO represents member countries, and the Via Campesina represents peasants and small scale farmers, meaning that the FAO is only as democratic and inclusive as the processes which take place in the countries of its membership, where for the Via Campesina inclusivity and discursive democracy are core to the common principles developed within the organization. These differences in principles and norms of both the Via Campesina and the FAO point to fundamental differences between the two organizations in their approaches to food security governance.

This divergence between the organizations in terms of principles and norms is further illustrated by the very differing positions of the two organizations toward the global political economy, for the FAO issues are analyzed through a narrower neoliberal lens, whereas for the Via Campesina issues are considered more holistically, taking into 
account the impact on the individuals impacted by its actions and the governance solutions it advances. This difference in position and approach is largely due to the differing membership, representation, and organizational structure of these organizations, however, what this means for food security is that there is a significant gap between the realities of small scale farmers and the policies and approaches which currently emerge from this regime of global governance. Further research is needed in order to suggest how alignment in this issue area might be achieved.

A significant area of convergence between the two organizations revolves around the role of rights in global food security governance solutions. Both organizations recognize that human rights instruments may provide important governance mechanisms in eliminating food insecurity, however, what is missing from the FAO approach is the right to define the agricultural systems where ones food is produced. However, despite this area of disagreement, both organizations recognize that the strength of right to food approaches is that human rights discourses largely being considered legitimate appeals in the current system of global governance. However, the lack of a system of global governance which can ensure these rights, whether at the level of the state, or at the supranational state level, is a significant obstacle to realizing the benefits of a right to food approach.

Areas of divergence between the texts were seen to signal points of tension where there are obvious problems which need to be addressed, and were seen to point to fundamental challenges at the heart of global food security governance. While areas of convergence were seen as important, as they represent models for how more synergistic positions between the multilateral system and small scale farmers might be achieved. If there is 
indeed the need to move toward to more progressive approaches of food sovereignty, as was the approach taken in this research, and if synergy within a regime is seen to be symbolic of its performance, then alignment of the global food security discourse with that of a food sovereignty discourse, and shifts toward this end, are seen as significant.

How these shifts may be seen to occur was also illustrated, where intelligent agency is seen as a vital component of negotiating and influencing hegemonic structures and discourses. Counterhegemonic discourses are seen to emerge because powerful hegemonic structures do not exist apart from actors who build and reinforce them, where actors working strategically are able to manipulate discourse and policy outcomes in a given issue area, and in so doing, bring about change.

When considering agency, the FAO puts forth a narrative of vulnerability, whereas the Via Campesina recognizes the agency of those impacted by food security policies. This divergence is important considering the important role that the recognition of agency has in terms of the democratic decision making, participation, and transparency seen to be necessary for a functioning system of global food security governance to be a reality. In order to engage in rational discourse, which results from democratic decision-making and meaningful and inclusive consultation, the FAO would need to shift its approach toward agency. By allowing for the inclusion of multiple voices and allowing for rational discourse to take place, meaningful participation and more democratic decision-making, can be seen to be the means through which agreement on global food security governance solutions might be realized. The intelligent agency of the actors in this regime, and the geopolitical shits and economic turmoil currently shaping a very different global 
governance reality, might provide opportunities for change to occur, and though this may not be achieved in the short term, due to the hegemonic influence of states and certain ideologies within the global food security governance regime, it was shown that this is an important goal for the regime in the long-term. 


\section{Chapter 6-Conclusion}

\section{Why this matters}

This research has used discourse analysis to critically examine the use of food security and food sovereignty discourses in the global food security governance regime. Critical political economy and global governance frameworks allowed for the convergences and divergences of the discourses of these organizations to be examined in terms of the broader hegemonic structures within which they are embedded, and in terms of the potential for change within the regime. Premised on the assumption that it is important that the global food security governance regime, as represented by the discourse of the FAO, take into account many of the concerns of the Via Campesina in terms of the organization's focus on rights, sovereignty, accountability, participation, and transparency, it was shown that though there are commonalities, and shifts may be seen to be taking place, there are significant areas of divergence between the two organizations, which represent fundamental differences in the norms and principles of the organizations, and hegemonic structures, which currently limit the possibility for change in line with food sovereignty objectives to occur.

However, it was shown that intelligent agency will be an important component of any possibility for movement forward in the more progressive direction envisioned by the Via Campesina. In the long-term, it is believed that this intelligent agency may be able to bring about the participation, inclusivity, and the type of rational discourse seen as needed in order to bring about more coherent, comprehensive global food security governance, and a more food secure world. 
Areas for further research

This research set out to show that the change to a food sovereignty discourse at the international level meant the beginning of a fundamental paradigmatic shift in the global discourse on food security. And while it was found that there are areas where this may be true, the underlying global governance reality is that there is still much room for change. There are also areas where change seems possible, or rather where the possibility for change might exist, and these areas deserve further consideration in the immediate future - by both academia in terms of building an adequate theory for analyzing the complex interconnections that characterize this realm of global governance, and also in terms of the organizations involved, and the prospect of gaining success or advancement in specific areas of concern to global food security governance.

One area specifically that requires further attention is the gap between the neoliberal approach underlying the policies of the FAO, and the more holistic approaches of the Via Campesina, and how alignment in this area might be achieved, this would require an in depth analysis of other regimes of global governance, and the relationships and power dynamics between these, and the food security governance regime.

As global food security governance is found to be lacking, greater attention is needed in order to further explore the ways in which the decision making, transparency, inclusivity, and the powerful discursive patterns which emerge from this important sphere of global governance could be improved. The processes of change within regimes of global governance, and within the food security regime more specifically, also deserve more attention, as in better understanding these processes there is the capacity to replicate 
successes of the past. However, as Sell (2009) recognizes, "Overall the discursive battle rages on. No one compelling frame has yet emerged" (Sell, 2009, p.197, emphasis in original), and there is no time within the foreseeable future where the discursive evolution or contest may be seen to be resolved.

\section{Normative conclusions}

Currently, more cohesion and synergy is needed in global food security governance. It is so vitally important that actors in this regime speak the same language, and that this language reflects the inclusion of multiple voices. What is needed now, is for as Via Campesina wants, for food sovereignty to be part of public thought and knowledge, as this approach more adequately invokes the policy options and responses necessary for true food security to be realized. Although we live in complex and ever changing times, and this complicates processes of governance at many levels, from the local to the global, this does not preclude the need to work toward a greater degree of synergy between actors and discourses in the realm of global food security governance. As Cooke, et al, illustrate: "The study of food thus forces us to confront the issues of individual, social, and environmental sustainability simultaneously and in a mutually consistent manner" (Cooke, et al, 2008a, p.101), and as the multiple discourses which emerge show, actors within the global food security governance regime are attempting to successfully negotiate this complexity in order to achieve food security, or rather food sovereignty outcomes. 


\section{References}

Agger, B. (1994). "Derrida for Sociology? A Comment on Fuchs and Ward". American Sociological Review 59(4):501-504.

Axworthy, L. (2001). "Human Security and Global Governance: Putting People First". Global Governance 7: 19-23.

Barrett, C.B. (2010). "Measuring Food Insecurity". Science 327: 835-828.

Berg, L.D. (2009). "Discourse Analysis". International Encyclopaedia of Human Geography. Rob Kitchin and Nigel Thrift (Eds.). Elsevier Ltd. 215-221.

Biermann, et al. (2009). "The Fragmentation of Global Governance Architectures: A Framework for Analysis". Global Environmental Politics 9(4); 14-40.

Borras, S.M. Jr, Edelman, M., and Kay, C. (2008). "Transnational Agrarian Movements: Origins and Politics, Campaigns and Impact”. Journal of Agrarian Change 8 (2 and 3): 169-204.

Braidotti, R. (2005). "A Critical Cartography of Feminist Post-postmodernism". Australian Feminist Studies 20(47): 169-180.

Braithwaite, J. and Drahos, P. (2000). "A Political Program for Sovereignty over Global Regulation". Global Business Regulation. Braithwaite, J. and Drahos, P., eds. Cambridge UP: Cambridge. 602-629.

Bremmer, I. and Gordon, D. (2011) "Top 10 Risks for 2011". Retrieved from http://eurasiagroup.net/pages/top-risks February 29, 2011.

Bremmer, I. (2011). "G-Zero". Retrieved from http://eurasia.foreignpolicy.com/posts/2011/01/07/g_zero, February 29, 2011.

Carr, E.R. (2006). "Postmodern conceptualizations, modernist applications: Rethinking the role of society in food security". Food Policy 31: 14-29.

Castree, N. (2008). "Neoliberalising nature: processes, effects, and evaluations" Environment and Planning 40: 153-173.

Clapp, J. (2009). "Food Price Volatility and Vulnerability in the Global South: considering the global economic context". Third World Quarterly 30(6): 1183-1196.

Clapp, J. (2009). "The Global Food Crisis and International Agricultural Policy: Which Way Forward?". Global Governance 15: 299-312.

Clapp, J. and Fuchs, D. (2009). “Agrifood Corporations, Global Governance, and Sustainability: A Framework for Analysis". Corporate Power in Global Agrifood Governance. Clapp and Fuchs, D., eds. The MIT Press: Cambridge, Massachusetts. 1-26.

Cocklin, C. (2003). "Water and Human Security". APN Newsletter. October: 3-5. 
Conceição, P. and Mendoza, R.U. (2009). "Anatomy of the Global Food Crisis". Third World Quarterly 30(6): 1159-1182.

Cooke, et al. (2008). "Introduction: Agriculture, Trade, and the Global Governance of Food". Globalizations 5(2): 99-106.

Cooke, et al. (2008). "Conclusion: Negotiating the Dynamics of Global Complexity'. Globalizations 5(2): 319-328.

Crang, M. (2003). "Telling materials". Using Social Theory: Thinking through Research, Pryke, M., et al (Eds.). Sage Publications, London, UK, 128-144.

Cresswell, T. (2009). "Discourse" (p. 211-214). International Encyclopaedia of Human Geography. Rob Kitchin and Nigel Thrift (Eds.). Elsevier Ltd.

Curran, S.R. (2008). "The Global Complexity Framework”. Globalizations 5(2): 107-109.

Dalby, S. (2007). "Anthropocene Geopolitics: Globalization, Empire, Environment and Critique". Geography Compass 1(1): 103-118.

Daly, H.E. (2002). "Policy, Possibility and Purpose". Worldviews 6(2): 183-197.

Dear, M. (1988). "The postmodern challenge: reconstructing human geography". Transactions of the Institute of British Geographers 13: 262-274.

Desmarais, A.A. (2002). "The Via Campesina: Consolidating an International Peasant and Farm Movement". The Journal of Peasant Studies 29 (2): 91-124.

Desmarais, A.A. (2007). "Globalization and the Power of Peasants: La Via Campesina". Fenwood Publishing Company: Halifax, Nova Scotia.

Desmarais, A.A. (2008). "The power of peasants: Reflections on the meanings of La Via Campesina". Journal of Rural Studies 24: 138-149.

Diccionario de la lengua española. (2011). Retrieved from http://www.rae.es/RAE/Noticias.nsf/Home?ReadForm, September 25, 2011.

Dixon, D.P. and Jones III. J.P. (2006). "Feminist Geographies of Difference, Relation, and Construction". From Approaches to Human Geography. Stuart Aitken and Gill Valentine (Eds.). London and Thousand Oaks, California. Sage Publications. 42-56.

Dryzek, J.S. (1999). "Global Ecological Democracy". Global Ethics and Environment. N. Law (Ed.) Routledege, London, 263-282.

Dupont, A. and Thirlwell, M. (2009). “A New Era of Food Insecurity?". Survival 51(3): 71-98.

Easterling, W. et al. (2007). "Food, Fibre, and Forest Products". IPPC, AR4, WG2, Ch. 5.

Erjavec, K. and Erjavec, E. (2009). "Changing EU agricultural policy discourses? The discourse analysis of Commissioner's speeches 2000-2007". Food Policy 34: 218-226. 
Feindt, P.H. and Flynn, A. (2009). "Policy stretching and institutional layering: British food policy between security, safety, quality, health and climate change". British Politics 4(3): 386-414.

Food and Agriculture Organization. (1975). "Report of the World Food Conference, Rome, 5-16 November 1974", United Nations, New York, 1975.

Food and Agriculture Organization. (2009). "The State of Agricultural Commodity Markets: High food prices and the food crisis - experiences and lessons learned". Retrieved from ftp://ftp.fao.org/docrep/fao/012/i0854e/i0854e.pdf, February 28, 2010.

Food and Agriculture Organization. (2009). "Towards a renewed Committee on World Food Security". Retrieved from

http://www.srfood.org/index.php/en/component/content/article/118-towards-a-renewedcommittee-on-world-food-security-, March 7, 2010.

Food and Agriculture Organization. (2011). "About FAO: Funding and expenditure". Retrieved from http://www.fao.org/about/en/, August 9, 2011.

Foucault, M. (1972). "Truth and Power". Power/knowledge: selected interviews and other writings, 1972-1977. Colin Gordon ed. Random House of Canada, Toronto. 109-133.

Fouilleux, E. (2009). “About Global Crises: The FAO's Role in International Agricultural and Food Policy Debates". Revue francaise de science politique 59(4): 757-782.

Friedland, W. (2004). "Agrifood Globalization and Commodity Systems". International Journal of the Sociology of Agriculture and Food 12: 5- 16.

Friedmann, H. (2000). "What on Earth is the Modern World-system? Food-getting and Territory in the Modern Era and Beyond". Journal of World-System Research VI(2): 480-515.

Fuchs, D. and Clapp, J. (2009). "Corporate Power and Global Agrifood Governance: Lessons Learned". Corporate Power in Global Agrifood Governance. Clapp and Fuchs, D., eds. The MIT Press: Cambridge, Massachusetts. 285-296.

Fuchs, et al. (2009). "Retail Power, Private Standards, and Sustainability in the Global Food System". Corporate Power in Global Agrifood Governance. Clapp and Fuchs, D., eds. The MIT Press: Cambridge, Massachusetts. 29-60

Fullbrook, D. (2010). "Food as Security". Food Security 2: 5-20.

Gehring, T. and Oberthür, S. (2009). "The Causal Mechanisms of Interaction between International Institutions". European Journal of International Relations 15(1): 125-156.

Germain, R.D. and Kenny, M. (1998). "Engaging Gramsci: international relations theory and the new Gramscians". Review of International Studies 24: 3-21.

Gibson-Graham, J.K. (1996). "The End of Capitalism (As We Knew It): A Feminist Critique of Political Economy", Oxford UK and Cambridge USA: Blackwell Publishers.

Gibson-Graham, J.K. (2003). "An Ethics of the Local". Rethinking Marxism 15(1): 49-74. 
Gibson-Graham, J.K. (2006). “A Postcapitalist Politics", Minneapolis: University of Minnesota Press.

Glasmeier, A. and Johnston, R. (2007). "Neo-Liberalism, Democracy and the State: Temporal and Spatial Constraints to Globalization". Space and Polity 11(1): 1-33.

Godfray, H.C.J. et al. (2010). "Food Security: The Challenge of Feeding 9 Billion People". Science 327: 812-818.

Godfray, H.C.J. et al. (2010). "The future of the global food system". Philosophical Transactions of the Royal Society B 365: 2769-2777.

Goodman, D. and Watts, M.J. (1997). “Agrarian Questions: Global appetite, local metabolism, culture, and industry in fin-du-siècle agro-food systems" Globalising Food: Agrarian Questions and Global Restructuring Goodman, D. and Watts, M.J., eds. Routledge, London.

Graham, Elspeth. (2005). "Theory and Theorizing". From Questioning Geography. Castree, N., Rogers, A., and Sherman, D., eds. Oxford. Blackwell. 258-371.

Habermas, J. (2008). "On the Architectonics of Discursive Differentiation: A Brief Response to a Major Controversy". Between naturalism and religion: philosophical essays. Polity Press, Cambridge, 77-97.

Habermas, J. (2008). "The Constitutionalization of International Law and the Legitimation Problems of a Constitution for World Society". Constellations 15(4): 444-455.

Habermas, J. (2009). "Introduction". Ratio Juris 12(4):329-335.

Hanson, S., Martin, D. and Fontaine, D. (2007). "What counts as activism? The role of individuals in creating change". Women's Studies Quarterly 34 (3 \& 4): 78-94.

Hira, A. and Cohn, T.H. (2003). "Toward a Theory of Global Regime Governance". International Journal of Political Economy 33(4): 4-27.

Hobden, S., and Jones, R.W. (2006). "Marxist Theories of International Relations". The Globalization of World Politics Baylis, J. and Smith, S., Oxford University Press, New York, 225-250.

Inter Pares. (2004). "Community Based Food Security Systems: Local Solutions for Ending Chronic Hunger and Promoting Rural Development". Inter Pares Occasional Paper Series, No. 4: Ottawa.

Ishii-Eiteman, M. (2009). "Food sovereignty and the International Assessment of Agricultural Knowledge, Science and Technology for Development". The Journal of Peasant Studies 36(3): 689-700.

Jarosz, L. (2011). "Defining World Hunger: Scale and Neoliberal Ideology in International Food Security Policy Discourse". Food Culture and Society. 14 (1):117-139. 
Johnson, L.C. (2009). "Feminism/Feminist Geography" . International Encyclopaedia of Human Geography. Rob Kitchin and Nigel Thrift (Eds.). Elsevier Ltd. 44-58.

Koltko-Rivera, M.E. (2004). "The Psychology of Worldviews". Review of General Psychology 8 (1): 3-58.

Krasner, S.D. (1982). "Structural causes and regime consequences; regimes as intervening variables". International Organizations 36(2): 185-205.

La Via Campesina (2009). "FAO: A Food Battle Won". Press release by Nora McKeon, October 22, 2009. Retrieved from http://www.viacampesina.org/en/index.php?option=com_content\&view=section\&layout=bl og\&id=8\&Itemid=30, March 7, 2010

Lang, T. (2010). "Crisis? What Crisis? The Normality of the Current food Crisis". Journal of Agrarian Change 10(1): 87-97.

Lazo Cividanes, Jorge. (2004). "Ideology and Anti-Globalization: An Approach to the Discourse of "La Via Campesina"'. Revista de Ciencia Politica 24(1): 169-188.

Levy, D.L. and Newell, P.J. (2002). "Business Strategy and International Environmental Governance: Toward a New-Gramscian Synthesis". Global Environmental Politics 2(4): 84-101.

Lio, M. and Liu, M.C. (2008). "Governance and agricultural productivity: A cross-national analysis". Food Policy 33: 504-512.

Maltais, A. et al. (2003). "Integrating Perspectives on Environmental Security". Stockholm Environment Institute, Report 2003-1.

Massey, D. (2004). “Geographies of Responsibility”. Geografiska Annaler B 86: 5-18.

Maxwell, et al. (2010). "Fit for purpose? Rethinking food security responses in protracted humanitarian crises". Food Policy 35: 91-97.

McMichael, P. (2009). "A Food Regime Analysis of the "World food Crisis"". Agriculture and Human Values 26: 281-295.

Minca, C. (2009). "Postmodernism/Postmodern Geography" . International Encyclopaedia of Human Geography. Rob Kitchin and Nigel Thrift (Eds.). Elsevier Ltd. 363-372.

Moss, P. (2000). "Taking on, Thinking about, and Doing Feminist Research". In: Feminist Geography in Practice: Research and Methods. Pamela Moss (Ed.). Blackwell Publishers, Oxford, UK, 1-20.

Moss, P. and Al-Hindi, K.F. (2008). "An Introduction: Feminisms, Geographies, Knowledges". In: Feminisms in Geography: Rethinking space, place, and knowledges, Moss, P. and AlHindi, K.F. (eds.). Rowan and Littlefield Publishers, Inc. Plymouth, UK, 1-27.

New Oxford English Dictionary Online (2011). Retrieved from http://oed.com/public/redirect/welcome-to-the-new-oed-online, October 14, 2011. 
Patel, R. (2007). "Transgressing Rights: La Via Campesina's call for food sovereignty". Feminist Economics 13(1): $87-116$.

Patel, R. (2009). "What does food sovereignty look like?". The Journal of Peasant Studies 36(3): 663-673.

Pingali, P., Raney, T., and Wiebe, K. (2008). "Biofuels and Food Security: Missing the Point" Review of Agricultural Economics 30(3): 506-516.

Pryke, M., Rose, G., and Whatmore, S. (2003). "Using Social Theory: Thinking through Research". Sage Publications, London, UK.

Rosegrant, W. and Clime S. (2003). "Global Food Security: Challenges \& Policies". Science 302: 1917-1919.

Rosendal, K.G. (2001). "Impacts of Overlapping International Regimes: The Case of Biodiversity". Global Governance 7(1): 95-117.

Ringler, C. (2008). "The Millennium Ecosystem Assessment: Tradeoffs between Food Security and the Environment" Turkish Journal for Agriculture and Forestry 32: 147-157.

Roubini, N. (2011). "Our G-Zero World". Retrieved from http://www.thestar.com/opinion/editorialopinion/article/940235--our-g-zero-world, February 29, 2011.

Salih, M. (2009). "Governance of Food Security in the $21^{\text {st }}$ Century". Facing Global Environmental Change 4(5): 501-507.

Schiavoni, C. (2009). "The global struggle for food sovereignty: from Nyéléni to New York". The Journal of Peasant Studies 36(3): 682-689.

Sell, S.K. (2009). "Corporations, Seeds, and Intellectual Property Rights Governance". Corporate Power in Global Agrifood Governance. Clapp and Fuchs, D., eds. The MIT Press: Cambridge, Massachusetts. 187-224.

Sen, A. (1999). "Development as freedom”. Oxford University Press, London.

Shaw, D.J. (2007). "World Food Security: A History since 1945". Palgrave Macmillan, New York, NY.

Shields, S., Bruff, I., and Macartney, H. (2011). "Critical International Political Economy: Dialogue, Debate and Dissensus". Palgrave Macmillan, New York.

Smythe, E. (2009). "In Whose Interests? Transparency and Accountability in the Global Governance of Food: Agribusiness, the Codex Alimentarius, and the World Trade Organization". Corporate Power in Global Agrifood Governance. Clapp and Fuchs, D., eds. The MIT Press: Cambridge, Massachusetts. 93-124.

Suppan, S. (2008). "Challenges for Food Sovereignty". The Fletcher Forum of World Affairs 32(1): $111-123$. 
Thrift, N. and Olds, K. (1996). "Refiguring the economic in economic geography". Progress in Human Geography 20(3): 311-337.

Thompson, J. and Scoones, I. (2009). "Addressing the dynamics of agri-food systems: an emerging agenda for social science research". Environmental Science and Policy 12: 386387.

Tibaijuka, A.K. (2004). "Food security in Africa: Agriculture, trade and the environment". New Economy 11 (3): 170-173.

Timmer, C.P. (2010). "Reflections on food crises past". Food Policy 35: 1-11.

United States Agency of International Development. (2009). "Food security assessment 2008$09 "$.

United States Department of State. (2010). "Contributions of International Organizations". Retrieved from http://www.state.gov/documents/organization/123615.pdf, on November $17,2011$.

Whatmore, S. and Thorne, L. (1997). "Nourishing Networks: Alternative geographies of food". An exert from Globalising Food: Agrarian Questions and Global Restructuring Goodman, D. and Watts, M.J., eds. Routledge, London.

Williams, M. (2009). "Feeding the World? Transnational Corporations and the Promotion of Genetically Modified Food". Corporate Power in Global Agrifood Governance. Clapp and Fuchs, D., eds. The MIT Press: Cambridge, Massachusetts. 155-186.

Young, O.R. (1982). "Regime dynamics: the rise and fall of international regimes". International Organizations 36(2): 277-297. 


\section{Appendix 1: Summary of discourse analysis results}

\begin{tabular}{|c|c|c|}
\hline Food Security theme & Via Campesina stance & FAO stance \\
\hline $\begin{array}{l}\text { Developed and developing, } \\
\text { North and South }\end{array}$ & $\begin{array}{l}\text { "We have realized that however } \\
\text { diverse our bases are - from } \\
\text { landless farmers in Bolivia to } \\
\text { organic farmers in Canada, from } \\
\text { plantation workers in Indonesia to } \\
\text { milk producers in Spain or } \\
\text { vegetable growers in the Congo - } \\
\text { we share a surprisingly common } \\
\text { analysis of the causes of the long } \\
\text { lasting crisis in agriculture" } \\
\text { (Via, 2009,p.4) }\end{array}$ & $\begin{array}{l}\text { "To ensure that hunger is } \\
\text { conquered in the years to come, } \\
\text { developing countries must be } \\
\text { assisted with the development, } \\
\text { economic and policy tools required } \\
\text { to boost their agricultural sectors in } \\
\text { terms of both productivity and } \\
\text { resilience in the face of crises". } \\
\text { (FAO, 2009, p.4) }\end{array}$ \\
\hline Synergy & \multicolumn{2}{|c|}{$\begin{array}{l}\text { - Both texts portray the economic links between North and South as an } \\
\text { important consideration in both long- and short-term responses to food } \\
\text { insecurity. } \\
\text { - There is agreement that a governance solution in this issue area is } \\
\text { needed. }\end{array}$} \\
\hline Contrasting positions & \multicolumn{2}{|c|}{$\begin{array}{l}\text { - The organizations differ on the types of responses needed in order to } \\
\text { address the disparity between North/South. } \\
\text { - There is an attempt in the Via Campesina text to focus on the } \\
\text { commonalities between North and South, and a tendency in the FAO } \\
\text { text to treat developed and developing countries differently. }\end{array}$} \\
\hline $\begin{array}{l}\text { The role of international trade } \\
\text { and domestic regulations }\end{array}$ & $\begin{array}{l}\text { "The volatility in the food markets } \\
\text { is mainly due to deregulation, the } \\
\text { lack of control on the big players } \\
\text { and the lack of necessary state } \\
\text { intervention at the international and } \\
\text { the national level to stabilize } \\
\text { markets" (La Via Campesina, 2009, } \\
\text { p.87) }\end{array}$ & $\begin{array}{l}\text { "Food security is a function not } \\
\text { only of production and market } \\
\text { access, but also of the environment } \\
\text { created by economic and political } \\
\text { institutions at all levels" } \\
\text { (FAO, 2009, p.47) }\end{array}$ \\
\hline Synergy & \multicolumn{2}{|c|}{$\begin{array}{l}\text { - There is agreement regarding the multifunctional and multidimensional } \\
\text { role of food. } \\
\text { - There is the need to consider dimensions other than trade when } \\
\text { constructing food policies. }\end{array}$} \\
\hline Contrasting positions & \multicolumn{2}{|c|}{$\begin{array}{l}\text { - An important area of divergence in this themed area relates to the role } \\
\text { of existing international institutions in global food security governance } \\
\text { - where the Via Campesina sees a need for drastic change and the FAO } \\
\text { does not. }\end{array}$} \\
\hline The role of rights & $\begin{array}{l}\text { "Human right instruments provide a } \\
\text { means to facilitate the elimination of } \\
\text { oppression. These instruments } \\
\text { attempt to cover all sphere of human } \\
\text { life. Indeed, human rights exist for } \\
\text { the oppressed to defend or obtain } \\
\text { their human standards in situations } \\
\text { of oppression" } \\
\text { (Via, 2009, p.173) }\end{array}$ & $\begin{array}{l}\text { "The Right to Food Guidelines also } \\
\text { recommend that states promote } \\
\text { good governance as an essential } \\
\text { factor for sustained economic } \\
\text { growth, sustainable hunger } \\
\text { eradication, as well as the } \\
\text { realization of all human rights } \\
\text { including the progressive } \\
\text { realization of the right to adequate } \\
\text { food" } \\
\text { (FAO, 2009, p.46) }\end{array}$ \\
\hline
\end{tabular}




\begin{tabular}{|c|c|c|}
\hline Synergy & \multicolumn{2}{|c|}{$\begin{array}{l}\text { - Whether it is a right to food, or food sovereignty approach, both texts } \\
\text { agree that the human right to food provides a model or a framework for } \\
\text { addressing the global problem of food insecurity. }\end{array}$} \\
\hline Contrasting positions & \multicolumn{2}{|c|}{$\begin{array}{l}\text { - When comparing the FAO definition of food as a human right, with } \\
\text { that of the Via Campesina definition of food sovereignty, missing from } \\
\text { the FAO definition of the right to food, and where the definition of } \\
\text { food sovereignty goes further, is the right to decide whether one } \\
\text { produces, earns, or purchases their food. }\end{array}$} \\
\hline The role of global governance & $\begin{array}{l}\text { Change is needed..."change that } \\
\text { improves livelihoods, enhances local } \\
\text { food production for local } \\
\text { consumption, and opens up } \\
\text { democratic spaces, change that } \\
\text { empowers the people of the land } \\
\text { with a great role, position, and stake } \\
\text { in decision-making on issues that } \\
\text { have an impact on their lives" } \\
\text { (La Via Campesina, 2009,p.41) }\end{array}$ & $\begin{array}{l}\text { "The persistence of } \\
\text { undernourishment and its } \\
\text { aggravation during the recent food } \\
\text { and economic crises underscore the } \\
\text { need for improved global food- } \\
\text { security governance to address } \\
\text { fundamental weaknesses in the } \\
\text { fight against hunger" } \\
\text { (FAO, 2009, p.46) }\end{array}$ \\
\hline Synergy & \multicolumn{2}{|c|}{$\begin{array}{l}\text { - The global governance of food and agriculture is lacking and this is } \\
\text { seen by both organizations to have very real implication for food } \\
\text { security. } \\
\text { - The FAO text argues that there is the need "to tackle the root causes of } \\
\text { hunger" (FAO, 2009, p.46), while the Via Campesina text puts forth } \\
\text { the position that the global governance of food "has to be dramatically } \\
\text { improved" (La Via Campesina, 2009, p.201). } \\
\text { - The governance and regulation of international agricultural trade may } \\
\text { be seen as an area where there is some level of agreement between both } \\
\text { texts }\end{array}$} \\
\hline Contrasting positions & \multicolumn{2}{|c|}{$\begin{array}{l}\text { - Though the texts agree that some level of regulation is necessary, the } \\
\text { extent to which this regulation would take place is seen as slightly } \\
\text { more contentious. } \\
\text { - An area of divergence between the two texts centers on the role of } \\
\text { current governance structures in solutions to achieving global food } \\
\text { security. } \\
\text { - The FAO text uses drawing and building, whereas the Via Campesina } \\
\text { text uses restructuring, in order to describe the changes which need to } \\
\text { take place. }\end{array}$} \\
\hline
\end{tabular}

